\title{
The systematic relationships and biogeographic history of ornithischian dinosaurs
}

Clint A Boyd

The systematic relationships of taxa traditionally referred to as 'basal ornithopods' or 'hypsilophodontids' remain poorly resolved since it was discovered that these taxa are not a monophyletic group, but rather a paraphyletic set of neornithischian taxa. Thus, even as the known diversity of these taxa has dramatically increased over the past two decades, our knowledge of their placement relative to each other and the major ornithischian subclades remained incomplete. This study employs the largest phylogenetic dataset yet compiled to assess basal ornithischian relationships ( 255 characters for 65 species level terminal taxa). The resulting strict consensus tree is the most well-resolved, stratigraphically consistent hypothesis of basal ornithischian relationships yet hypothesized. The only non-iguanodontian ornithopod (= basal ornithopod) recovered in this analysis isHypsilophodon foxii. The majority of former 'hypsilophodontid' taxa are recovered within a single clade (Parksosauridae) that is situated as the sister-taxon to Cerapoda. The Parksosauridae is divided between two subclades, the Orodrominae and the Thescelosaurinae. This study does not recover a clade consisting of the Asian taxaChangchunsaurus,Haya, and/eholosaurus(=Jeholosauridae). Rather, the former two taxa are recovered as basal members of Thescelosaurinae, while the latter taxon is recovered in a clade withYueosaurusnear the base of Neornithischia.The endemic South American clade Elasmaria is recovered within the Thescelosaurinae as the sister taxon toThescelosaurus.

This study supports the origination of Dinosauria and the early diversification of Ornithischia within Gondwana. Neornithischia first arose in Africa by the Early Jurassic before dispersing to Asia before the late Middle Jurassic, where much of the diversification among non-cerapodan neornithischians occurred. Under the simplest scenario the Parksosauridae originated in North America, with at least two later dispersals to Asia and one to South America. However, when ghost lineages are considered an alternate dispersal hypothesis has thescelosaurines dispersing from Asia into South America (via North America) during the Early Cretaceous, then back into North America in the latest Cretaceous. The latter hypothesis may explain the dominance of orodromine taxa prior to 
the Maastrichtian in North America and the sudden appearance and wide distribution of thescelosaurines in North America beginning in the early Maastrichtian. While the diversity of parksosaurids has greatly increased over the last fifteen years, a ghost lineage of over 40 myr is present between the base of Parksosauridae and Cerapoda, indicating that much of the early history and diversity of this clade is yet to be discovered. This new phylogenetic hypothesis provides a comprehensive framework for testing further hypotheses regarding evolutionary patterns and processes within Ornithischia. 
1 Clint A. Boyd, North Dakota Geological Survey, Bismarck, North Dakota, U.S.A.

2

3 *Corresponding author: Clint Boyd, 600 East Boulevard Avenue, Bismarck, North Dakota

4 58505, (608) 335-8015, clintboyd@stratfit.org 


\section{INTRODUCTION}

6 In recent years, considerable controversy arose surrounding the systematic relationships

7 of taxa traditionally considered to be basal members of Ornithopoda (i.e., heterodontosaurids and

8 hypsilophodontids). Once considered to be a stable, well supported portion of the ornithischian

9 evolutionary tree (e.g., Sereno, 1999), Ornithopoda (sensu Sereno, 1998) is now rarely recovered

10 as a monophyletic group in phylogenetic analyses of ornithischian relationships owing to the

11 recovery of heterodontosaurids near the base of Ornithischia (e.g., Spencer, 2007, Butler et al.,

12 2008a). That situation prompted Butler et al. (2008a) to redefine Ornithopoda (see Table 1),

13 removing heterodontosaurids as internal specifiers, and restricting the contents of Ornithopoda to

14 only those taxa more closely related to Iguanodontia than to Marginocephalia. Despite this

15 attempt to provide stability to use of the taxon name Ornithopoda, the exact contents of the clade

16 remain poorly understood (Liu 2004; Butler, 2005; Butler et al., 2008a; Boyd et al., 2009).

17 The recognition of Hypsilophodontidae as a paraphyletic set of taxa (Scheetz, 1999;

18 Butler et al., 2008a; Boyd et al., 2009, Brown et al., 2011) raised the question of whether all of

19 these taxa belong within Ornithopoda (sensu Butler et al., 2008a), or if some represent non-

20 cerapodan, basal neornithischian taxa. Efforts to address this question via phylogenetic analyses

21 have proven extremely difficult, with the position of former 'hypsilophodontid' taxa remaining

22 fluid between analyses, with little consensus reached (e.g., Scheetz, 1999; Weishampel et al.,

23 2003; Butler, 2005). Given the high level of confusion regarding their systematic position, some

24 authors (i.e., Boyd et al., 2009) chose conservatively to refer to all non-marginocephalian, non-

25 iguanodontian neornithischian taxa as 'basal neornithischians' until this question is adequately

26 addressed. However, the majority of researchers continue to refer to these taxa as basal

27 ornithopods or basal cerapodans, despite the fact that the use of those names implies resolved 
28 placement of the taxa relative to Marginocephalia lacking in most recent phylogenetic analyses

29 of ornithischian relationships (e.g., Butler et al., 2008a, 2011; Makovicky et al., 2011).

Given the difficulties outlined above, phylogenetic analyses of basal ornithischian and/or

31 neornithischian relationships tended to include few basal neornithischian taxa (e.g., Spencer,

32 2007), focusing on the most complete, well known taxa (e.g., Hypsilophodon) and ignoring less

33 complete, but morphologically informative taxa (e.g., Zephyrosaurus). Moreover, smaller scale

34 analyses of basal neornithischian relationships tended to include a noticeable level of geographic

35 bias among the included taxa. For example, the dataset published by Scheetz (1999) and its

36 subsequent modifications (e.g., Varricchio et al., 2007; Boyd et al., 2009; Brown et al., 2011)

37 largely sample North American neornithischian taxa, with a few Asian taxa included. Along

38 those same lines, analyses of South American taxa tend to heavily sample endemic taxa, while

39 largely ignoring taxa from outside the continent (e.g., Coria, 1999; Novas et al., 2004; Calvo et

40 al., 2007). Although these analyses may individually give the impression that the relationships of

41 basal neornithischian taxa are well resolved, in truth the broader interrelationships of these taxa

42 relative to each other and to the major ornithischian subclades (e.g., Marginocephalia) remain

43 ambiguous.

44 The most extensive analysis of ornithischian relationships yet conducted sought to

45 address, among other issues, the interrelationships of fifteen basal neornithischian taxa (Butler et

46 al., 2008a). That analysis met with limited success, ultimately requiring the incorporation of a

47 combination of less-than-strict consensus methods and the removal of six basal neornithischian

48 taxa to resolve the relationships of the remaining taxa. Butler et al. (2008a) conclude their

49 discussion of these 'hypsilophodontid' taxa (their usage) by commenting on the need for further

50 work on the relationships of these important but enigmatic taxa. 
During the past decade there was a sharp increase in the number of new basal

neornithischian taxa described from across the globe, including new taxa from Asia (e.g., Zan et al., 2005, Huh et al., 2011; Makovicky et al., 2011; Zheng et al., 2012), North America (e.g., Varricchio et al., 2007; Brown et al., 2011; Brown et al., 2013), South America (Novas et al., 2004, Calvo et al., 2007), and Africa (Butler, 2005). Those new taxa provide a wealth of information regarding basal ornithischian evolutionary trends and patterns, though most have yet to be included in a large-scale analysis of basal ornithischian relationships. The aim of this study is to robustly assess basal neornithischian dinosaur relationships using a newly constructed species-level dataset that is the largest yet assembled for this purpose both in the number of terminal taxa and characters. The goals of this study include assessment of the systematic relationships of Australian basal neornithischians, which were never before included in a broad analysis of basal ornithischian relationships, determination of the position of Marginocephalia within Neornithischia to clarify the contents of the clade Ornithopoda, clarification of the interrelationships of those taxa generally referred to as 'hypsilophodontids' and their placement relative to the major ornithischian subclades, and comparison of the results of this analysis to 66 those of other recent phylogenetic analyses of basal ornithischian relationships (i.e., Buchholz,

67 2002; Spencer, 2007; Butler et al., 2008a: see Fig. 1). The results of this phylogenetic analysis 68 provide new insight into the evolutionary and biogeographic history of basal ornithischian 69 dinosaurs and broader relationships within the clade. See Table 1 for a list of phylogenetic 70 definitions used in this study.

\section{Institutional Abbreviations:} and Paleoanthropology, Beijing, People's Republic of China; LACM, Natural History Museum 
74 of Los Angeles County, Los Angeles, California, USA; MOR, Museum of the Rockies,

75 Bozeman, Montana, USA; NCSM: North Carolina Museum of Natural Sciences, Raleigh, North

76 Carolina, USA; NMV: National Museum of Victoria, Melbourne, Australia; PU, Peking

77 University, Beijing, People’s Republic of China; PKUP, Peking University, Beijing, People’s

78 Republic of China; ROM, Royal Ontario Museum, Toronto, Ontario, Canada; RSM, Royal

79 Saskatchewan Museum, Regina, Saskatchewan, Canada; SAM, Iziko South African Museum,

80 Cape Town, South Africa; SDSM, South Dakota School of Mines and Technology, Rapid City,

81 South Dakota, TMM, Texas Memorial Museum, Austin, Texas, USA; USA; UMNH VP, Utah

82 Museum of Natural History, Salt Lake City, Utah, USA; USNM, Smithsonian Institution,

83 National Museum of Natural History, Washington, D. C., USA; UW, University of Wyoming,

84 Geological Museum, Laramie, Wyoming, USA; YPM, Yale Peabody Museum, New Haven,

85 Connecticut, USA.

86

87

88

89

90

91

92

93

94

95

96

\section{MATERIALS AND METHODS}

\section{Dataset Construction}

The core of this dataset is composed of characters compiled from four prior analyses of neornithischian relationships (Weishampel and Heinrich, 1992; Scheetz, 1999; Weishampel et al., 2003; Butler, 2005). The characters from those analyses were first combined into a single dataset totaling 309 characters. Those characters were then analyzed and congruent characters were combined, character states were assessed and modified when required, and three characters were excluded (characters 53, 58, and 112 of Scheetz, 1999), reducing the dataset to 232 characters. Eleven additional characters were added from other published analyses (Xu et al., 2002; Varricchio et al., 2007; Butler et al., 2008a; McDonald et al., 2010; Nesbitt et al., 2010) largely to address relationships amongst outgroup taxa (e.g., Silesauridae) and within 
97 ornithischian subclades (e.g., Dryosauridae). Finally, twelve new characters were added based on

98 personal observations. The final dataset consists of 255 characters. Supplementary Table 1

99 provides the character descriptions, Supplementary Table 2 provides the reference sources for

100 each character, Supplementary Table 3 contains the final data matrix, and Table 2 contains the

101 list of specimens examined and references consulted for each taxon.

\section{Taxon Selection}

103 The purpose of this analysis is to assess the relationships of non-iguanodontian, non-

104 marginocephalian neornithischian taxa (i.e., basal neornithischians). Specifically, all taxa

105 previously included as members of the paraphyletic clades 'Fabrosauridae' and

106 'Hypsilophodontidae' were sampled, as were basal members of Iguanodontia whose

107 relationships with 'hypsilophodontid' taxa remains ambiguous (e.g., Gasparinisaura

108 cincosaltensis). To determine the position of these taxa relative to major ornithischian subclades,

109 basal members of five additional ornithischian clades (see below) were included in the analysis.

110 This approach was chosen rather than coding each clade as a supraspecific terminal taxon

111 because use of species-level exemplars has been shown to increase the accuracy of phylogenetic

112 analyses (Wiens, 1998; Prendini, 2001), ensuring that the results of this analysis are as accurate

113 as possible. As a result, this study represents the first analysis of basal ornithischian relationships

114 conducted entirely at the species level and analyzed using a single dataset. In addition to the

115 ornithischian taxa included in this analysis, six non-ornithischian outgroup taxa, including three

116 non-dinosaurian taxa, were included to root the tree. In total, sixty-five species level terminal

117 taxa were included in this analysis. Each of these taxa is briefly discussed below. 


\section{Taxa of Interest}

119 The twenty-seven taxa discussed below constitute the focus of this investigation.

121 Agilisaurus louderbacki Peng 1990

122 The holotype of Agilisaurus louderbacki consists of a nearly complete skeleton from the

123 Middle Jurassic lower Shaximiao Formation in Sichuan Province, China. This taxon was

124 originally referred to the Fabrosauridae by Peng $(1990,1992)$, a clade now recognized as a

125 paraphyletic assemblage of basal ornithischian taxa (Butler et al., 2008a). Phylogenetic analyses

126 have recovered Agilisaurus as either a basal euornithopod (Buchholz, 2002; Weishampel et al.,

127 2003), or as a basal neornithischian (e.g., Scheetz, 1999; Butler, 2005; Varricchio et al., 2007;

128 Butler et al., 2008a; Boyd et al., 2009, Brown et al., 2011). Two other basal neornithischian taxa

129 are also known from that portion of the formation: Hexinlusaurus multidens, and Xiaosaurus

130 dashanpensis. Hexinlusaurus multidens was previously considered to represent a second species

131 of Agilisaurus by Peng $(1990,1992)$ based on several shared characters, but a reassessment of

132 this referral by Barrett et al. (2005) found this referral to be unwarranted.

134 Anabisetia saldiviai Coria and Calvo 2002

135 The South American taxon Anabisetia saldiviai is known from the Late Cretaceous

136 Lisandro Formation of Argentina and is based upon a partial skull and postcranial skeleton. It

137 was first reported by Coria (1999), but was not formally named and described until 2002 by

138 Coria and Calvo (2002). This taxon has been recovered as either an euiguanodontian (e.g., Coria,

139 1999; Coria and Calvo, 2002) or as a basal iguanodontian (e.g., Butler et al., 2008a). 
141 Atlascopcosaurus loadsi Rich and Rich 1989

142 The Australian taxon Atlascopcosaurus loadsi, from the Early Cretaceous Eumeralla

143 Formation (Otway Group: Agnolin et al., 2010), is based upon the holotype maxilla and a few

144 referred specimens including isolated teeth, a maxilla, and dentaries (Rich and Rich, 1989). This

145 taxon was originally referred to the Hypsilophodontidae, and most subsequent treatments

146 accepted that referral (e.g., Rich and Vickers-Rich, 1999). Norman et al. (2004c) suggested that

147 Atlascopcosaurus may be closely related to the South American taxon Gasparinisaura. Agnolin

148 et al. (2010) referred to Atlascopcosaurus as a non-dryomorph ornithopod that shares many

149 features in common with both Gasparinisaura and another South American taxon, Anabisetia,

150 perhaps indicating that these three taxa share a close phylogenetic relationship. However, the

151 latter author also considered Atlascopcosaurus to be a nomen dubium, though the exact reasons

152 for that referral are not discussed. This study considered Atlascopcosaurus to be a diagnosably

153 distinct taxon, and it was retained in the phylogenetic analysis.

155 Changchunsaurus parvus Zan et al. 2005

156 Changchunsaurus parvus is based on a single specimen consisting of a complete skull

157 with partial postcranial skeleton recovered from the 'middle' Cretaceous Quantou Formation of

158 Jilin Province, China. The anatomy of the holotype was recently redescribed and its systematic

159 relationships were analyzed for the first time (Jin et al., 2010; Butler et al., 2011). Additionally,

160 this taxon was included in an analysis of the systematic relationships of the Asian taxon Haya

161 griva (Makovicky et al., 2011). Changchunsaurus parvus was recovered by Butler et al. (2008a)

162 and Makovicky et al. (2011) near the base of Ornithopoda as the sister taxon to Jeholosaurus

163 shangyuanensis, another small-bodied taxon from the Early Cretaceous of China. 
Gasparinisaura cincosaltensis Coria and Salgado 1996

The holotype of Gasparinisaura cincosaltensis is a nearly complete skull and partial

postcranial skeleton from the Late Cretaceous Rio Colorado Formation of Argentina. Additional material that provided more information regarding the postcranial anatomy of this taxon was referred to this taxon by Salgado et al. (1997). Considerable controversy surrounds the phylogenetic position of this taxon, with various hypotheses placing it as a hypsilophodontid

171 (e.g., Butler, 2005), a basal euornithopod (Weishampel et al., 2003), a basal iguanodontian (e.g.,

172 Scheetz, 1999; Varricchio et al., 2007; Boyd et al., 2009), or as an euiguanodontid (e.g., Coria 173 and Salgado, 1996; Salgado et al., 1997).

174

The holotype and referred specimens of Haya griva preserve representative portions of nearly the entire skeleton. This taxon was recovered from the Khugenetslavkant locality within the Late Cretaceous Javkhlant Formation of Mongolia. The phylogenetic analysis conducted by Makovicky et al. (2011), which used the dataset published by Butler et al. (2011), recovered $H$. griva as the sister taxon to a clade consisting of the Asian taxa Jeholosaurus shangyuanensis and

181 Changchunsaurus parvus. In the strict consensus tree, the clade containing those three taxa was 182 recovered in a polytomy at the base of Neornithischia. Han et al. (2012) also recovered those

183 three taxa in a clade, which they named Jeholosauridae, and suggested that the Asian taxa

184 Koreanosaurus and Yueosaurus may also belong to that clade.

185

186 Hexinlusaurus multidens (He and Cai 1983) 

anterior-most portion of the skull, most of the mandibles, and the distal portion of the tail, as well as a second, disarticulated specimen (He and Cai, 1984). It was recovered from the Middle

190 Jurassic lower Shaximiao Formation of Sichuan Province, China. The species was originally

191 referred to the taxon Yandusaurus (He and Cai, 1983, 1984), but subsequent authors referred it to

192 either Othnielosaurus (e.g., Paul, 1996) or the contemporaneous taxon Agilisaurus (e.g., Peng, 193 1990, 1992). A recent review of the morphology and taxonomy of the species by Barrett et al.

194 (2005) led them to erect a new taxon for this species, Hexinlusaurus. Hexinlusaurus multidens

195 was included in many prior cladistic analyses of ornithischian relationships, though it was

196 usually labeled as Yandusaurus (e.g., Weishampel and Heinrich, 1992; Scheetz, 1999).

197 Regardless of its designation, it is recovered as a basal member of either Hypsilophodontidae 198 (e.g., Weishampel and Heinrich, 1992), Euornithopoda (e.g., Buchholz, 2002), or Neornithischia 199 (e.g., Scheetz, 1999; Butler, 2005; Varricchio et al., 2007; Butler et al., 2008a; Boyd et al., 200 2009).

Hypsilophodon foxii Huxley 1869

referred to the Hypsilophodontidae. Multiple specimens preserving representative portions of the 
210 while others recover at least a reduced version of a monophyletic Hypsilophodontidae (e.g.,

211 Butler, 2005).

212

213 Jeholosaurus shangyuanensis $\mathrm{Xu}$ et al. 2000

214 Jeholosaurus shangyuanensis is a small-bodied taxon from the Early Cretaceous Yixian

215 Formation of the Liaoning Province in China. The holotype and paratype specimens largely

216 preserve only cranial material, and the cranial anatomy of this taxon was recently redescribed in

217 detail based on the discovery of additional referred specimens (Barrett and Han, 2009). The

218 postcranial anatomy of this taxon remained poorly known until additional material was described

219 by Han et al. (2012). The systematic position of the taxon remains poorly resolved, with the most

220 extensive analysis of ornithischian relationships placing it in an unresolved position at the base

221 of Ornithopoda (Butler et al., 2008a), though the analysis of Han et al. (2012) recovered

222 Jeholosaurus in a clade with Changchunsaurus parvus and Haya griva that they named

223 Jeholosauridae. The analysis presented herein incorporates unpublished data from several

224 undescribed specimens of J. shangyuanensis curated at Peking University in Beijing, China that

225 consist of articulated cranial and postcranial skeletons that provide new insights into the

226 phylogenetic position of $J$. shangyuanensis.

228 Kaiparowits orodromine (Gates et al., 2013)

229 The 'Kaiparowits orodromine' is a small-bodied taxon from the Late Cretaceous

230 Kaiparowits Formation of Utah (Gates et al., 2013). The best specimen preserves fragmentary

231 cranial and postcranial elements from an immature individual that preserves autapomorphic traits

232 that make it diagnosably distinct from all other known ornithischian taxa (Boyd, 2012). Several 
233 other presumably juvenile specimens are also referable to this taxon, including an articulated

234 manus from one individual and a set of left and right pedes from another individual, providing

235 insight into the morphology of much of the postcranial skeleton.

237 Koreanosaurus boseongensis Huh et al. 2011

238 Koreanosaurus boseongensis is based upon two partially articulated postcranial

239 skeletons, designated as the holotype and paratype, and a third specimen consisting of a

240 fragmentary hind limb. All of these specimens were recovered from the Late Cretaceous Seonso

241 Conglomerate of South Korea. Koreanosaurus boseongensis was tentatively referred to the

242 Ornithopoda by Huh et al. (2011) as the sister taxon to Orodromeus; however, no phylogenetic

243 analysis was conducted in the original publication (Huh et al., 2011).

Leaellynasaura amicagraphica Rich and Rich 1989

247 Group: Agnolin et al., 2010) of Australia, is known from a holotype specimen (partial left

248 portion of a skull) and several referred specimens. Three of the referred specimens were found at

249 the same locality as the holotype specimen, and it was argued repeatedly that all of these

250 specimens belong to the holotype individual (Rich and Rich, 1989; Rich et al., 2010) based upon

251 analysis of the original site map and the fact that several of the blocks containing these fossils

252 interlock with each other. Leaellynasaura amicagraphica was originally assigned to the

253 Hypsilophodontidae (Rich and Rich, 1989), and others have referred to it as a non-iguanodontian

254 ornithopod positioned more basally than Gasparinisaura (Agnolin et al., 2010), which is

255 consistent with the original referral. However, others argued that it is a non-dryomorph 
256 iguanodontian (Herne and Salisbury, 2009). The most recent assessment of the anatomy of

257 Leaellynasaura outlined character evidence supporting the latter taxonomic placement, though

258 only referred the taxon to Ornithopoda (Rich et al., 2010).

259

260

Lesothosaurus diagnosticus Galton 1978

261

Lesothosaurus diagnosticus is a small-bodied taxon from the "Red Beds" of the Early

262 Jurassic Upper Elliot Formation, southern Africa. Numerous specimens are referred to this taxon

263 (see Butler [2005] for a review) and together they preserve much of the cranial and postcranial

264 skeleton. The systematic position of Lesothosaurus remains contentious; it is hypothesized as

265 either a basal ornithischian (e.g., Norman et al., 2004a), a basal neornithischian (e.g., Scheetz,

266 1999; Varricchio et al., 2007; Butler, 2005; Boyd et al., 2009) or a basal thyreophoran (Spencer,

267 2007; Butler et al., 2008a). Clarifying the relationships of this taxon is a key step to

268 understanding the evolutionary history of Ornithischia. Controversy also surrounds the

269 taxonomic diversity of non-heterodontosaurid ornithischian taxa from the Upper Elliot

270 Formation. Butler (2005) recognized the presence of two taxa, L. diagnosticus and Stormbergia

271 dangershoeki. Other authors (e.g., Knoll, 2002a, 2002b) argued that the material referred to $S$.

272 dangershoeki actually represents the adult form of L. diagnosticus, and histological evidence

273 consistent with that interpretation was presented by Knoll et al. (2010). Neither of these taxa

274 preserve distinct autapomorphies; rather, they are differentiated based upon unique combinations

275 of character states, many of which are plesiomorphic for Ornithischia (Butler, 2005). However,

276 because the synonymy of these taxa is not yet formally proposed, L. diagnosticus and S.

277 dangershoeki are treated as distinct taxa in this study. 
279 Macrogryphosaurus gondwanicus Calvo et al. 2007

280 Macrogryphosaurus gondwanicus is a large-bodied taxon from the Late Cretaceous

281 Portezuelo Formation of Argentina. The holotype and only known specimen consists of an

282 incomplete postcranial skeleton preserving almost the entire vertebral column with associated

283 cervical and dorsal ribs, both pelvic girdles, a sternal plate, and four intercostal plates (Calvo et

284 al., 2007). Macrogryphosaurus gondwanicus was previously recovered as a basal

285 euiguanodontian and the sister taxon to Talenkauen santacrucensis (Calvo et al., 2007). A new

286 clade, Elasmaria Calvo et al. 2007, was erected by Calvo et al. (2007) to contain these two taxa.

287 The most recent analysis of this taxon's systematic relationships recovers it in an unresolved

288 position within a more inclusive Elasmaria that contains several other Gondwanan taxa

289 (Rozadilla et al., 2016).

290

291 Notohypsilophodon comodorensis Martinez 1998

292

Notohypsilophodon comodorensis is based on a partial postcranial skeleton from the Late

293 Cretaceous Bajo Barreal Formation in Argentina. Described as the first hypsilophodontid

294 recognized from South America, it was previously recovered either as an unresolved position at

295 the base of Ornithopoda (Coria, 1999) or as an ornithopod within the clade Elasmaria along with

296 several other Gondwanan taxa (Rozadilla et al., 2016).

297

298 Orodromeus makelai Horner and Weishampel 1988

299 Orodromeus makelai was briefly described by Horner and Weishampel (1988) based on a

300 nearly complete skull and postcranial skeleton from the Late Cretaceous, upper Two Medicine

301 Formation of Montana. Numerous specimens from that formation are referred to this taxon, and 
302 its anatomy is relatively well known. However, the most extensive descriptive work on this taxon

303 completed to date is an unpublished dissertation (Scheetz, 1999), though additional accounts of

304 the long bone histology of this taxon were published (Horner et al., 2009). In phylogenetic

305 analyses, O. makelai is consistently recovered as the sister taxon of Zephyrosaurus schaffi (e.g.,

306 Scheetz, 1999; Buchholz, 2002; Varricchio et al., 2007), though the placement of those two taxa

307 within Neornithischia remains problematic.

308

309 Oryctodromeus cubicularis Varricchio et al. 2007

310 Oryctodromeus cubicularis was originally described based on a presumed adult holotype

311 (premaxillae, partial braincase, and postcranial elements) and a paratype consisting of

312 disarticulated cranial and postcranial elements from at least two immature individuals, all

313 recovered from a single locality within the early Late Cretaceous Blackleaf Formation of

314 Montana. Subsequently, additional material referable to this taxon was described from the

315 contemporaneous Wayan Formation of Idaho (Krumenacker, 2010), which extends the

316 geographical range of Oryctodromeus and adds to our knowledge of its anatomy. This taxon is

317 always recovered within a clade along with Orodromeus makelai and Zephyrosaurus schaffi

318 (e.g., Varricchio et al., 2007; Brown et al., 2013). More recently, a new taxon from the upper

319 Oldman Formation of Alberta, Albertadromeus syntarsus Brown et al. 2013, was also recovered 320 within that clade, which is now named Orodrominae (Brown et al., 2013).

Othnielosaurus consors (Marsh 1894)

324 autapomorphies; thus, it was declared a nomen dubium by Galton (2007). A partial, articulated 
325 skeleton previously referred to this taxon, BYU ESM-163R from the Upper Jurassic Morrison

326 Formation of North America, was erected as the holotype of a new taxon, Othnielosaurus

327 consors, and all material previously referred to Othnielia rex is now referred to $O$. consors.

328 Galton (1973) originally referred BYU ESM-163R to the Hypsilophodontidae. Phylogenetic

329 analyses recovered $O$. consors (or the conspecific $O$. rex) as closely related to the Asian basal

330 neornithischian taxa Agilisaurus louderbacki, Hexinlusaurus multidens, and Yandusaurus

331 hongheensis at the base of either Hypsilophodontidae (e.g., Weishampel and Heinrich, 1992),

332 Euornithopoda (e.g., Buchholz, 2002), or Neornithischia (e.g., Scheetz, 1999; Varricchio et al.,

333 2007; Butler et al., 2008a; Boyd et al., 2009).

335 Parksosaurus warreni (Parks 1926)

336 An articulated specimen preserving a partial skull and relatively complete postcranial

337 skeleton was discovered in the Late Cretaceous Tolman Member of the Horseshoe Canyon

338 Formation (Edmonton Group) of Alberta, Canada (Eberth and Braman, 2012) and was

339 recognized as the holotype of a new species of Thescelosaurus, Thescelosaurus warreni (Parks,

340 1926). Sternberg $(1937,1940)$ subsequently removed this species from Thescelosaurus and

341 placed it in its own taxon, Parksosaurus. Recent analysis of all specimens previously referred to

342 the taxon Thescelosaurus upheld the validity of Parksosaurus, finding it to be diagnostically

343 distinct from all specimens previously referred to Thescelosaurus (Boyd et al., 2009). The

344 systematic placement of $P$. warreni remains uncertain, with phylogenetic analyses hypothesizing

345 it as either the sister taxon to Gasparinisaura (e.g., Buchholz, 2002; Butler et al., 2008a),

346 Thescelosaurus (e.g., Weishampel et al., 2003; Boyd et al., 2009; Brown et al., 2011), or

347 Hypsilophodon (e.g., Weishampel and Heinrich, 1992). Boyd (2014) argued for a close 
348 relationship between Parksosaurus and Thescelosaurus based on examination of the most

349 complete skull yet referred to Thescelosaurus neglectus and of the recently re-prepared holotype

350 skull of $P$. warreni, but that hypothesis was not tested in a phylogenetic analysis. Those new

351 characters observations are included in this study.

352

353 Qantassaurus intrepidus Rich and Vickers-Rich 1999

354 Qantassaurus intrepidus, from the Early Cretaceous Wonthaggi Formation (Strzelecki

355 Group: Agnolin et al., 2010) of Australia, is known from the holotype dentary and two referred

356 dentaries, which are diagnosed by their relatively short anteroposterior length compared to their

357 dorsoventral thickness. Qantassaurus intrepidus originally was referred to the

358 Hypsilophodontidae (Rich and Vickers-Rich, 1999), and was also considered a non-dryomorph

359 ornithopod (Agnolin et al., 2010), though those two statements are not mutually exclusive

360 considering 'hypsilophodontids' have traditionally placed at the base of Ornithopoda, below the

361 clade Dryomorpha (e.g., Butler et al., 2008a) .The systematic relationships of Qantassaurus were

362 never investigated in a phylogenetic analysis prior to this study.

363

364 Stormbergia dangershoeki Butler 2005

365 All specimens of Stormbergia dangershoeki are from the 'Red Beds' of the Lower

366 Jurassic upper Elliot Formation of southern Africa. The holotype and paratype are partial

367 postcranial skeletons. Although some authors considered these specimens to represent a valid

368 taxon (e.g., Butler, 2005; Butler et al., 2008a), others argue that the morphological differences

369 noted between Stormbergia dangershoeki and the contemporaneous Lesothosaurus diagnosticus

370 are a result of ontogenetic variation within a single taxon, with $L$. diagnosticus representing the 
371 smaller, presumably juvenile form and $S$. dangershoeki representing the larger, presumably adult

372 form (Knoll, 2002a, 2002b; Knoll et al., 2010). There is some support for that hypothesis based

373 on histological evidence (Knoll et al., 2010), but further study is needed before the question of

374 the validity of S. dangershoeki is satisfactorily answered. Additionally, phylogenetic analyses

375 that include both of these taxa consistently place them in disparate positions within the base of

376 Ornithischia based on the presence of unique combinations of key ornithischian characters in

377 each taxon (e.g., Butler et al., 2008a). Therefore, both L. diagnosticus and S. dangershoeki are

378 retained as terminal taxa.

379

380 Talenkauen santacrucensis Novas et al. 2004

381 The holotype and only known specimen of Talenkauen santacrucensis consists of a

382 fragmentary skull and partial postcranial skeleton from the Late Cretaceous Pari Aike Formation

383 in the Santa Cruz Province of Argentina. Prior phylogenetic analyses recovered Talenkauen as

384 either a basal euiguanodontian (e.g., Novas et al., 2004; Calvo et al., 2007) or as a basal

385 iguanodontian (e.g., Butler et al., 2008a). In the only phylogenetic analysis that included both

386 Talenkauen and the South American taxon Macrogryphosaurus gondwanicus (also from the Late

387 Cretaceous of Argentina), these two taxa were recovered as sister taxa and identified as part of a

388 new clade, Elasmaria (Calvo et al., 2007).

389

390 Thescelosaurus assiniboiensis Brown et al. 2011

391 Thescelosaurus assiniboiensis is known from a single specimen consisting of a

392 fragmentary skull and partial postcranial skeleton from the Late Cretaceous Frenchman

393 Formation of Saskatchewan, Canada, though other material from that formation are likely 
394 referable to this taxon. Originally referred to the type species of Thescelosaurus (T. neglectus),

395 the holotype of T. assiniboiensis preserves autapomorphic traits that make it diagnosably distinct

396 from all other ornithischian taxa (Brown et al., 2011). Both prior phylogenetic analyses that

397 included this taxon placed it within a Thescelosaurus clade as the sister taxon to Parksosaurus

398 warreni (Boyd et al., 2009; Brown et al., 2011).

Thescelosaurus garbanii Morris 1976

401

The holotype of Thescelosaurus garbanii is a fragmentary postcranial skeleton consisting

402 of a few vertebrae and a partial hind limb from the Hell Creek Formation of Montana. Despite

403 the incomplete nature of this specimen, it preserves an apomorphic structure of the ankle that

404 makes it diagnosably distinct from all other ornithischian taxa. Additionally, Boyd et al. (2009)

405 confirmed the referral of this species to the taxon Thescelosaurus based upon the preservation of

406 a diagnostic set of character states present in the hind limb, recovering it in a phylogenetic

407 analysis as part of a Thescelosaurus clade.

408

409

Thescelosaurus neglectus Gilmore 1913

410

Thescelosaurus neglectus is a relatively large-bodied taxon from the Late Cretaceous of

411 North America and is the type species for the taxon Thescelosaurus. This taxon is known from

412 numerous specimens, one of which includes a well-preserved, complete skull (Boyd, 2014). A

413 recent review of specimens referred to Thescelosaurus and other closely related taxa resulted in

414 the synonymization of the contemporaneous taxon Bugenasaura with Thescelosaurus and

415 confirmed the separation of Thescelosaurus and Parksosaurus (Boyd et al., 2009). The

416 systematic position of $T$. neglectus within Ornithischia remains hotly debated. It was originally 
417 thought to be closely related to basal ankylopollexians (i.e., Camptosaurus dispar) within

418 Ornithopoda, based on a preliminary examination of the hypodigm material (Gilmore, 1913), but

419 was soon after referred to the Hypsilophodontidae (Gilmore, 1915). That referral was upheld by

420 most subsequent authors for more than sixty years (e.g., Parks, 1926; Swinton, 1936; Janensch,

421 1955; Romer, 1956, 1966; Thulborn, 1970, 1972), with a few notable exceptions. Sternberg

422 (1940) placed T. neglectus in its own clade within Hypsilophodontidae, which he named

423 Thescelosaurinae (=Thescelosauridae of Sternberg [1937]), a referral that was followed by some

424 authors (e.g., Kuhn, 1966; Morris, 1976). Galton (1971a, b, 1972, 1973, 1974b) argued against

425 the placement of T. neglectus within Thescelosaurinae and even Hypsilophodontidae, instead

426 referring the taxon to Iguanodontidae. Galton $(1995,1997$, and 1999) later reassessed that

427 referral and instead assigned T. neglectus to the Hypsilophodontidae. Despite these taxonomic

428 disagreements, the placement of T. neglectus within Ornithopoda (sensu Butler et al., 2008a) was

429 uncontested by all these authors.

430 Inclusion of T. neglectus in recent phylogenetic analyses of ornithischian relationships

431 brought into question its placement within Ornithopoda (sensu Butler et al., 2008a). Several

432 analyses that included $T$. neglectus do not include marginocephalian taxa, making it impossible

433 to determine if $T$. neglectus is placed within a monophyletic Ornithopoda because they do not

434 offer a strong assessment of ornithopod monophyly (e.g., Weishampel and Heinrich, 1992;

435 Scheetz, 1999; Varricchio et al., 2007; Boyd et al., 2009). Additionally, the strict consensus trees

436 produced by Butler (2005), Spencer (2007), and Butler et al. (2008a) placed T. neglectus in a

437 large polytomy at the base of Neornithischia, a position that precludes its definitive referral to

438 Ornithopoda. Another published study (Buchholz, 2002) did not include the strict consensus tree

439 of the recovered set of ten most parsimonious trees, presenting only one of the recovered most 
440 parsimonious trees, making it impossible to determine if T. neglectus was recovered within

441 Ornithopoda in all ten of the most parsimonious trees. Finally, Weishampel et al. (2003) set their

442 supraspecific terminal taxon Marginocephalia as an outgroup taxon, making the unambiguous

443 recovery of T. neglectus within Ornithopoda a certainty. Thus, in no previous phylogenetic

444 analysis of ornithischian relationships was the placement of T. neglectus within Ornithopoda

445 unambiguously confirmed (sensu Butler et al., 2008a).

446

447 Yandusaurus hongheensis He 1979

$448 \quad$ Yandusaurus hongheensis is based on a fragmentary skull and postcranial skeleton from

449 the Middle Jurassic upper Shaximiao Formation of Sichuan, China. Though this taxon is listed as

450 being included in several prior phylogenetic analyses of ornithischian relationships (e.g.,

451 Weishampel and Heinrich, 1992; Scheetz, 1999), in most of these cases the taxon included was

452 the more complete species 'Yandusaurus' multidens, which was subsequently removed from

453 Yandusaurus and placed in a new taxon, Hexinlusaurus (Barrett et al., 2005). The most recent

454 phylogenetic analysis that included $Y$. hongheensis as a terminal taxon recovered it in an

455 unresolved position within Neornithischia (Butler et al., 2008a).

456

457 Yueosaurus tiantaiensis Zheng et al. 2012

458

This taxon is known from a single, fragmentary postcranial skeleton from the Late

459 Cretaceous Liangtoutang Formation of Zhejiang Province, China. Despite the fragmentary nature

460 of the specimen, the presence of three autapomorphies on the scapula confirms the validity of

461 this taxon. The systematic relationships of $Y$. tiantaiensis have never been assessed in a

462 phylogenetic analysis. 
Zephyrosaurus schaffi Sues 1980

465

Zephyrosaurus schaffi, a North American taxon from the Early Cretaceous Cloverly

466 Formation, is based upon an incomplete skull and extremely fragmentary postcranial skeleton.

467 Additional material referable to this taxon is known, but remains either undescribed or described

468 only in an unpublished thesis (Kutter, 2004), limiting our understanding of the taxon. In

469 phylogenetic analyses, it is frequently recovered as the sister taxon to Orodromeus makelai (e.g.,

470 Weishampel and Heinrich, 1992; Scheetz, 1999; Varricchio et al., 2007; Boyd et al., 2009) and

471 was recovered within the clade Orodrominae by Brown et al. (2013).

\section{Basal Ornithischian Taxa}

473

Two basal ornithischian taxa that are not considered part of the ingroup and do not fall

474 within any of the major ornithischian subclades, but are key for evaluating ornithischian

475 relationships, were included. These two taxa provide important insights into the early evolution

476 of ornithischian dinosaurs. Pisanosaurus mertii Casamiquela 1967 is traditionally considered the

477 most basal ornithischian taxon yet discovered, a hypothesis supported by phylogenetic analyses

478 of ornithischian relationships (e.g., Butler, 2005; Spencer, 2007; Butler et al., 2008a). Eocursor

479 parvus Butler et al. 2007 is currently considered a non-genasaurian, ornithischian dinosaur,

480 situated between the clades Heterodontosauridae and Thyreophora (e.g., Butler et al., 2007).

481 Alternatively, Spencer (2007) recovered Eocursor as a basal neornithischian, but still basal to the

482 Heterodontosauridae, which was also placed within Neornithischia. 


\section{Species Exemplars of Major Ornithischian Subclades}

485

486

487

488

489

490

491

492

493

494

495

496

497

498

499

500

501

502

503

504

505 Thyreophora Nopsca 1915 (Sensu Butler et al., 2008a) biogeographic dispersal within Ornithischia.

Heterodontosauridae Kuhn 1966 (Sensu Sereno, 2005) represent the full temporal range of this clade.

The following ornithischian taxa were included in this analysis to represent major subclades whose monophyly is supported by prior analyses of ornithischian relationships (e.g., Butler et al., 2008a). Inclusion of species-level exemplars from all four major ornithischian subclades is critical for accurately resolving the relationships of the twenty-seven taxa under study in this analysis and obtaining a clear understanding of character evolution and patterns of

The phylogenetic position of Heterodontosauridae has been problematic over the past two decades (e.g., Sereno, 1999; Buchholz, 2002; Butler, 2005; Butler et al., 2008a), being hypothesized either within Ornithopoda (e.g., Sereno, 1999), as the sister-taxon to Marginocephalia (e.g., Buchholz, 2002), near the base of Neornithischia (e.g., Butler, 2005), or outside of Genasauria (e.g., Butler et al., 2008a). Regardless of the placement of this clade within Ornithischia, a monophyletic core was consistently recovered. Six taxa were selected to represent this clade: the African taxa Abrictosaurus consors (Thulborn 1974), Heterodontosaurus tucki Crompton and Charig 1962, and Lycorhinus angustidens Haughton 1924; the European taxon Echinodon becklesii Owen 1861; the North American taxon Fruitadens haagarorum Butler et al. 2010; and, the Asian taxon Tianyulong confuciusi Zheng et al. 2009. When combined these taxa 
The monophyly of Thyreophora is one of the most stable components within Ornithischia

507 (e.g., Norman, 1984; Cooper, 1985; Sereno, 1986, 1999; Butler et al., 2008a). The European taxa

508 Emausaurus ernsti Haubold 1991 and Scelidosaurus harrisonii Owen 1861 and the North

509 American taxon Scutellosaurus lawleri Colbert 1981 were long recognized as the most basal

510 members of the Thyreophora (e.g., Sereno, 1999; Butler 2005; Butler et al., 2008a), and are here

511 included as its representatives. New character data for the $S$. lawleri was incorporated from study

512 of additional referred specimens examined by the author and currently under study at The

513 University of Texas at Austin (see Table 2).

514

515 Marginocephalia Sereno 1986 (Sensu Butler et al., 2008a)

516 The monophyly of Marginocephalia was questioned by some researchers (e.g., Dodson,

517 1990; Sullivan, 2006), but recent phylogenetic analyses of the Ornithischia all support the

518 monophyly of this clade (e.g., Butler et al., 2008a). Six marginocephalian taxa whose position

519 within Marginocephalia is confirmed by recent studies (e.g., Butler et al., 2008a) were included

520 in this analysis. These taxa include the ceratopsian dinosaurs Archaeoceratops oshimai Dong and

521 Azuma 1997, Liaoceratops yanzigouensis Xu et al. 2002, and Yinlong downsi Xu et al. 2006, and

522 the pachycephalosaurian dinosaur Wannanosaurus yansiensis Hou, 1997. Two additional taxa

523 whose exact positions within Marginocephalia remain uncertain were also included:

524 Micropachycephalosaurus hongtuyanensis Dong, 1978 and Stenopelix valdensis Meyer 1857.

525 These six taxa were chosen based upon their presumed basal position within Marginocephalia

526 and because their anatomy is more completely known than other basally positioned taxa (e.g.,

527 Chaoyangsaurus Zhao et al. 1999). 
529 Iguanodontia Dollo 1888 (Sensu Sereno, 2005)

530 Iguanodontia is a subclade within Ornithopoda, making the inclusion of species-level

531 exemplars from this clade crucial to elucidating the relationships of the taxa of interest in this

532 analysis, some of which were previously proposed to be situated within Iguanodontia (e.g.,

533 Gasparinisaura cincosaltensis, Talenkauen santacrucensis). Therefore, fourteen iguanodontian

534 species were included in this study. These species are divided into three groups. The Australian 535 species Muttaburrasaurus langdoni Bartholomai and Molnar 1981, the European species

536 Rhabdodon priscus Matheron 1869, Zalmoxes robustus (Nopcsa 1900), and Zalmoxes

537 shqiperorum Weishampel et al. 2003, and the North American species Tenontosaurus dossi

538 Winkler et al. 1997 and Tenontosaurus tilletti Ostrom 1970 are included as non-dryomorph basal

539 iguanodontian representatives. The European species Callovosaurus leedsi (Lydekker 1889) and

540 Valdosaurus canaliculatus (Galton 1975), the North American species Dryosaurus altus (Marsh

541 1878), and the African species Dysalotosaurus lettowvorbecki Virchow 1919 and Elrhazosaurus

542 nigeriensis (Galton and Taquet 1982) are included to represent the iguanodontian subclade

543 Dryosauridae (sensu Sereno, 2005) based on the phylogenetic hypothesis published by

544 McDonald et al. (2010). Finally, the North American species Camptosaurus dispar (Marsh

545 1879), the European species Iguanodon bernissartensis Boulenger 1881, and the African species

546 Ouranosaurus nigeriensis Taquet 1976 are included as representatives of the clade

547 Ankylopollexia.

\section{Outgroup Taxa}

549 The following taxa were included as outgroups to Ornithischia. Three of these taxa were 550 included to represent basal Saurischia, the sister taxon to Ornithischia (Sereno, 1999). The 
551 remaining taxa were selected based upon the phylogenetic results presented by Nesbitt et al.

552 (2010) because they represent successive sister taxa to Dinosauria.

553

554 Saurischia Seeley, 1887

555 The monophyly of Dinosauria is well-supported, with Saurischia recognized as the sister

556 taxon to Ornithischia (e.g., Novas, 1996; Sereno, 1999; Nesbitt et al., 2009, 2010). Three basal

557 theropod dinosaurs Herrerasaurus ischigualastensis Reig 1963, Sanjuansaurus gordilloi Alcober

558 and Marinez 2010, and Tawa hallae Nesbitt et al. 2009, were selected to represent this clade

559 based upon the phylogenetic results presented by Nesbitt et al. (2009) and Alcober and Martinez

560 (2010).

561

562 Silesauridae Nesbitt et al., 2010

563 Based upon the phylogenetic analysis by Nesbitt et al. (2010), the clade Silesauridae is

564 the sister taxon to Dinosauria, making it a preferred outgroup for analyses of basal ornithischian

565 relationships. The two taxa selected for inclusion in this analysis, Asilisaurus kongwe Nesbitt et

566 al. 2010; and, Silesaurus opolensis Dzik 2003, represent basal and derived members of this

567 clade, respectively.

568

569

Marasuchus lilloensis (Romer 1972)

570 This species originally was referred to the taxon Lagosuchus (Romer 1972). Subsequent

571 revision of this taxon led Sereno and Arcucci (1994) to refer it to the new taxon Marasuchus.

572 Marasuchus liloensis was previously included as an outgroup taxon in analyses of ornithischian

573 relationships (e.g., Spencer, 2007; Butler et al., 2008a), and the phylogenetic analysis of 
574 ornithodiran relationships by Nesbitt et al. (2010) confirms this species is the sister taxon to a

575 clade composed of Silesauridae + Dinosauria. Therefore, this species was included in this

576 analysis as a third successive outgroup to Ornithischia.

\section{Taxa A Priori Excluded from Study}

Several putative basal ornithischian taxa were excluded from this analysis. Many of these taxa are fragmentary and were referred to Ornithischia based upon dental characters, a practice that was recently shown to be unreliable for accurately referring fragmentary taxa to Ornithischia (e.g., Irmis et al., 2007). A brief discussion of these taxa and the reasons for their exclusion is given below. It should be noted that none of the taxa discussed below were ever included in prior phylogenetic analyses of ornithischian relationships for many of the same reasons listed here.

Additionally, several taxa were named since this study was initiated and unfortunately could not 585 be included in this version of the dataset, though certainly will be included in future versions (e.g., Albertadromeus, Kulindadromeus, Laquintasaura, Morrosaurus, Trinisaura; Coria et al., 2013; Brown et al., 2013; Godefroit et al., 2014; Barrett et al., 2014; Rozadilla et al., 2016). This latter set of taxa are not discussed below.

The holotype of Drinker nisti is a partial subadult individual preserving parts of the upper and lower jaws, vertebral centra, and partial fore and hind limbs (Bakker et al., 1990). Additional specimens referred to this taxon include isolated teeth and disarticulated postcranial elements.

594 All of this material is from the Late Jurassic Morrison Formation of Wyoming. These specimens were briefly described and partially figured (Bakker et al., 1990), but their current location is unknown, preventing further elucidation of their anatomy. As a result, this taxon was excluded 
597 from the present analysis owing to a lack of relevant morphological data, despite the fact that the 598 taxon is considered valid by some authors (e.g., Norman et al., 2004c). 599

600 Fulgurotherium australe von Huene 1932

601 This poorly known taxon from the Early Cretaceous Wallangalla Sandstone Member of 602 the Griman Creek Formation of Australia (Agnolin et al., 2010) is based on a partial, opalised 603 femur. Although several other femora were referred to this taxon from this and other formations 604 (Rich and Rich, 1989; Rich and Vickers-Rich, 1999), those referrals are suspect considering that 605 the holotype femur does not preserve any autapomorphic traits. Noting this problem, Rich and 606 Vickers-Rich (1999) considered F. austral to be a "form taxon" that was useful for 607 distinguishing between morphologically distinct subsets of femora recovered from Early 608 Cretaceous sediments in Australia. Although Norman et al. (2004c) considered the taxon to be 609 valid, other authors regard it as a nomen dubium (e.g., Butler, 2005; Agnolin et al., 2010) and 610 this study follows the latter opinion.

611

612 Geranosaurus atavus Broom 1911

613 This taxon is based upon a dentary and limb elements from the Jurassic Cave Sandstone 614 of South Africa. This taxon is currently considered to represent a nomen dubium (Norman et al., 615 2004c).

616

617 Gongbusaurus shiyii Dong et al. 1983 
619 difficulty of accurately assigning taxa based on isolated teeth to Ornithischia (e.g., Irmis et al., 620 2007), this taxon is considered of dubious validity and is excluded from this study.

621

622 Gongbusaurus wucaiwanensis Dong 1989

623 The holotype of Gongbusaurus wucaiwanensis consists of a fragmentary left mandible, 624 three caudal vertebrae, and an incomplete forelimb (Dong, 1989). The paratype consists of two 625 sacral vertebrae, eight caudal vertebrae, and a pair of complete hind limbs. The location of the 626 type material of this taxon is currently unknown (Butler et al., 2008a) and the original

627 description is brief and poorly figured. Additional specimens were since discovered that may be 628 referable to this taxon and remain under study by other authors (Xu, pers. comm., 2007), but they 629 remain unpublished. One of those specimens was personally examined by the author and it does 630 appear to represent a distinct species, but until it is published and demonstrated that this 631 specimen is referable to Gongbusaurus wucaiwanensis, it is unwise (and unethical) to include it 632 in this analysis. Therefore, this taxon is excluded from this study.

633

634 Hypsilophodon wielandi Galton and Jensen 1979

635 This taxon is based upon an isolated femur collected from the Early Cretaceous Lakota

636 Sandstone of South Dakota. The specimen does not preserve any autapomorphies or a unique 637 combination of characters and is considered to be a nomen dubium (Norman et al., 2004c). 638

639 Nanosaurus agilis Marsh $1877 \mathrm{~b}$ 
641 specimens collected from the Late Jurassic Morrison Formation of Colorado. This taxon is

642 generally considered a nomen dubium owing to the lack of autapomorphic features preserved on

643 this material (Norman et al., 2004c); though some authors have suggested it may be diagnosably

644 distinct (Galton, 2007). This study follows the former opinion and excludes N. agilis from the 645 current study.

646

647 "Proctor Lake Ornithopod” (Sensu Winkler and Murray 1989)

648 This taxon is known from multiple specimens from the Early Cretaceous Twin Mountain

649 Formation of Texas. Despite the wealth of morphological information this taxon preserves, it has 650 yet to be formally described. It is currently under study by other researchers (Winkler, pers.

651 comm., 2010), precluding its inclusion in this study while that work is being completed. 652

653 Xiaosaurus dashanpensis Dong and Tang 1983

654 Xiaosaurus dashanpensis is based upon a fragmentary skeleton from the Middle Jurassic 655 lower Shaximiao Formation of Sichuan, China. As discussed by Barrett et al. (2005), all of the 656 apomorphies proposed by Dong and Tang (1983) are actually symplesiomorphies of 657 Ornithischia, causing many to consider this taxon a nomen dubium (e.g., Norman et al., 2004a). 658 However, this taxon does possess a single autapomorphy of the humerus that indicates it is a 659 valid taxon (Barrett et al., 2005). Despite this, this study follows the advice of Butler et al. 660 (2008a) in considering the hypodigm too fragmentary and poorly figured/described to be 661 included in a phylogenetic analysis. 


\section{Analysis}

663 The data matrix was compiled using the program Mesquite v.2.74 (Maddison and

664 Maddison, 2009). The final dataset was then exported as a TNT file and opened in the program

665 Tree analysis using New Technology (TNT: Goloboff et al., 2008). All characters were run

666 unordered (non-additive setting in TNT). The dataset was then analyzed using the traditional

667 search option, which is analogous to the heuristic search option in the phylogenetic program

668 PAUP* (Swofford, 2002). The search was run using the tree bisection reconnection (TBR)

669 swapping algorithm. Branches were collapsed if the minimum possible branch length was equal

670 to zero. The search utilized 10,000 replicates with a maximum of 10,000 trees saved during each

671 replicate. A standard bootstrap analysis was run using the program TNT for 1000 replicates

672 (each using a heuristic search of 100 replicates). The results are shown in Figure 2.

\section{Evaluation of Stratigraphic Congruence}

674 The strict consensus phylogenetic hypothesis generated by this analysis was compared to

675 the phylogenetic hypotheses of ornithischian relationships of Buchholz (2002), Spencer (2007)

676 and Butler et al. (2008a) using stratigraphic consistency metrics. These metrics assume that as

677 our understanding of the fossil record increases, phylogenetic hypotheses should become

678 increasingly congruent with the stratigraphic record (Pol et al., 2004). Under that assumption, the

679 phylogenetic hypothesis that exhibits the closest fit to the fossil record best estimates the

680 topology of the true tree. For this investigation the stratigraphic consistency measures minimum

681 implied gap (MIG: Benton and Storrs, 1994; Wills, 1999), modified manhattan stratigraphic

682 measure (MSM*: Pol and Norell, 2001) and the gap excess ratio (GER: Wills, 1999) were

683 selected because those metrics are least affected by variations in tree size and shape (Pol et al.,

684 2004). The metric modified gap excess ratio (GER*; Wills et al., 2008) was not calculated 
685 because the software used in this analysis (see below) does not provide those values.

686 Additionally, accurately comparing stratigraphic congruence values calculated from different

687 tree topologies requires that each tree includes an identical set of terminal taxa (Gauthier et al.,

688 1988; Wills et al., 2008). Therefore, when conducting these comparisons each tree topology was

689 trimmed to include only those taxa that are present in both trees.

690 Calculations were conducted using the program Assistance with Stratigraphic

691 Consistency Calculations v. 4.0.0a (ASCC: Boyd et al., 2011a). That program provides the user

692 with an interactive framework for designing an analysis and entering the required data (e.g., tree

693 topology, taxon ages) and then calculates the final values. In situations where the tree topology

694 being analyzed was incompletely resolved (i.e., polytomies were present), that systematic

695 uncertainty was incorporated into the calculations using the ComPoly approach (Boyd et al.,

696 2011a), which allows the full range of variation this uncertainty imparts in stratigraphic

697 consistency values to be described. The presence of uncertainty in the age of the oldest known

698 record for each taxon was addressed using the methods outlined by Pol and Norell (2006), which

699 allow the full range of possible dates to be defined rather than having to select a single date for

700 each terminal taxon. Incorporating all of these methods into this analysis ensured that the

701 conclusions drawn from comparing the resulting stratigraphic consistency values are as accurate

702 as possible.

703

Six comparisons were conducted during this study. The strict consensus tree topology

704 generated by this analysis was compared to the tree reported by Buchholz (2002), the strict

705 consensus tree by Spencer (2007), and the strict consensus, majority rule consensus, maximum

706 agreement, and derivative strict reduced consensus trees by Butler et al. (2008a). The topology of

707 three of these trees can be seen in Figure 1. Values were also calculated for the unaltered strict 
708 consensus tree topology generated by this analysis (i.e., prior to being trimmed for comparison

709 with other tree topologies). All of the resulting values are shown in Table 3.

\section{Reconstructing Patterns of Historical Biogeography}

711 Numerous researchers discussed and/or modeled patterns of historical biogeographic

712 dispersal of ornithischian taxa (e.g., Sereno, 1997, 1999; Upchurch et al., 2002; Butler et al.,

713 2006; Brusatte et al., 2010). However, patterns of biogeographic dispersal within basal

714 Ornithischia were never reconstructed within an inclusive phylogenetic hypothesis of

715 ornithischian relationships. Given that this study is the most comprehensive analysis of basal

716 ornithischian relationships yet conducted, the phylogenetic hypothesis produced by this analysis

717 provides a comprehensive framework within which to reconstruct biogeographical patterns

718 within basal Ornithischia.

719 A variety of methods and programs exist for reconstructing patterns of historical

720 biogeography (Ronquist, 1996, 1997; Hausdorf, 1998; Ree et al., 2005; Ree and Smith, 2008).

721 The approach employed here involves incorporating time calibrated branch lengths set equal to

722 the implied missing fossil record for each taxon when reconstructing the geographic distribution

723 of ancestral taxa. This allows older taxa, which are positioned closer to the ancestral nodes and

724 are more likely to have remained in or near the ancestral geographic region, to have a larger

725 influence over what geographic region is optimized at each node.

726 Reconstruction of historical biogeography was conducted using the program Mesquite

727 v.2.74 (Maddison and Maddison, 2009). Three separate analyses focused on reconstructing the

728 ancestral geographic ranges of basal ornithischian taxa were conducted. Before conducting those

729 analyses, a new character was added to the dataset to represent the geographic range(s) of the

730 terminal taxa. This character had six possible states, one for each continent represented in the 
731 dataset (no taxa from Antarctica were included in this analysis). Each taxon was then assigned a

732 single state based upon their known geographic ranges. Each of the species included in this

733 analysis are known from a single continent, precluding the need for polymorphic codings.

734 For all three analyses, the strict consensus topology recovered during the phylogenetic

735 analysis was loaded into Mesquite and opened within a new tree window. In the first analysis, all

736 branch lengths in the tree were set equal to one (Tree $>$ Alter/Transform Branch Lengths $>$

737 Assign All Branch Lengths). The trace character history option was then selected (Analysis >

738 Trace Character History), the Stored Characters option was selected, and the Parsimony

739 Ancestral States reconstruction method was chosen. The second analysis was similar to the first,

740 except that in the last step the Likelihood Ancestral States reconstruction method was selected

741 (using the default probability models).

742 In the third analysis, the branch lengths in the tree were manually set equal to the missing

743 fossil record inferred for each branch (in myr). Implied missing fossil records were calculated for

744 each branch by hand using the oldest possible age for each terminal taxon included in the

745 analysis (see Table 2 for ages used for each taxon) and these values were assigned to their

746 respective branches by selecting the appropriate branch in the tree and then choosing the Assign

747 Selected Branch Lengths option (Tree $>$ Alter/Transform Branch Lengths $>$ Assign Selected

748 Branch Lengths). Branch lengths for branches with no implied missing fossil record were set

749 equal to 1 . Once these data were entered, the character history of the geographic character was

750 traced using the Likelihood Ancestral States reconstruction method (using the default probability

751 models). The tree topology incorporating age-weighted branch lengths was not analyzed using

752 the Parsimony Ancestral States method because that type of analysis does not take into account

753 branch lengths when reconstructing ancestral states. The resulting character state optimizations 
754 for the geographic character were recorded for all nodes in the tree during all three analyses (see

755 Supplementary Table 5).

\section{RESULTS OF PHYLOGENETIC ANALYSIS}

757

758

759

760

761

762

763

764

765

766

767

768

769

770

771

772

773

774

775

Analysis of the dataset as outlined above resulted in the recovery of thirty-six most parsimonious trees of length 868 (consistency index $[\mathrm{CI}]=0.37$; retention index $[\mathrm{RI}]=0.65$; rescaled consistency index $[\mathrm{RCI}]=0.24)$. The strict consensus of these thirty-six trees and the resulting bootstrap support values are shown in Figure 2. The details of the strict consensus tree topology are discussed in detail below. It should be noted that in the following discussion existing phylogenetic nomenclature was utilized whenever possible (see Table 1 for a list of phylogenetic definitions). Numbers given below in parentheses refer to the character number:character state being discussed. Descriptions of the characters cited below can be found in Supplementary Table 1, and a list of unambiguous character state changes within the tree is given in Supplementary Table 4. All characters discussed below are unambiguously optimized synapomorphies.

\section{Ornithischia}

The monophyly of Ornithischia is supported in this analysis by the unambiguous presence of at least a slight buccal emargination of the maxilla (19:1), the development of a distinct coronoid process of the mandible (82:1), and by the presence of a dentary contribution to the anterior portion of the coronoid process (80:1). Pisanosaurus mertii is recovered as the basalmost member of Ornithischia, consistent with previous analyses of the clade (e.g., Sereno, 1999; Butler et al., 2008a) and is plesiomorphic with respect to all other ornithischians in possessing a lateral extension of the tibia that extends posterior to the medial margin of the fibula, but fails to 
776 contact the entire posterior margin of the fibula and calcaneum (229:1). The fragmentary nature

777 of the holotype and only known specimen of $P$. mertii complicates optimization of several

778 previously proposed synapomorphies of Ornithischia that cannot be assessed in this taxon. Thus,

779 it is uncertain whether the presence of a predentary bone $(2: 1)$, an edentulous region anterior to

780 the first premaxillary tooth (7:1), a preacetabular process of the ilium that extends anterior to the

781 pubic peduncle (187:1), a posteroventrally oriented pubis (194:2), or a pendant fourth trochanter

782 (219:2) represent synapomorphies of Ornithischia as a whole, or of all ornithischians excluding

783 Pisanosaurus.

784

785

786

787

788

789

790

791

792

793

794

795

796

797

798

\section{Heterodontosauridae}

This analysis supports the findings of Butler et al. (2008a) in placing a monophyletic Heterodontosauridae (represented by Abrictosaurus consors, Echinodon becklesii; Eocursor parvus, Fruitadens haagarorum, Heterodontosaurus tucki, Lycorhinus angustidens, and Tianyulong confuciusi) outside of Genasauria, contra the findings of Sereno $(1986,1999)$, Buchholz (2002), Butler (2005), and Spencer (2007). This placement is supported by the presence of a lateral extension of the tibia that extends posterior to the entire fibula and calcaneum (229:2) in all ornithischian taxa except Pisanosaurus. Heterodontosauridae is placed outside of Genasauria based on the retention of a 'v-shaped' dentary symphysis (73:0) and the absence of a well-developed ventral process of the predentary (71:1). This study recovers Eocursor parvus as the basal-most member of Heterodontosauridae owing to the retention in this taxon of a 'V-shaped' dentary symphysis (71:1), the loss of the ventral acetabular flange of the ilium (183:1), and the presence of a horizontal brevis shelf of the ilium (189:1). Both of the latter states are present within Neornithischia in all taxa more closely related to Cerapoda than to Agilisaurus louderbacki (Fig. 2). Eocursor was previously recovered outside of Genasauria 
799 positioned between the clades Heterodontosauridae and Thyreophora (Butler et al., 2007), or as a

800 non-cerapodan basal neornithischian (Spencer, 2007). While no characters are unambiguously

801 optimized as synapomorphies of Heterodontosauridae, all heterodontosaurids more closely

802 related to Heterodontosaurus than to Echinodon are united in possessing maxillary and dentary

803 teeth with denticles restricted to the apical third of the crown (134:1), as opposed to the condition

804 in all other ornithischian taxa (except Chaoyangsaurus youngi) where denticles extend along the 805 margin of most of the crown.

\section{Genasauria}

807

All ornithischians except Pisanosaurus mertii and the heterodontosaurids are recovered within the clade Genasauria based upon the presence of a well-developed ventral process of the

809 predentary (71:1) and a 'spout-shaped' dentary symphysis (73:1). The contents of this node-

810 based clade (sensu Butler et al., 2008a) are split between two less-inclusive clades, Thyreophora 811 and Neornithischia.

\section{Thyreophora}

813 The presence of postcranial osteoderms (253:1) is traditionally considered to diagnose the

814 clade Thyreophora; however, this analysis recovers Lesothosaurus diagnosticus, which lacks

815 postcranial osteoderms, as the most basal member of Thyreophora. This placement is supported

816 based on the presence of a horizontal ridge on the surangular $(86: 1)$. The position of $L$.

817 diagnosticus varies in recent phylogenetic analyses, with some recovering this taxon as the sister

818 taxon to Genasauria (Sereno, 1986, 1999; Buchholz, 2002), as a basal neornithischian (Butler,

819 2005), or as a basal thyreophoran (Spencer, 2007; Butler et al., 2008a). The fluidity of the

820 systematic position of $L$. diagnosticus was interpreted by Butler et al. (2008a) as evidence that 
821 the anatomy of this taxon closely resembles the basal genasaurian condition, making it a crucial

822 taxon for evaluating the relationships of basal ornithischian taxa. Alternatively, if L. diagnosticus

823 is the juvenile form of Stormbergia dangershoeki, as suggested by Knoll et al. (2010), the

824 retention of an unusual suite of unique and derived features in the former taxon may be an

825 artifact of its ontogenetic status rather than a true reflection of its systematic position. All

826 thyreophorans to the exclusion of L. diagnosticus are united in possessing postcranial osteoderms

827 (253:1) and an anterior process of the jugal that is mediolaterally broader than dorsoventrally

828 deep (32:1). Scelidosaurus harrisonii and Emausaurus ernsti are united in possessing the

829 apomorphic condition of a dentary tooth row that in sinuous in lateral view $(78: 1)$.

\section{Neornithischia}

831 Neornithischian taxa are united in possessing a tab shaped obturator process on the

832 ischium (203:1) and an articulation between a sacral rib and the ischiadic peduncle of the ilium

833 (190:1). The former character is lost in Marginocephalia and Rhabdodontidae. Like Butler et al.

834 (2008a) and Spencer (2007), this analysis places several taxa outside of the node-based clade

835 Cerapoda as non-cerapodan basal neornithischians, though the set of taxa here included under

836 this designation is larger than in any previous analysis. Twenty-two taxa in this study are

837 recovered as non-cerapodan basal neornithischians (Fig. 2).

838 Stormbergia dangershoeki is placed below Agilisaurus louderbacki as the most-basal

839 neornithischian taxon based upon the retention in $S$. dangershoeki of a pubic peduncle of the

840 ilium that is larger than the ischiadic peduncle (192:0). Complementarily, the presence of a

841 reduced pubic peduncle (192:1) is an unambiguously optimized synapomorphy of all

842 neornithischian taxa more closely related to Cerapoda than to S. dangershoeki. All

843 neornithischian taxa more closely related to Cerapoda than to Agilisaurus louderbacki lack a 
844 ventral acetabular flange of the ilium (183:1; state present convergently in heterodontosaurids),

845 possess a weakly developed or absent supra-acetabular rim on the ilium (184:1; reversed in

846 Zalmoxes and present convergently in L. diagnosticus), and display a horizontal brevis shelf on

847 the ilium (189:1; present convergently in heterodontosaurids).

848 Jeholosaurus shangyuanensis and Yueosaurus tiantaiensis both possess a relatively

849 straight humerus that lacks a posterior flexure at the level of the deltopectoral crest (167:0),

850 which is plesiomorphic for Ornithischia. The clade consisting of $J$. shangyuanensis $+Y$.

851 tiantaiensis is unambiguously united with all other neornithischians in possessing a distinct

852 'trench' (i.e., fossa trochanteris) between the greater trochanter and the head of the femur

853 (212:1). Other important characters that unite these taxa include the presence of six or more

854 sacral vertebrae (148:2; convergently present in some heterodontosaurids), lateral swelling of the

855 ischiadic peduncle of the ilium (191:1; apomorphically reversed in Stenopelix valdensis [Butler

856 and Sullivan, 2009]), and a lesser trochanter of the femur that is anteroposteriorly narrow and

857 closely appressed to the greater trochanter (217:2; also present in Leaellynasaura amicagraphica

858 and some heterodontosaurids and reversed in Callovosaurus leedsi) with its dorsal extent

859 approximately level with the head of the femur (218:1; also present in some heterodontosaurids).

860 Othnielosaurus consors is positioned as more closely related to Cerapoda than to the

861 clade consisting of $J$. shangyuanensis $+Y$. tiantaiensis based on the presence of neural spines on

862 the caudal vertebrae that extend posteriorly beyond the caudal centra (152:1; reversed in

863 Orodromeus makelai, Parksosaurus warreni and Zalmoxes robustus) and a tibia with a triangular

864 cross-sectional shape (227:0; reversed in Koreanosaurus boseongensis, Parksosaurus warreni,

865 and some iguanodontians, convergently present in Stormbergia dangershoeki). Othnielosaurus

866 consors is placed below a clade consisting of Cerapoda + Parksosauridae (see Table 1 for 
867 definitions) based on the retention of a dentary with a dorsoventral height that is less than $20 \%$ of

868 its length (77:0) and dentary teeth that lack a prominent primary ridge (139:0), though both of

869 these characters display a relatively low CI (0.25 and 0.17 , respectively).

\section{Cerapoda}

871 Cerapodan taxa differ from all other neornithischian taxa in possessing dorsomedially

872 sloped or horizontal distal condyles of the quadrate (52:0; convergently present in Thyreophora),

873 maxillary crowns that taper to the root (120:1; convergently present in Jeholosaurus

874 shangyuanensis and Heterodontosaurus tucki, and reversed in Yinlong downsi), asymmetrically

875 distributed enamel on the 'cheek' teeth (123:1; convergently present in Abrictosaurus consors

876 and Heterodontosaurus tucki), and dentary crowns with ridges restricted to the lingual surface

877 (124:1; reversed in the unnamed clade of Gondwanan iguanodontians recovered in this analysis

878 and convergently present in Heterodontosaurus tucki). This node-based clade (sensu Butler et

879 al., 2008a) is subdivided into the stem-based clades Marginocephalia and Ornithopoda (see Table

8801 for definitions).

881 Marginocephalia

882 A monophyletic Marginocephalia is recovered; however, because the cranial morphology

883 of Stenopelix valdensis and Micropachycephalosaurus hongtuyanensis remain poorly

884 understood, the presence of both a parietosquamosal shelf (58:1) and exclusion of the

885 premaxillae from the internal nares (11:1) are not unambiguously optimized as synapomorphies

886 of this clade. However, the presence of a dorsoventrally flattened anterior process of the pubis

$887(197: 3)$ is recovered as an unambiguous synapomorphy of the clade. Another proposed

888 marginocephalian synapomorphy, a shortened postpubic process (Butler et al., 2008a), was not 
889 assessed in this study because it could only be scored for a single marginocephalian taxon

890 (Stenopelix valdensis) included in this study (published data for Yinlong downsi does not

891 sufficiently describe the anatomy of the pubis).

\section{Ornithopoda}

893

This study recovers a more restricted Ornithopoda than previously proposed (Fig. 2),

894 consisting only of Hypsilophodon foxii + Iguanodontia. The stem-based clade Ornithopoda and

895 the recently named node-based clade Clypeodonta (Hypsilophodon foxii + Edmontosaurus

896 regalis: Norman, 2015) have the same taxonomic contents in this study; therefore, the latter

897 clade is not discussed herein because Ornithopoda has priority. Ornithopod taxa are

898 unambiguously united in possessing maxillary crowns that are shorter than wide (132: states 0 or

899 1; reversed in Qantassaurus intrepidus and convergently present in Pisanosaurus mertii).

900

901

902

903

904

905

906

907

908

909

910

\section{Hypsilophodontidae}

The only member of this clade is Hypsilophodon foxii, supporting prior assertions that the traditional contents of this clade represent a paraphyletic assemblage of taxa and not a monophyletic grouping (e.g., Scheetz, 1999; Buchholz, 2002; Butler et al., 2008a), contra the findings of Sereno (1986, 1999), Butler (2005), and Spencer (2007).

\section{Iguanodontia}

Iguanodontians are unambiguously united in possessing a jugal wing of the quadrate that is positioned well dorsal to the distal condyles (49:1). They also display sacral neural spines that are at least twice the height of the sacral centra (149:1 or 2 ; state 1 convergently acquired in Oryctodromeus cubicularis). Four of the taxa of interest to this study are positioned at the base

of Iguanodontia as part of a previously unrecognized clade: the South American taxa Anabisetia 
911 saldiviai and Gasparinisaura cincosaltensis, and the Australian taxa Atlascopcosaurus loadsi

912 and Qantassaurus intrepidus. The placement of G. cincosaltensis in a clade at the base of

913 Iguanodontia makes the contents of the stem-based Iguanodontia (sensu Sereno, 2005) and the

914 node-based Euiguanodontia (sensu Coria and Salgado, 1996) identical. As Iguanodontia has

915 priority, the clade name Euiguanodontia is not used in the remainder of this discussion.

\section{Unnamed Clade of Gondwanan Taxa}

917 Character support is low for this clade, which is expected given that the Australian taxa

918 are known only from disarticulated maxillae and dentaries. They are united in possessing

919 mandibular teeth with vertical ridges present on both sides of the crown (124:0), which is the

920 plesiomorphic ornithischian condition. These taxa are positioned basal to all other

921 iguanodontians because they lack 'lozenge-shaped' dentary crowns (136:0), and robust (i.e.,

922 thickened) postorbitals (61:1), which are unambiguously optimized synapomorphies of more

923 derived iguanodontians. The recovery of this clade supports hypotheses presented by various

924 authors some Australian (e.g., Atlascopcosaurus) and South American taxa (e.g.,

925 Gasparinisaura) were closely related (e.g., Norman et al., 2004c; Agnolin et al., 2010). The

926 characters supporting the remainder of the iguanodontian taxa included in this study are not

927 discussed as they were not a part of the taxa of interest.

\section{Parksosauridae}

929 This study supports the results of Boyd et al. (2009), Brown et al. (2011), and Brown et

930 al. (2013) in recovering a clade of taxa traditionally recognized as 'hypsilophodontid' taxa;

931 however, Hypsilophodon foxii is not placed within this clade, precluding the application of the

932 clade name Hypsilophodontidae. Several other names could be applied to this clade. The stem- 
933 based clade Parksosauridae was first defined by Buchholz (2002) as the most inclusive clade

934 containing Parksosaurus warreni, but not Hypsilophodon foxii, Dryosaurus altus, or Iguanodon

935 bernissartensis. Alternatively, Brown et al. (2013) defined the node-based clade

936 Thescelosauridae as Thescelosaurus neglectus, Orodromeus makelai, their most recent common

937 ancestor, and all of its descendants. In this study both of those clade names contain the exact

938 same set of fourteen taxa. Given that the former name has taxonomic priority over the latter

939 name, this study utilizes the name Parksosauridae (Fig. 2), though the definition is slightly

940 modified to ensure stability (see Table 1).

941 In this study all parksosaurids are unambiguously united in possessing a posterolateral

942 concavity within the posterior end of the premaxilla, near the lateral margin, for receipt of the

943 anterolateral boss of the maxilla (14:1). They also possess a modestly flared oral margin of the

944 premaxilla (5:1; reversed in Haya griva and Orodromeus makelai and convergently present in

945 Agilisaurus louderbacki), fused premaxillae (255:1; reversed in Haya griva and Orodromeus

946 makelai), a flattened lateral surface of the greater trochanter (213:1; convergently evolved in

947 Gasparinisaura cincosaltensis and Zalmoxes), and a braincase with an angle of less than 35

948 degrees between its base and the long axis (98:1; convergently present in Hypsilophodon foxii).

\section{Orodrominae}

950 The contents of Orodrominae recovered in this study match that proposed in Brown et al.

951 (2013), consisting of four North American taxa (Orodromeus makelai, Oryctodromeus

952 cubicularis, Zephyrosaurus schaffi, and the 'Kaiparowits orodromine') and one Asian taxon

953 (Koreanosaurus boseongensis). Two unambiguous synapomorphies unite these taxa: presence of

954 a sharp and pronounced scapular spine (158:1); and, fibular shaft ' $D$-shaped' in cross-section

955 throughout it length (233:1). Additionally, these taxa are united by the presence of a sharp 
956 ventral keel on the cervical vertebrae (143:1; convergently evolved in the dryosaurid

957 Valdosaurus canaliculatus). Among the five taxa here referred to Orodrominae, O. makelai, Z.

958 schaffi, and the 'Kaiparowits orodromine' are united in displaying a tall, posterolaterally directed

959 jugal horn (38:3; convergently present in Heterodontosaurus tucki).

\section{Thescelosaurinae}

961 The clade name Thescelosaurinae was first proposed by Sternberg (1940) and was first

962 phylogenetically defined by Brown and Druckenmiller (2011), though a slightly different

963 definition is used here to ensure stability (see Table 1). The stem-based clade Thescelosaurinae is

964 the sister-taxon to the stem-based clade Orodrominae, which together comprise the stem-based

965 clade Parksosauridae. Thescelosaurines are united in possessing two supraorbital bones that are

966 not fused to the orbital margin (23:2; convergently present in Agilisaurus louderbacki) and a

967 dorsally projecting 'finger-like' process on the surangular anterior to the jaw joint (86:2;

968 convergently present in the iguanodontian Tenontosaurus tilletti), though both of these characters

969 suffer from missing data both within and outside the clade. Haya griva and Changchunsaurus

970 parvus differ from all other thescelosaurines in possessing dentaries with parallel dorsal and

971 ventral margins (75:1) and an anterior tip of the dentary positioned at approximately mid-height

972 (74:1). The remaining seven thescelosaurines differ from most basal ornithischians in possessing

973 a femur with the fourth trochanter extending onto the distal half of the shaft (221:1; convergently

974 present in some iguanodontian taxa and other large-bodied ornithischian taxa not included in this

975 analysis), partial ossification of the sternal segments of the cranial dorsal ribs (157:1;

976 convergently present in Othnielosaurus consors and Hypsilophodon foxii), placement of the

977 obturator process of the ischium along the distal $60 \%$ of the ischial shaft (204:1; convergently

978 present in Hypsilophodon foxii), and a femoral shaft bowed in anterior view (209:1; convergently 
979 present in Jeholosaurus shangyuanensis and some basal iguanodontians). The three species of

980 Thescelosaurus and Elasmaria are recovered as sister taxa to the exclusion of all other

981 parksosaurids based on the presence of an ilium with a sinuous dorsal margin (185:1; straight in

982 all other parksosaurids), a low olecranon process of the ulna (169:0), and the presence of a femur

983 that is longer than the tibia (226:1; convergently present in most basal iguanodontians and

984 Scelidosaurus harrisonii).

\section{Elasmaria}

986 This analysis recovers a slightly more inclusive Elasmaria clade than was originally

987 proposed (see Calvo et al., 2007 and Table 1), though not as inclusive as in other recent analyses

988 (Rozadilla et al., 2016). In addition to Talenkauen santacrucensis and Macrogryphosaurus

989 gondwanicus, the Patagonian taxon Notohypsilophodon comodorensis is placed within this clade.

990 All three taxa possess a highly reduced deltopectoral crest on the humerus (168:2; convergently

991 present in basal iguanodontian Anabisetia saldiviai). T. santacrucensis and M. gondwanicus both

992 retain the primitive condition of an epipophysis on cervical vertebra three (145:0; present in all

993 ornithischians positioned below Agilisaurus louderbacki), which Calvo et al. (2007) used to

994 diagnose this clade, and an ovoid, or subcylindrical, ischial shaft (205:1; convergently present in

995 Zephyrosaurus schaffi and many iguanodontians). Because the presence or absence of both of

996 these characters cannot be assessed in Notohypsilophodon due to preservational issues, it is

997 unclear if they unite all elasmarians, or if they are diagnostic for a more restricted clade

998 composed of $T$. santacrucensis and M. gondwanicus. The presence of thin mineralized plates on

999 the anterior portion of the thoracic ribcage (= intercostal plates: Butler and Galton, 2008; Boyd et

1000 al., 2011b) was also proposed to diagnose this clade (e.g., Calvo et al., 2007; Rozadilla et al.,

1001 2016). However, these structures are more widely distributed among basal neornithischian and 
1002 basal ornithopod taxa (i.e., Hypsilophodon foxii, Othnielosaurus consors, Parksosaurus warreni,

1003 and Thescelosaurus neglectus: Butler and Galton, 2008; Boyd et al., 2011b) and do not diagnose

1004 this clade.

1005 HISTORICAL BIOGEOGRAPHY OF ORNITHISCHIA

The results of the three analyses of basal ornithischian historical biogeography are

1007 presented in Figures 3 (parsimony) and 4 (likelihood). To simplify comparisons between these

1008 sets of results, they will be referred to as follows: parsimony-based analysis (PB); likelihood-

1009 based analysis with equal branch lengths (LEB); and, likelihood-based analysis with time

1010 calibrated branch lengths set equal to implied missing fossil records (LFR). Additionally, a time-

1011 calibrated version of the strict consensus tree presented from Figure 2 is shown in Figure 5. By

1012 combining the temporal and geographic information presented in these figures, the

1013 biogeographic history of basal Ornithischia can be reconstructed and discussed in detail.

1014 The LFR analysis reconstructs the ancestral area of the common ancestor of Dinosauria +

1015 Silesauridae (sensu Nesbitt et al., 2010) as Africa, while the other two analyses place the origin

1016 in South America. This difference reflects the fact that the African taxon Asilisaurus kongwe

1017 Nesbitt et al. 2010 is the oldest taxon included in this analysis, giving it more weight in the LFR

1018 analysis. All three analyses reconstruct the origin of Dinosauria and Ornithischia in South

1019 America, which is consistent with some prior proposals (e.g., Sereno, 1997). Considering two of

1020 the three basal theropods included in this study and the basal-most ornithischian taxon,

1021 Pisanosaurus mertii, are all from South America, this result is unsurprising. Ornithischia

1022 diverged from its sister taxon Saurischia by the early Late Triassic at the very latest (Fig. 5).

1023 The ancestral area of the most recent common ancestor of the clade consisting of

1024 Heterodontosauridae + Genasauria is optimized as Africa by all three analyses, with this split 
1025 likely taking place during the Late Triassic. Likewise, all three analyses reconstruct a period of

1026 rapid diversification of Heterodontosauridae to have occurred in Africa during either the Late

1027 Triassic or Early Jurassic (contra the results of Pol et al. [2011]), with the lineages leading to

1028 Echinodon becklesii, Fruitadens hagaarorum and Tianyulong confuciusi later dispersing into

1029 Europe, North America, and Asia, respectively. These dispersals could have occurred anytime

1030 during the Jurassic.

1031 The origin of Genasauria is hypothesized by all three analyses to have occurred in Africa

1032 during the Early Jurassic at the latest, and possibly during the Late Triassic, and the early

1033 diversification of Thyreophora also transpired in Africa, assuming the placement of

1034 Lesothosaurus diagnosticus at the base of this clade is accurate. There exists disagreement

1035 regarding the pattern of dispersal within Thyreophora. The LFR and LEB analyses slightly favor

1036 a scenario where basal thyreophorans dispersed from Africa into North America (giving rise to

1037 the Scutellosaurus lawleri lineage) and then migrating into Europe. The PB analysis is equivocal

1038 as to whether this is the case or if basal thyreophorans dispersed from Africa directly into

1039 Europe, with Scutellosaurus lawleri dispersing separately into North America. Either way, the

1040 diversification of these basal members of Thyreophora was completed before the late Early

1041 Jurassic. However, if L. diagnosticus is not a basal thyreophoran, then these reconstructed

1042 patterns could change dramatically.

1043 The species Stormbergia dangershoeki constrains the origin of the Neornithischia to the

1044 Early Jurassic at the latest, and all three analyses agree that this clade arose in Africa. Sometime

1045 before the late Middle Jurassic there is an extensive radiation of neornithischian taxa, though the

1046 poor fossil record of neornithischian taxa during the Early and early Middle Jurassic make it

1047 impossible to determine precisely how rapidly this radiation occurred. However, all three 
1048 biogeographic analyses agree that this radiation occurred in Asia (Figs. 3 and 4). All three

1049 analyses remain in agreement regarding the diversification of Neornithischia occurring within

1050 Asia until the most recent common ancestor of the clade consisting of Othnielosaurus consors +

1051 (Parksosauridae + Cerapoda). At this node, the LEB analysis slightly favors North America as

1052 the ancestral area (50.7\% versus $42.9 \%$ for Asia), while the LFR analysis strongly favors Asia

1053 (81.1\% versus $8.8 \%$ for North America). The PB analysis is equivocal. The situation is similar

1054 for the most recent common ancestor of the clade consisting of Parksosauridae + Cerapoda.

1055 The earliest known parksosaurid taxa, Changchunsaurus parvus and Zephyrosaurus

1056 schaffi, are present in the middle Early Cretaceous (Fig. 5). However, a long ghost lineage is

1057 present for Parksosauridae, stretching from at least the Bathonian until the Aptian, a time span of

1058 at least 40 myr. The LEB and LFR analyses agree that the basal split within Parksosauridae that

1059 gave rise to the clades Orodrominae and Thescelosaurinae occurred in North America by the

1060 Aptian (the PB analysis is undecided between North America and Asia). Both the LEB and LFR

1061 analyses also agree that the diversification of orodromine taxa occurred in North America during

1062 the Cretaceous, with the lineage leading to Koreanosaurus boseongensis splitting from

1063 Oryctodromeus cubicularis either during or prior to the Cenomanian, with the former taxon

1064 eventually dispersing into Asia by the Santonian (Figs 4 and 5). The PB analysis largely agrees

1065 with this interpretation, though it is equivocal as to whether at least some of the diversification of

1066 orodromine taxa occurred in Asia (Fig. 3).

1067 Substantial disagreement exists between all three analyses regarding the pattern of

1068 geographic dispersals present within Thescelosaurinae. In the PB analysis (Fig. 3),

1069 thescelosaurines originated in either North America or Asia. The most recent common ancestor

1070 of the clade composed of Changchunsaurus parvus and Haya griva was located in Asia, and this 
1071 clade arose by the Aptian. The ancestral area for most of the remaining thescelosaurines was

1072 North America, though a single lineage dispersed to South America by the Cenomanian, giving

1073 rise to Elasmaria. The LEB analysis largely agrees with this interpretation (Fig. 4A), though it

1074 sets the origin of Thescelosaurinae within North America, with the clade consisting of C. parvus

1075 and $\mathrm{H}$. griva dispersing into Asia by the Aptian. The results of the LRF analysis strongly contrast

1076 with both of the other analyses. The LRF analysis (Fig. 4B) places the basal split within

1077 Thescelosaurinae in Asia prior to the Aptian. The sister taxon to the C. parvus + H. griva clade

1078 then migrates into South America (possibly by way of North America). Prior to the Cenomanian,

1079 two thescelosaurine lineages disperse into North America from South America. The first gives

1080 rise to Parksosaurus warreni, while the second gives rise to the Thescelosaurus clade.

1081 The LFR and LEB analyses place the origin of Cerapoda within Asia prior to the late

1082 Middle Jurassic (Fig 4), though the PB analysis finds North America, Europe, and Asia equally

1083 likely areas (Fig. 3). The diversification of Marginocephalia occurred most likely in Asia by the

1084 Late Jurassic (the PB analysis is uncertain if this occurs in Asia or Europe owing to the basal

1085 position of Stenopelix valdensis).

1086 Extensive disagreement exists between each of the three analyses concerning the

1087 biogeographic history of basal iguanodontians, and each set of results will be discussed

1088 separately. The PB analysis (Fig. 3) places the origin of Iguanodontia in Europe. The ancestral

1089 location of the newly recognized Gondwanan clade of iguanodontians was either in Europe,

1090 Australia, or South America. The pattern of geographic dispersals within the Gondwanan

1091 iguanodontian clade is not sufficiently resolved in this analysis to permit further comment. The

1092 majority of the remaining iguanodontian taxa were endemic to Europe, with a single lineage

1093 dispersing to North America by the Aptian that gave rise to Tenontosaurus. The pattern of 
1094 geographic dispersals involving Dryosaurus altus and Dysalotosaurus lettowvorbecki are

1095 unresolved. The LEB analysis (Fig. 4A) also places the origin of Iguanodontia in Europe;

1096 however, the basal split within the Gondwanan iguanodontian clade is placed in Australia. After

1097 this split, the ancestral area of the remaining members of the clade moves to South America, with

1098 Qantassaurus intrepidus dispersing back to Australia before the Valanginian. The remaining

1099 diversification follows that recovered by the PB analysis, though it recovers Africa as the

1100 ancestral area for the most recent common ancestor of $D$. altus and D. lettowvorbecki, with the

1101 former migrating into North America by the Late Jurassic.

1102 The results of the LRF analysis contrast sharply with those of both the PB and LEB

1103 analyses (Fig. 4B). The LRF analysis places the origin of the Iguanodontia in Asia, requiring the

1104 lineage leading to Hypsilophodon foxii to disperse into Europe by the Aptian. The most recent

1105 common ancestor of the Gondwanan iguanodontian clade and Dryomorpha was also situated in

1106 Asia. The basal divergence within the Gondwanan iguanodontian clade occurred within

1107 Australia, as did all subsequent diversification within the clade, requiring two separate dispersals

1108 from Australia into South America. Above this clade, the ancestral area changes to Europe, with

1109 the lineage leading to the Tenontosaurus clade later migrating to North America and

1110 diversifying. The LFR analysis contradicts the LEB analysis in that the most recent common

1111 ancestor of the clade containing D. altus and D. lettowvorbecki migrates from Europe into North

1112 America, with the latter taxon then migrating to Africa (Fig. 4B versus 4A). One additional

1113 difference between the LFR analysis and the others is that the origin of Ankylopollexia is

1114 hypothesized to have occurred in North America and not Europe owing to the basal placement of

1115 the Jurassic taxon Camptosaurus dispar. 


\section{RESULTS OF STRATIGRAPHIC CONGRUENCE ANALYSIS}

1117 The results of the stratigraphic congruence analysis are shown in Table 3. Comparisons

1118 were limited in some cases by the necessity of trimming each tree topology to only include

1119 congruent sets of taxa. In the most extreme case, the strict consensus topology generated by this

1120 analysis was trimmed from sixty-five terminal taxa to sixteen to facilitate comparison with the

1121 strict consensus topology from Spencer (2007), limiting the amount of data available to compare

1122 these tree topologies (see Fig. 1B versus Fig. 2). An additional complicating factor was the high

1123 number of taxa placed within polytomies in each tree topology (e.g., 14 out of 35 taxa are placed

1124 in unresolved positions in the strict consensus tree of Butler et al. [2008a]). As a result, the

1125 minimum and maximum recovered values for each metric tend to be are highly disparate,

1126 lowering the chances of being able to select one tree topology as more congruent with the

1127 stratigraphic record of first appearances than another.

1128 Despite these methodological difficulties, most of these comparisons resulted in the

1129 selection of one topology as more congruent with the stratigraphic record (Table 3). In five of the

1130 six comparisons made, the strict consensus tree produced by this analysis was found to be more

1131 stratigraphically congruent than the alternative topology, and in the sixth case the two trees were

1132 found to be equally congruent (Table 3). This latter result may be at least in part due to the small

1133 number of taxa shared between these two analyses (sixteen shared taxa); however, the topology

1134 from Buchholz (2002) only shares nineteen taxa in common with the strict consensus topology of

1135 this analysis, and in that case the topology from this analysis is clearly more congruent with the

1136 stratigraphic record of first appearances (Table 3). Most importantly, the strict consensus tree

1137 topology recovered in this study is found to be more congruent with the stratigraphic record of 
1138 first appearances than any of the tree topologies put forth by Butler et al., (2008a), which was the

1139 most comprehensive analysis of basal ornithischian relationships prior to this study.

\section{DISCUSSION}

1141 The strict consensus topology produced by this analysis (Fig. 2) is the most inclusive and

1142 well-resolved phylogenetic hypothesis of ornithischian relationships to date. This tree topology is

1143 equally congruent or more congruent with the stratigraphic record of first appearances than any

1144 other ornithischian phylogeny published in the last decade and a half (Fig. 5; Table 3).

1145 Comparing the results of this study to those of other recently published ornithischian

1146 phylogenetic hypotheses (i.e., Buchholz, 2002; Spencer, 2007; and Butler, 2008a) provides

1147 important insights into those areas of the ornithischian evolutionary tree where our understanding

1148 is improving, where a consensus is beginning to be reached on contentious relationships, and

1149 where further improvement is needed.

1150 Both this analysis and that of Butler et al. (2008a), recover a monophyletic

1151 Heterodontosauridae positioned outside of Genasauria at the base of Ornithischia, though more

1152 derived than Pisanosaurus mertii. This is in strong contrast to the traditional placement of

1153 Heterodontosauridae within Ornithopoda, a placement that has not been recovered since Sereno

1154 (1999). Thus, support is building for the removal of Heterodontosauridae from Genasauria.

1155 However, heterodontosaurids do convergently share some features with basal neornithischian

1156 taxa more closely related to Cerapoda than to Agilisaurus louderbacki (e.g., loss of a ventral

1157 acetabular flange on the ilium). This may account for the recovery of Heterodontosauridae at the

1158 base of Neornithischia outside of Cerapoda by the more restricted analysis conducted by Spencer

1159 (2007). Buchholz (2002) included only one heterodontosaurid, Heterodontosaurus tucki, in his

1160 analysis of ornithischian relationships, recovering it as the sister taxon to a supraspecific terminal 
1161 taxon representing Marginocephalia. The only other phylogenetic analysis to recover this set of

1162 relationships also included $H$. tucki as the only representative of Heterodontosauridae (Xu et al.,

1163 2006). These unconventional results are likely a result of the fact that $H$. tucki is a relatively

1164 derived member of Heterodontosauridae (Pol et al., 2011; this analysis), and is not an ideal

1165 exemplar species for representing Heterodontosauridae in phylogenetic analyses, at least not by

1166 itself.

1167 This analysis recovers Eocursor parvus as a non-genasaurian ornithischian, as did Butler

1168 et al. (2007) and Pol et al. (2011), contrasting with its placement as a basal neornithischian by

1169 Spencer (2007). Unlike Butler et al. (2007) and Pol et al. (2011), this analysis identifies E.

1170 parvus as the basal-most heterodontosaurid. Butler (2010) provides a detailed list of features that

1171 separate E. parvus from heterodontosaurids, many of which are included as characters in this

1172 analysis (e.g., distribution of denticles on the tooth crowns and development of the coronoid

1173 process). Despite the inclusion of this evidence, Eocursor is positioned at the base of

1174 Heterodontosauridae based in part on the presence of some of the same features that are

1175 convergently shared between other heterodontosaurids and basal neornithischians more closely

1176 related to Cerapoda than to Agilisaurus louderbacki (e.g., presence of a ventral acetabular flange

1177 on the ilium). As such, it seems more plausible that Eocursor was a basal heterodontosaurid,

1178 which requires only two losses of these features within Ornithischia, as opposed to interpreting

1179 three independent losses near the base of Ornithischia.

1180 This analysis recovers a very restricted Ornithopoda, which contains only Hypsilophodon

1181 foxii and Iguanodontia. Such a restricted Ornithopoda has never been recovered before in a

1182 published analysis, though the largely unpublished analysis of ornithischian relationships

1183 summarized in Liu (2004) recovered an even more restricted Ornithopoda that included an 
1184 identical set of taxa as Iguanodontia. The reduced size of Ornithopoda in the study presented

1185 here is a result of the relatively high placement of Marginocephalia on the tree relative to other

1186 analyses (e.g., Sereno, 1999; Butler et al., 2008a). As a result, most taxa previously referred to

1187 the Hypsilophodontidae are now non-cerapodan basal neornithischians, with the exception of $H$.

1188 foxii. Despite not being strongly supported in the bootstrap analysis (Fig. 2), the placement of

1189 Marginocephalia on the tree is by far the most parsimonious placement given the character data

1190 analyzed. Moving Marginocephalia down the tree a single node to a position below

1191 Parksosauridae adds seven steps to the total tree length. Positioning Marginocephalia further

1192 down below Jeholosaurus shangyuanensis (the location recovered by Butler et al. [2008a])

1193 increases the tree length by nine steps. Thus, the recovered position of Marginocephalia is

1194 relatively well supported by the character data used in this study.

1195 A clade composed solely of North American basal neornithischians was first recovered

1196 by Boyd et al. (2009) in their analysis of specimens previously referred to Thescelosaurus. This

1197 analysis recovers a similar clade, here termed Parksosauridae, though it now also contains Asian

1198 and South American taxa that were not included as terminal taxa by Boyd et al. (2009). The

1199 recovery of a monophyletic Parksosauridae significantly reduces the length of the inferred ghost

1200 lineages of many of its constituent members. For example, Thescelosaurus neglectus was once

1201 inferred to possess one of the longest ghost lineages in all of Dinosauria ( 105 myr: Weishampel

1202 and Heinrich, 1992). Based on its position in the strict consensus tree, the inferred ghost lineage

1203 for this taxon is reduced by more than two-thirds (Figure 5). Thus, not only is Parksosauridae

1204 well-supported by the character evidence, it also greatly improves the stratigraphic congruence

1205 of that subsection of the tree topology. However, a sizeable ghost lineage still exists at the base

1206 of Parksosauridae, extending $\sim 40$ myr from the Early Cretaceous back into the Middle Jurassic 
1207 (Fig. 5). This implies that there is still much to learn regarding the early evolution and

1208 diversification of parksosaurids.

1209 Recent analyses of the relationships of basal neornithischian taxa from Asia (e.g.,

1210 Changchunsaurus parvus, Haya griva) have shown some support for a clade of basal

1211 neornithischian taxa endemic to Asia (Butler et al., 2011; Makovicky et al., 2011; Han et al.,

1212 2012). In its most inclusive form (Makovicky et al., 2011; Han et al., 2012) this clade consists of

1213 Haya griva as the sister taxon to a subclade composed of Jeholosaurus shangyuanensis +

1214 Changchunsaurus parvus. The exact position of this clade within Ornithischia is unresolved in

1215 the strict consensus trees of both Butler et al. (2011) and Makovicky et al. (2011), though the

1216 maximum agreement subtrees presented by both authors place this clade near the base of

1217 Ornithopoda and the strict reduced consensus tree of Han et al. (2012) produces a similar result.

1218 However, Makovicky et al. (2011) cautioned that character support for these relationships was

1219 weak and that the large number of homoplastic characters displayed by these three taxa hinted at

1220 their possibly paraphyly. A different set of relationships is recovered for these taxa in this

1221 analysis. A clade consisting of C. parvus and H. griva is situated at the base of Thescelosaurinae

1222 within Parksosauridae (Fig. 2), while J. shangyuanensis is positioned outside of Parksosauridae

1223 near the base of Neornithischia. Given the incongruence between the results presented here and

1224 those of prior studies (e.g., Butler et al., 2011; Makovicky et al., 2011; Han et al., 2012), a brief

1225 discussion of the characters supporting the placement of these taxa in the present analysis is

1226 warranted.

1227 This study incorporates new character data for J. shangyuanensis based on personal

1228 examination of multiple articulated and nearly complete specimens in the collections at Peking

1229 University, allowing much of the postcranial skeleton to be analyzed for the first time and for a 
1230 clearer understanding of the cranial anatomy to be achieved (see Table 2 for a list of specimens

1231 examined). As a result, a set of key differences between $J$. shangyuanensis and the Asian taxa $C$.

1232 parvus and $\mathrm{H}$. griva were noted that are crucial to determining the position of these taxa within

1233 Neornithischia. The ventral process of the predentary of $J$. shangyuanensis is unilobate (72:0),

1234 while in C. parvus and H. griva it is bifurcate (72:1). Six premaxillary teeth are present in $J$.

1235 shangyuanensis (112:0) in contrast to C. parvus and H. griva that display five premaxillary teeth

1236 (112:1). The morphology of the dentary of J. shangyuanensis is distinctly different than that of

1237 C. parvus and H. griva. In J. shangyuanensis, the anterior tip of the dentary is positioned close to

1238 the ventral margin (74:2), the ventral and dorsal margins of the dentary converge anteriorly

1239 (75:0), and the dorsoventral height of the dentary just anterior to the coronoid process is less than

$124020 \%$ of the total length of the dentary (77:0). Alternatively, in C. parvus and H. griva the anterior

1241 tip of the dentary is positioned at midheight (74:1), the ventral and dorsal margins of the dentary

1242 are subparallel (75:1), and the dorsoventral height of the dentary just anterior to the rising

1243 coronoid process is greater than $20 \%$ of the total length of the dentary (77:1). Additionally, the

1244 crowns of the dentary teeth in J. shangyuanensis lack a prominent primary ridge (139:0), while a

1245 primary ridge is present on the dentary crowns of both C. parvus and H. griva (139:1). In the

1246 postcranial skeleton, the lateral surface of the greater trochanter of the femur is convex in $J$.

1247 shangyuanensis (213:0), while the lateral surface of the greater trochanter of the femur is

1248 flattened in C. parvus and H. griva (213:1). That character is an unambiguous synapomorphy of

1249 Parksosauridae, clearly indicating C. parvus and H. griva are parksosaurids, while $J$.

1250 shangyuanensis is positioned outside of this clade. Overall, the character evidence outlined

1251 above strongly argues against a close relationship between $J$. shangyuanensis and either $C$.

1252 parvus or H. griva. 
1254 referred to either Hypsilophodontidae (e.g., Notohypsilophodon comodorensis) or Iguanodontia

1255 (e.g., Anabisetia saldiviai) tended to be relatively restricted in scope, focusing largely on South

1256 American taxa (e.g., Coria, 1999; Novas et al., 2004; Calvo et al., 2007; Rozadilla et al., 2016).

1257 Those investigations often recovered South American taxa in an endemic clade (Coria, 1999;

1258 Calvo et al., 2007; Rozadilla et al., 2016), or closely situated to one another as part of a South

1259 American 'grade' of taxa (Novas et al., 2004). Several studies discussed tentative character

1260 support for some or all of these taxa forming a clade of strictly South American or Gondwanan

1261 taxa (Coria and Calvo, 2002; Novas et al., 2004; Calvo et al., 2007; Ibiricu et al., 2010). Thus,

1262 the recovery in this study of an iguanodontian clade comprised entirely of Gondwanan taxa is not

1263 unexpected. In fact, Coria (1999) previously recovered a clade composed of Gasparinisaura

1264 cincosaltensis + Anabisetia saldiviai, the same two South American taxa recovered as a part of

1265 this Gondwanan clade. Coria (1999) also suggested that G. cincosaltensis and A. saldiviai had

1266 evolved from other Gondwanan taxa and likely dispersed into South America via Antarctica,

1267 possibly from Australia, prior to the Cretaceous (Coria, 1999:57). The structure of the strict

1268 consensus tree obtained by this study (Fig. 2), the results of the biogeographic reconstructions

1269 (Figs. 3 and 4), the inferred distribution of ghost lineages for the taxa recovered within the

1270 Gondwanan clade (Fig. 5), and the recent discovery of iguanodontian taxa from Antarctica

1271 (Morrosaurus antarcticus and Trinisaura santamartaensis: Coria et al., 2013; Rozadilla et al.,

1272 2016) that appear to share a close relationship with several South American iguanodontian taxa

1273 (e.g., Rozadilla et al., 2016) all support this interpretation.

1274 No prior analysis recovered a close relationship between any South American and

1275 Laurasian taxa, though some authors have suggested certain South American taxa more closely 
1276 resembled Laurasian taxa than other Gondwanan taxa (e.g., Talenkauen santacrucensis; Novas et

1277 al., 2004). The placement of the South American taxa Macrogryphosaurus gondwanicus,

1278 Notohypsilophodon comodorensis, and Talenkauen santacrucensis within Thescelosaurinae

1279 amongst the North American taxa Thescelosaurus and Parksosaurus warreni provide insight into

1280 the evolution of the ornithischian fauna of South America. The South American ornithischian

1281 taxa treated in this study are supported as parts of two distinct radiations that dispersed into

1282 South America at different times via separate geographic paths. Based on the results presented in

1283 this study, basal iguanodontian taxa dispersed into South America from Australia (possibly via

1284 Antarctica) during the Late Jurassic or the beginning of the Early Cretaceous (Figs 4 and 5).

1285 Alternatively, thescelosaurine taxa most likely dispersed into South America from Asia (via

1286 North America) sometime during the latter portion of the Early Cretaceous, and then diversified, 1287 giving rise to Elasmaria (Figs. 4 and 5).

1288 The close relationship between the South American members of Elasmaria and the North

1289 American taxa Thescelosaurus and Parksosaurus warreni may also answer some questions

1290 regarding the known stratigraphic distribution of parksosaurid taxa in North America during the

1291 Cretaceous. During most of the Cretaceous, orodromine taxa were the dominant basal

1292 neornithischian taxa present in North American faunas (Sues, 1980; Scheetz, 1999; Weishampel

1293 et al., 2004; Varricchio et al., 2007; Krumenacker, 2010; Brown et al., 2013; Gates et al., 2013).

1294 At the end of the Campanian, all orodromine taxa disappear from the North American fossil

1295 record. In the Maastrichtian the thescelosaurine taxa Thescelosaurus and Parksosaurus warreni

1296 appear in the North American fossil record, which may be an example of faunal replacement

1297 (Boyd et al., 2009; Brown et al., 2011). The results of the LFR biogeographic analysis suggest

1298 that the lineages leading to these latter two taxa may have originated in South America, and then 
1299 dispersed into North America during the Maastrichtian. This observation strengthens the

1300 paleontological support for the presence of a land bridge and associated faunal interchange

1301 between North and South America during the latest Cretaceous (Brett-Surman and Paul, 1985;

1302 Rage, 1986; Hutchinson and Chiappe, 1998; Ezcurra and Agnolin, 2011).

\section{CONCLUSION}

1304 Our understanding of the basal relationships within Ornithischia and amongst the major

1305 ornithischian sub-clades is improving, aided by the discovery and description of new taxa,

1306 redescripion and re-evaluation of previously named taxa, and the implementation of improved

1307 phylogenetic methods and practices. While the phylogenetic hypothesis presented in Figure 2 is

1308 among the best resolved, most stratigraphically consistent hypotheses yet proposed for this clade,

1309 additional improvements are needed. Clarification of the possible synonymization of

1310 Lesothosaurus diagnosticus and Stormbergia dangershoeki will help resolve questions regarding

1311 the split between and early evolution within the clades Thyreophora and Neornithischia. While

1312 support is building for the recognition of a clade of 'hypsilophodontids' that does not include

1313 Hypsilophodon (=Parksosauridae), the exact position of that clade relative to Marginocephalia

1314 and its taxonomic contents still fluctuates between analyses. While repositioning Parksosauridae

1315 within Ornithopoda substantially increases the length of the strict consensus tree obtained in this

1316 study, the future inclusion of additional character information, in terms of new characters,

1317 character state observations, and/or terminal taxa, will more robustly test this placement.

1318 Additionally, while the current placement of Parksosauridae does decrease the ghost lineages for

1319 several parksosaurid taxa (e.g., Thescelosaurus), the ghost lineage for the base of Parksosauridae

1320 is still the longest within Ornithischia, indicating there is much regarding the early evolution

1321 within Neornithischia yet to learn. Finally, the complete absence of thescelosaurines and the 
1322 dominance of orodromines in North America during most of the Cretaceous, followed by the

1323 abrupt disappearance of orodromines and wide geographic distribution of thescelosaurines in

1324 North America during the Maastrichtian remains an interesting puzzle. Increased North

1325 American sampling will help to further clarify if this temporal segregation is a real pattern or an

1326 artifact of sampling/preservation and additional work on non-cerapodan neornithischians from

1327 South America will provide additional information regarding biogeographic dispersals of

1328 thescelosaurines during the Cretaceous.

1329 Given the differences between the phylogenetic hypothesis presented in this study and

1330 those presented by Butler et al. (2008a), the natural next step is to work towards combining the

1331 character state observations presented in those datasets together (i.e., combining congruent

1332 characters, reaching a consensus on the description and scoring of character states, and removing

1333 or modifying characters and character states that are demonstrated to be influenced by

1334 tokogenetic and ontogenetic processes). The resulting dataset, possibly supplemented with

1335 additional new characters, would allow for these alternate hypotheses to be compared against a

1336 new phylogenetic hypothesis that considers all of the evidence put forth by those two studies.

1337 Such a dataset would not only be the most comprehensive test yet of basal ornithischian

1338 relationships, but would also form an excellent starting point for constructing a single dataset

1339 aimed at testing the evolutionary relationship of all ornithischian dinosaurs at the species level.

1340 Achieving such a goal will require the cooperation of numerous researchers, but would allow

1341 ornithischian relationships to be tested in such a way that all available character evidence is

1342 brought to bear on every evaluation of systematic relationships and ensure that homology

1343 statements within Ornithischia remain consistent across analyses. It would also gaurenee that

1344 analyses of taxa positioned higher up the ornithischian tree will be properly rooted and character 
1345 states correctly polarized. In the current technological age where data sharing and collaboration

1346 are easier than ever and analysis of large datasets is easily accommodated by a variety of search

1347 methods, the development of separate, competing phylogenetic datasets for the same taxonomic

1348 group should be abandoned and the construction of large scale datasets that include all available

1349 character observations is a goal that should be embraced by the entire research community.

\section{ACKNOWLEDGEMENTS}

1351 Thank you to the members of my dissertation committee, J. Clarke, C. Bell, D.

1352 Cannatella, P. Makovicky, and T. Rowe, for provided me with valuable guidance during the

1353 course of my graduate studies that greatly improved the quality of my research. I would also like

1354 to thank the former members of my committee at North Carolina State University (J. Hibbard,

1355 M. Schweitzer, and B. Wiegmann) for their guidance and efforts on my behalf during my time at

1356 NCSU, which was very much appreciated.

1357 Access to collections and specimens was generously provided by C. Mehling and M.

1358 Norell (AMNH), X. Xing (IVPP), J. Horner and B. Baziak (MOR), V. Schneider and D. Russell

1359 (NCSM), K. Q. Gao (Peking University), S. Shelton and M. Greenwald (SDSM), J. Nelson

1360 (TLAM), M. Carrano and M. Brett-Surman (USNM), S. Sampson, M. Getty, and R. Irmis

1361 (UMNH), and D. Brinkman and C. Norris (YPM). P. Brinkman (NCSM) provided guidance and

1362 collaborated in the preparation of NCSM 15728 and M. Brown (VPL) provided instruction in the

1363 preparation of several new specimens of Scutellosaurus. D. Evans (ROM) provided information

1364 on the anatomy of ROM 804. D.A. Winkler provided anatomical information about the 'Proctor

1365 Lake ornithopod.' D. Varricchio provided additional information on the anatomy of MOR 1636a.

1366 C.M. Brown provided photographs of several specimens referred to Thescelosaurus, information

1367 regarding orodromine material from the Dinosaur Park Formation, and details regarding the 
1368 anatomy of Parksosaurus. P. M. Galton provided encouragement and enlightening conversations

1369 over the years regarding basal ornithischian taxa. T. P. Cleland provided select photographs of

1370 NCSM 15728 and USNM 7758. S. Nesbitt provided access to photographs of several basal

1371 ornithischian taxa from South Africa. I am indebted to S. Masters for bringing the basal

1372 neornithischian material from the Kaiparowits Formation of Utah to my attention and A. Titus of

1373 the Utah Bureau of Land Management for assistance in locating additional specimens referable

1374 to that new taxon. The Willi Hennig Society provided free access to the phylogenetic program

1375 TNT. The Polyglot Paleontologist website provided access to multiple translations of important

1376 scientific research papers on ornithischian dinosaurs. A. D. B. Behlke, T. P. Cleland, A. DeBee,

1377 D. R. Eddy, T. Gates, J. L. Green, M. L. Householder, J. Hutchinson, E. A. Johnson, D. Ksepka,

1378 K. Lamm, S. Nesbitt, K. Pickett, D. Pol, R. Scheetz, N. A. Smith, H. D. Sues, editor J. Anquetin,

1379 and reviewers P. Makovicky and A. McDonald provided thoughtful comments on previous drafts

1380 of my dissertation and this manuscript that greatly improved the final product.

\section{REFERENCES}

1382 Agnolin F. L., M. D. Ezcurra, D. F. Pais, and S. W. Salisbury. 2010. A reappraisal of the

1383 Cretaceous non-avan dinosaur faunas from Australia and New Zealand: evidence for their

1384 Gondwanan affinities. Journal of Systematic Paleontology 8:257-300.

1385 Alcober, O. A., and R. N. Martinez. 2010. A new herrerasaurid (Dinosauria, Saurischia) from the

$1386 \quad$ Upper Triassic Ischigualasto Formation of northwestern Argentina. ZooKeys 63:55-81.

1387 Bakker, R. T., P. M. Galton, J. Siegwarth, and J. Filla. 1990. A new latest Jurassic vertebrate

1388 fauna from the highest levels of the Morrison Formation at Como Bluff, Wyoming. Part

1389 4. The dinosaurs: A new Othnielia-like hypsilophodontid. Hunteria 2:1-24. 
1390 Barrett, P. M., and F.-L. Han. 2009. Cranial anatomy of Jeholosaurus shangyuanensis

1391 (Dinosauria: Ornithischia) from the Early Cretaceous of China. Zootaxa 2072:31-55.

1392 Barrett, P. M., R. J. Butler, and F. Knoll. 2005. Small-bodied ornithischian dinosaurs from the

1393 Middle Jurassic of Sichuan, China. Journal of Vertebrate Paleontology 25:823-834.

1394 Barrett, P. M., R. J. Butler, R. J. Twitchett, and S. Hutt. 2011. New material of Valdosaurus

1395 canaliculatus (Ornithischia: Ornithopoda) from the Lower Cretaceous of southern

1396 England. Special Papers in Palaeontology 86:131-163.

1397 Barrett, P. M., R. J. Butler, R. Mundil, T. M. Scheyer, R. B. Irmis, and M. R. Sánchez-Villagra.

1398 2014. A paleoequatorial ornithischian and new constraints on early dinosaur

1399 diversification. Proceedings of the Royal Society: B 281:20141147.

1400 Bartholomai, A., and R. E. Molnar. 1981. Muttaburrasaurus, a new iguanodontid (Ornithischia:

1401 Ornithopoda) dinosaur from the Lower Cretaceous of Queensland. Memoirs of the

$1402 \quad$ Queensland Museum 20:319-349.

1403 Benton, M. J., and G. W. Storrs. 1994. Testing the quality of the fossil record: paleontological

$1404 \quad$ knowledge is improving. Geology 22:111-114.

1405 Bonaparte, J. F. 1976. Pisanosaurus mertii Casamiquela and the origin of the Ornithischia.

$1406 \quad$ Journal of Paleontology 50:808-820.

1407 Bonaparte, J. F., and J. E. Powell. 1980. A continental assemblage of tetrapods from the Upper

1408 Cretaceous bed of El Brete, northwestern Argentina (Sauropoda-Coelurosauria-

1409 Carnosauria-Aves). Memoires de la Societe Geologique, France 139:19-28.

1410 Boulenger, G. A. 1881. Sur l'arc pelvien chez les dinosauriens de Bernissart. Bulletins de

1411 L'Académie royale de Belgique, 3eme série 1:600-608. 
1412 Boyd, C. A. 2012. Taxonomic revision of latest Cretaceous North American basal

1413 neornithischian taxa and a phylogenetic analysis of basal ornithischian relationships. The

$1414 \quad$ University of Texas at Austin, Austin, $432 \mathrm{pp}$.

1415 Boyd, C. A. 2014. The cranial anatomy of the neornithischian dinosaur Thescelosaurus

1416 neglectus. PeerJ 2:3669.

1417 Boyd, C. A., C. M. Brown, R. D. Scheetz, and J. A. Clarke. 2009. Taxonomic revision of the 1418 basal neornithischian taxa Thescelosaurus and Bugenasaura. Journal of Vertebrate $1419 \quad$ Paleontology 29:758-770.

1420 Boyd, C. A., T. P. Cleland, N. L. Marrero, and J. A. Clarke. 2011a. Exploring the effects of 1421 phylogenetic uncertainty and consensus trees on stratigraphic consistency scores: a new 1422 program and a standardized method. Cladistics 26:1-9.

1423 Boyd, C. A., T. P. Cleland, and F. E. Novas. 2011b. Osteogenesis, homology, and function of the 1424 intercostal plates in ornithischian dinosaurs (Tetrapoda, Sauropsida). Zoomorphology $1425 \quad 130: 305-313$.

1426 Brett-Surman, M. K., and G. S. Paul. 1985. A new family of bird-like dinosaurs linking Laurasia 1427 and Gondwanaland. Journal of Vertebrate Paleontology 5:133-138.

1428 Broom, R. 1911. On the dinosaurs of the Stormberg, South Africa. Annals of the South African $1429 \quad$ Museum 7:291-308.

1430 Brown, B. 1908. The Ankylosauridae, a new family of armored dinosaurs from the Upper 1431 Cretaceous. Bulletin of the American Museum of Natural History 24:187-201.

1432 Brown, C. M. and P. Druckenmiller. 2011. Basal ornithopod (Dinosauria: Ornithischia) teeth 1433 from the Prince Creek Formation (early Maastrichtian) of Alaska. Canadian Journal of $1434 \quad$ Earth Sciences 48:1342-1354. 
1435 Brown, C. M., C. A. Boyd, and A. Russell. 2011. A new basal ornithopod dinosaur (Frenchman

1436 Formation, Saskatchewan, Canada), and implications for late Maastrichtian ornithischian

1437 diversity in North America. Zoological Journal of the Linnean Society 163:1157-1198.

1438 Brown, C. M., D. C. Evans, M. J. Ryan, and A. P. Russell. 2013. New data on the diversity and 1439 abundance of small-bodied ornithopods (Dinosauria, Ornithischia) from the Belly River 1440 Group (Campanian) of Alberta. Journal of Vertebrate Paleontology. 33:495-520.

1441 Brusatte, S. L., S. J. Nesbitt, R. B. Irmis, R. J. Butler, M. J. Benton, and M. A. Norell. 2010. The 1442 origin and early radiation of dinosaurs. Earth-Science Reviews 101:68-100.

1443 Buchholz, P. W. 2002. Phylogeny and biogeography of basal Ornithischia; pp. 18-34 in D. E.

1444 Brown (ed.), The Mesozoic in Wyoming. Tate Geological Museum, Casper.

1445 Butler, R. J. 2005. The 'fabrosaurid' ornithischian dinosaurs of the Upper Elliot Formation

1446 (Lower Jurassic) of South Africa and Lesotho. Zoological Journal of the Linnean Society $1447 \quad 145: 175-218$.

1448 Butler, R. J. 2010. The anatomy of the basal ornithischian dinosaur Eocursor parvus from the 1449 lower Elliot Formation (Late Triassic) of South Africa. Zoological Journal of the Linnean $1450 \quad$ Society 160:648-684.

1451 Butler, R. J., and P. M. Galton. 2008. The 'dermal armour' of the ornithopod dinosaur 1452 Hypsilophodon from the Wealden (Early Cretaceous: Barremian) of the Isle of Wight: a 1453 reappraisal. Cretaceous Research 29:636-642.

1454 Butler, R. J., and R. M. Sullivan. 2009. The phylogenetic position of the ornithischian dinosaur 1455 Stenopelix valdensis from the Lower Cretaceous of Germany and the early fossil record 1456 of Pachycephalosauria. Acta Palaeontologica Polonica 54:21-34. 
1457 Butler, R. J., and Q. Zhao. 2009. The small-bodied ornithischian dinosaurs

1458 Micropachycephalosaurus hongtuyanensis and Wannanosaurus yansiensis from the Late 1459 Cretaceous of China. Cretaceous Research 30:63-77.

1460 Butler, R. J., P. Upchurch, D. B. Norman, and J. Parish. 2006. A biogeographical analysis of the 1461 ornithischian dinosaurs; pp. 13-16 in P. M. Barrett and S. E. Evans (eds.), Ninth

1462 Symposium on Mesozoic Terrestrial Ecosystems and Biota. The Natural History 1463 Museum, London.

1464 Butler, R. J., R. M. H. Smith, and D. B. Norman. 2007. A primitive ornithischian dinosaur from 1465 the Late Triassic of South Africa, and the early evolution and diversification of 1466 Ornithischia. Proceedings of the Royal Society B 274:2041-2046.

1467 Butler, R. J., P. Upchurch, and D. B. Norman. 2008a. The phylogeny of the ornithischian 1468 dinosaurs. Journal of Systematic Paleontology 6:1-40.

1469 Butler, R. J., L. B. Porro, and D. B. Norman. 2008b. A juvenile skull of the primitive 1470 ornithischian dinosaur Heterodontosaurus tucki from the 'Stormberg' of southern Africa. $1471 \quad$ Journal of Vertebrate Paleontology 28:702-711.

1472 Butler, R. J., P. M. Galton, L. B. Porro, L. M. Chiappe, D. M. Henderson, and G. M. Erickson. 1473 2010. Lower limits of ornithischian dinosaur body size inferred from a new Upper 1474 Jurassic heterodontosaurid from North America. Proceedings of the Royal Society B $1475 \quad 277: 375-381$.

1476 Butler, R. J., L. Y. Jin, J. Chen, and P. Godefroit. 2011. The postcranial osteology and 1477 phylogenetic position of the small ornithischian dinosaur Changchunsaurus parvus from 1478 the Quantou Formation (Cretaceous: Aptian-Cenomanian) of Jilin Province, northeastern 1479 China. Palaeontology 54:667-683. 
1480 Calvo, J. O., J. D. Porfiri, and F. E. Novas. 2007. Discovery of a new ornithopod dinosaur from

1481 the Portezuelo Formation (Upper Cretaceous), Neuquen, Patagonia, Argentina. Arquivos 1482 do Museu Nacional 65:471-483.

1483 Casamiquela, R. M. 1967. Un nuevo dinosaurio ornitischio Triásico (Pisanosaurus mertii:

1484 Ornithopoda) de la Formación Ischigualasto, Argentina. Ameghiniana 4:47-64.

1485 Colbert, E. H. 1981. A primitive ornithischian dinosaur from the Kayenta Formation of Arizona. 1486 Bulletin of the Museum of Northern Arizona 53:1-61.

1487 Cooper, M. R. 1985. A revision of the ornithischian dinosaur Kangnasaurus coetzeei Haughton 1488 with a classification of the Ornithischia. Annals of the South African Museum 95:2811489317.

1490 Coria, R. A. 1999. Ornithopod dinosaurs from the Neuquen Group, Patagonia, Argentina; pp. 47-

60 in Y. Tomida, T. H. Rich, and P. Vickers-Rich (eds.), Proceedings of the Second 1492 Gondwana Dinosaur Museum. National Science Museum Monographs, Tokyo.

1493 Coria, R. A., and J. O. Calvo. 2002. A new iguanodontian ornithopod from Neuquen Basin, 1494 Patagonia, Argentina. Journal of Vertebrate Paleontology 22:503-509.

1495 Coria, R. A., and L. Salgado. 1996. A basal iguanodontian (Ornithischian: Ornithopoda) from the 1496 Late Cretaceous of South America. Journal of Vertebrate Paleontology 16:445-457.

1497 Coria, R. A., J. J. Moly, M. Reguero, S. Santillana, and S. Marenssi. 2013. A new ornithopod 1498 (Dinosauria; Ornithischia) from Antarctica. Cretceous Research 41:186-193.

1499 Crompton, A. W., and A. J. Charig. 1962. A new ornithischian from the Upper Triassic of South $1500 \quad$ Africa. Nature 196:1074-1077.

1501 Dodson, P. 1990. Marginocephalia; pp. 562-563 in D. B. Weishampel, P. Dodson, and H. 1502 Osmólska (eds.), The Dinosauria: First Edition. University of California Press, Berkeley. 
1503 Dollo, L. 1882. Première note sur les dinosauriens de Bernissart. Bulletin de Museum Royal de 1504 Histoire Naturelles de Belgique 1:161-180.

1505 Dollo, L. 1888. Iguanodontidae et Camptonotidae. Comptes Rendus de Académie des Sciences (Paris) 106:775-777.

1507 Dong, Z. 1978. A new genus of Pachycephalosauria from Laiyang, Shantung. Vertebrata $1508 \quad$ PalAsiatica 16:225-228.

1509 Dong, Z. 1989. On a small ornithopod (Gongbusaurus wucaiwanensis sp. nov.) from Kelamaili 1510 Junggar Basin, Xinjiang, China. Vertebrata PalAsiatica 27:140-146.

1511 Dong, Z., and Z. Tang. 1983. Note on the new mid-Jurassic ornithopod from the Sichuan Basin, 1512 China. Vertebrata PalAsiatica 21:168-172.

1513 Dong, Z., and Y. Azuma. 1997. On a primitive neoceratopsian from the Early Cretaceous; pp. 1514 68-89 in Z. M. Dong (ed.), Sino-Japanese Silk Road Dinosaur Expedition. China Ocean $1515 \quad$ Press, Beijing.

1516 Dong, Z., S. Zhou, and Z. Zhang. 1983. Dinosaurs from the Jurassic of Sichuan. Palaeontologica $1517 \quad$ Sinica, New Series C 23:1-145.

1518 Dzik, J. 2003. A beaked herbivorous archosaur with dinosaur affinities from the early Late 1519 Triassic of Poland. Journal of Vertebrate Paleontology 23:556-574.

1520 Eberth, D. A., and D. R. Braman. 2012. A revised stratigraphy and depositional history for the 1521 Horseshoe Canyon Formation (Upper Cretaceous), southern Alberta plains. Canadian $1522 \quad$ Journal of Earth Scieces 49:1053-1086.

1523 Ezcurra, M. D., and F. L. Agnolin. 2011. A new global palaeobiogeographical model for the Late 1524 Mesozoic and Early Tertiary. Systematic Biology. 
1525 Forster, C. A. 1990. The postcranial skeleton of the ornithopod dinosaur Tenontosaurus tilletti. 1526 Journal of Vertebrate Paleontology 10:273-294.

1527 Galton, P. M. 1971a. Hypsilophodon the cursorial non-arboreal dinosaur. Nature 231:159-161.

1528 Galton, P. M. 1971b. The mode of life of Hypsilophodon, the supposedly arboreal ornithopod 1529 dinosaur. Lethaia 4:453-465.

1530 Galton, P. M. 1972. Classification and evolution of ornithopod dinosaurs. Nature 239:464-466.

1531 Galton, P. M. 1973. Redescription of the skull and mandible of Parksosaurus from the Late 1532 Cretaceous with comments on the family Hypsilophodontidae (Ornithischia). Life 1533 Science Contributions, Royal Ontario Museum 89:1-21.

1534 Galton, P. M. 1974a. The ornithischian dinosaur Hypsilophodon from the Wealden of the Isle of 1535 Wight. Bulletin of the British Museum (Natural History) Geology 25:1-152.

1536 Galton, P. M. 1974b. Notes on Thescelosaurus, a conservative ornithopod dinosaur from the 1537 Upper Cretaceous of North America, with comments on ornithopod classification. $1538 \quad$ Journal of Paleontology 48:1048-1067.

1539 Galton, P. M. 1975. English hypsilophodontid dinosaurs (Reptilia: Ornithischia). Palaeontology $1540 \quad 18: 741-752$.

1541 Galton, P. M. 1977. The ornithopod dinosaur Dryosaurus and a Laurasia-Gondwanaland 1542 connection in the Upper Jurassic. Nature 268:230-232.

1543 Galton, P. M. 1978. Fabrosauridae, the basal family of ornithischian dinosaurs (Reptilia:

1544 Ornithopoda). Paläontologische Zeitschrift 52:138-159.

1545 Galton, P. M. 1980. European Jurassic ornithopod dinosaurs of the families Hypsilophodontidae 1546 and Camptosauridae. Neues Jahrbuch für Geologie und Paläontologie, Abhandlungen $1547 \quad 160: 73-95$. 
1548 Galton, P. M. 1981. Dryosaurus, a hypsilophodontid dinosaur from the Upper Jurassic of North

1549 America and Africa. Postcranial skeleton. Paläontologische Zeitschrift 55:271-312.

1550 Galton, P. M. 1983. The cranial anatomy of Dryosaurus, a hypsilophodontid dinosaur from the

1551 Upper Jurassic of North America and east Africa, with a review of hypsilophodontids

1552 from the Upper Jurassic of North America. Geologica et Palaeontologica 17:207-243.

1553 Galton, P. M. 1989. Crania and endocranial casts from ornithopod dinosaurs of the families

1554 Dryosauridae and Hypsilophodontidae (Reptilia: Ornithischia). Geologica et

$1555 \quad$ Palaeontologica 23:217-239.

1556 Galton, P. M. 1995. The species of the basal hypsilophodontid dinosaur Thescelosaurus Gilmore

1557 (Ornithischia: Ornithopoda) from the Late Cretaceous of North America. Neues Jahrbuch

1558 für Geologie und Paläontologie Abhandlungen 198:291-311.

1559 Galton, P. M. 1997. Cranial anatomy of the basal hypsilophodontid dinosaur Thescelosaurus

1560 neglectus GILMORE (Ornithischia: Ornithopoda) from the Upper Cretaceous of North

$1561 \quad$ America. Revue de Paleobiologie 16:231-258.

1562 Galton, P. M. 1999. Cranial anatomy of the hypsilophodontid dinosaur Bugenasaura infernalis

1563 (Ornithischia: Ornithopoda) from the Upper Cretaceous of North America. Revue de

$1564 \quad$ Paleobiologie 18:517-534.

1565 Galton, P. M. 2007. Teeth of ornithischian dinosaurs (mostly Ornithopoda) from the Morrison

1566 Formation (Upper Jurassic) of the western United States; pp. 17-47 in K. Carpenter (ed.),

1567 Horns and Beaks: Ceratopsian and Ornithopod Dinosaurs. Indiana University Press,

1568 Bloomington and Indianapolis. 
1569 Galton, P. M. 2009. Notes on Neocomian (Late Cretaceous) ornithopod dinosaurs from England

1570 - Hypsilophodon, Valdosaurus, "Camptosaurus", "Iguanodon" - and referred specimens

1571 from Romania and elsewhere. Revue de Paleobiologie 28:211-273.

1572 Galton, P. M., and J. A. Jensen. 1973. Small bones of the hypsilophodontid dinosaur Dryosaurus 1573 altus from the Upper Jurassic of Colorado. Great Basin Naturalist 33:129-132.

1574 Galton, P. M., and J. A. Jensen. 1979. Remains of ornithopod dinosaurs from the Lower 1575 Cretaceous of North America. Brigham Young University Geological Studies 25:1-10.

1576 Galton, P. M., and P. Taquet. 1982. Valdosaurus, a hypsilophodontid dinosaur from the Lower 1577 Cretaceous of Europe and Africa. Geobios 15:147-159.

1578 Gao, K-Q., and N. H. Shubin. 2012. Late Jurassic salamandroid from western Liaoning, China.

1579 Proceedings of the National Academy of Sciences 109:5767-5772.

1580 Garcia, G., M. Pincemaille, M. Vianey-Liaud, B. Marandat, E. Lorenz, G. Cheylan, H. Cappetta,

1581 J. Michaux, and J. Sudre. 1999. Découverte du premier squelette preque complet de 1582 Rhabdodon priscus (Dinosauria, Ornithopoda) du Maastrichtien inférieur de Provence.

1583 Comptes Rendus de l'Académie des Sciences à Paris, Sciences de la Terre et des

$1584 \quad$ Planètes. 328:415-421.

1585 Gates T. A., E. K. Lund, C. A. Boyd, M. A. Getty, D. D. deBlieux, J. I. Kirkland, and D. C.

1586 Evans. 2013. Ornithopod dinosaurs from the Grand Staircase-Escalante National

1587 Monument Region, Utah, and their role in paleobiogeographic and macroevolutionary

1588 studies; pp. 463-481 in A. Titus and M. A Loewen (eds.), At the top of the Grand

1589 Staircase: the Late Cretaceous in Utah. Indiana University Press, Bloomington.

1590 Gauthier, J., A. G. Kluge, and T. Rowe. 1988. Amniote phylogeny and the importance of fossils.

$1591 \quad$ Cladistics 4:105-209. 
1592 Gilmore, C. W. 1913. A new dinosaur from the Lance Formation of Wyoming. Smithsonian $1593 \quad$ Miscellaneous Collections 61:1-5.

1594 Gilmore, C. W. 1915. Osteology of Thescelosaurus, an orthopodous dinosaur from the Lance

1595 Formation of Wyoming. Proceedings of the United States National Museum 49:591-616.

1596 Gilmore, C. W. 1931. A new species of troodont dinosaur from the Lance Formation of

1597 Wyoming. Proceedings of the United States National Museum 79:1-6.

1598 Godefroit, P., V. Codrea, and D. B. Weishampel. 2009. Osteology of Zalmoxes shqiperorum

1599 (Dinosauria, Ornithopoda), based on new specimens from the Upper Cretaceous of Nalat-

$1600 \quad$ Vad (Romania). Geodiversitas 31:525-553.

1601 Godefroit, P., S. M. Sinitsa, D. Dhouailly, Y. L. Bolosky, A. V. Sizov, M. E. McNamara, M. J.

1602 Benton, and P. Spagna. 2014. A Jurassic ornithischian dinosaur from Siberia with both 1603 feathers and scales. Science 345:451-455.

1604 Goloboff, P. A., J. S. Farris, and K. C. Nixon. 2008. TNT, a free program for phylogenetic $1605 \quad$ analysis. Cladistics 24:774-786.

1606 Gow, C. E. 1975. A new heterodontosaurid from the Redbeds of South Africa showing clear 1607 evidence of tooth replacement. Zoological Journal of the Linnean Society 57:335-339.

1608 Gow, C. E. 1981. Taxonomy of the Fabrosauridae (Reptilia, Ornithischia) and the Lesothosaurus 1609 myth. South African Journal of Science 77:43-43.

1610 Gow, C. E. 1990. A tooth-bearing maxilla referable to Lycorhinus angustidens Haughton, 1924

1611 (Dinosauria, Ornithischia). Annals of the South African Museum 99:367-380.

1612 Han, F-L., P. M. Barrett, R. J. Butler, and X. Xing. 2012. Postcranial anatomy of Jeholosaurus 1613 shangyuanensis (Dinosauria, Ornithischia) from the Lower Cretaceous Yixian Formation 1614 of China. Journal of Vertebrate Paleontology 32:1370-1395. 
1615 Haubold, H. 1991. Ein neuer Dinosaurier (Ornithischia, Thyreophora) aus dem unteren Jura des 1616 nördlichen Mitteleuropa. Revue de Paléobiologie 9:149-177.

1617 Haughton, S. H. 1924. The fauna and stratigraphy of the Stormberg Series. Annals of the South $1618 \quad$ African Museum 12:323-497.

1619 Hausdorf, B. 1998. Weighted ancestral area analysis and a solution of the redundant distribution $1620 \quad$ problem. Systematic Biology 47:445-456.

1621 He, X. 1979. A newly discovered ornithopod dinosaur-Yandusaurus from Zigong, China; pp. 1622 116-123, Contribution to International Exchange of Geology. Part 2, Stratigraphy and 1623 Paleontology. Geological Publishing House, Beijing.

1624 He, X. L., and K. J. Cai. 1983. A new species of Yandusaurus (hypsilophodont dinosaur) from 1625 the Middle Jurassic of Dashanpu, Zigong, Sichuan. Journal of Chengdu College of 1626 Geology, Supplement 1:5-14.

1627 He, X. L., and K. J. Cai. 1984. The Middle Jurassic dinosaurian fauna from Dashanpu, Zigong, 1628 Sichuan., The Ornithopod Dinosaurs, Volume 1. Sichuan Scientific and Technological 1629 Publishing House, 1-71 pp.

1630 Herne, M. C., and S. W. Salisbury. 2009. The status of Leaellynasaura amicagraphica 1631 (Dinosauria: Ornithischia) from the Early Cretaceous of southeastern Australia. 1632 Geological Society of Australia Abstracts 93:35.

1633 Hopson, J. A. 1975. On the generic separation of the ornithischian dinosaurs Lycorhinus and 1634 Heterodontosaurus from the Stormberg Series (Upper Triassic) of South Africa. South 1635 African Journal of Science 71:302-305.

1636 Horner, J., and D. B. Weishampel. 1988. A comparative embryological study of two 1637 ornithischian dinosaurs. Nature 332:256-257. 
1638 Horner, J. R., A. de Ricqles, K. Padian, and R. D. Scheetz. 2009. Comparative long bone

1639 histology and growth of the "hypsilophodontid" dinosaurs Orodromeus makelai,

1640 Dryosaurus altus, and Tenontosaurus tilletti (Ornithischia: Euornithopoda). Journal of

$1641 \quad$ Vertebrate Paleontology 29:734-747.

1642 Hou, L.-H. 1977. A new primitive Pachycephalosauria from Anhui, China. Vertebrata

$1643 \quad$ PalAsiatica 15:198-202.

1644 Huh, M., D.-G. Lee, J.-K. Kim, J.-D. Lim, and P. Godefroit. 2011. A new basal ornithopod

1645 dinosaur from the Upper Cretaceous of South Korea. Neues Jahrbuch für Geologie und

1646 Paläontologie Abhandlungen 259:1-24..

1647 Hutchinson, J. R., and L. M. Chiappe. 1998. The first known alvarezsaurid (Theropoda: Aves)

1648 from North America. Journal of Vertebrate Paleontology 18:447-450.

1649 Huxley, T. J. 1869. On Hypsilophodon, a new genus of Dinosauria. Abstracts of the Proceedings

$1650 \quad$ of the Geological Society of London 204:3-4.

1651 Ibiricu, L. M., R. D. Martinez, M. C. Lamanna, G. A. Casal, M. Luna, J. D. Harris, and K. J.

1652 Lacovara. 2010. A medium-sized ornithopod (Dinosauria: Ornithischia) from the Upper

1653 Cretaceous Bajo Barreal Formation of Lago Colhue Huapi, southern Chubut Province,

1654 Argentina. Annals of Carnegie Museum 79:39-50.

1655 Irmis, R. B., W. Parker, and S. J. Nesbitt. 2007. Early ornithischian dinosaurs: the Triassic

1656 record. Historical Biology 19:3-22.

1657 Janensch, W. 1955. Der Ornithopode Dysalotosaurus der Tendaguruschichten.

$1658 \quad$ Palaeontographica (supplement 7) 3:105-176.

1659 Jin, L. Y., J. Chen, S. Q. Zan, R. J. Butler, and P. Godefroit. 2010. Cranial anatomy of the small

1660 ornithischian dinosaur Changchunsaurus parvus from the Quantou Formation 
(Cretaceous: Aptian-Cenomanian) of Jilin Province, northeastern China. Journal of Vertebrate Paleontology 30:196-214.

1663 Knoll, F. 2002a. Nearly complete skull of Lesothosaurus (Dinosauria: Ornithischia) from the 1664 Upper Elliot Formation (Lower Jurassic: Hettangian) of Lesotho. Journal of Vertebrate $1665 \quad$ Paleontology 22:238-243.

1666 Knoll, F. 2002b. New skull of Lesothosaurus (Dinosauria: Ornithischia) from the Upper Elliot 1667 Formation (Lower Jurassic) of southern Africa. Geobios 35:595-603.

1668 Knoll, F., K. Padian, and A. de Ricqles. 2010. Ontogenetic change and adult body size of the 1669 early ornithischian dinosaur Lesothosaurus diagnosticus: Implications for basal ornithischian taxonomy. Gondwana Research 17:171-179.

1671 Krumenacker, L. J. 2010. Chronostratigraphy and paleontology of the mid-Cretaceous Wayan 1672 Formation of eastern Idaho, with a description of the first Oryctodromeus specimens 1673 from Idaho. Department of Geological Sciences, Brigham Young University, Provo, $1674 \quad$ Utah, $88 \mathrm{pp}$.

1675 Kuhn, O. 1966. Die Reptilien, System und Stammesgeschichte. Oeben Verlag, Kraillingen bei München, Germany, 154 pp.

1677 Kutter, M. M. 2004. New material of Zephyrosaurus schaffi (Dinosauria; Ornithischia) from the

1678 Cloverly Formation (Aptian-Albian) of Montana and the phylogeny of 1679 Hypsilophodontidae. Biological Sciences, University of the Pacific, Stockton, California, $168075 \mathrm{pp}$.

1681 Linnaeus, C. 1758. Systema Naturae per Raegna Tria Naturae. Volume 1. Regnum Animale. 1682 10th Edition. Trustees, British Museum (Natural History), London, 823 pp.

1683 Liu, J. 2004. Phylogeny of Ornithischia. Journal of Vertebrate Paleontology 24 (suppl.):84A. 
1684 Lydekker, R. 1889. On the remains and affinities of five genera of Mesozoic reptiles. Quarterly 1685 Journal of the Geological Society of London 45:41-59.

1686 Maddison, W. P., and D. R. Maddison. 2009. Mesquite: a modular system for evolutionary $1687 \quad$ analysis. 2.71.

1688 Makovicky, P. J., B. M. Kilbourne, R. W. Sadleir, and M. A. Norell. 2011. A new basal 1689 ornithopod (Dinosauria, Ornithischia) from the Late Cretaceous of Mongolia. Journal of $1690 \quad$ Vertebrate Paleontology 31:626-640.

1691 Marsh, O. C. 1877a. New order of extinct Reptilia (Stegosauria) from the Jurassic of the Rocky 1692 Mountains. American Journal of Science, Series 3, 14:513-514.

1693 Marsh, O. C. 1877b. Notice of some new vertebrate fossils. American Journal of Science, Series $1694 \quad 3,14: 249-256$.

1695 Marsh, O. C. 1878. Principal characters of American Jurassic dinosaurs. American Journal of $1696 \quad$ Science, Series 3, 16:411-416.

1697 Marsh, O. C. 1879. Notice of new Jurassic reptiles. American Journal of Science, Series 3, $1698 \quad 18: 501-505$.

1699 Marsh, O. C. 1881. Principal characters of American Jurassic dinosaurs. Part V. American $1700 \quad$ Journal of Science, Series 3, 21 417-423.

1701 Marsh, O. C. 1889. Notice of gigantic horned Dinosauria from the Cretaceous. American Journal 1702 of Science, Series 3, 38:173-175.

1703 Marsh, O. C. 1894. The typical Ornithopoda of the American Jurassic. American Journal of $1704 \quad$ Science, Series 3, 43:85-90. 
1705 Martinez, R. D. 1998. Notohypsilophodon comodorensis gen. et sp. nov. un Hypsilophodontidae

1706 (Ornithischia: Ornithopoda) del Cretacico superior de Chubut, Patagonia central,

1707 Argentina. Acta Geologica Leopoldensia 21:119-135.

1708 Matheron, P. 1869. Notes sur les reptiles fossiles des dépôts fluvio-lucustres crétacés du bassin à

1709 lignite de Fuveau. Bulletin de la Société Géologique de France, ser. 2, 26:781-795.

1710 McDonald, A. T., J. I. Kirkland, D. D. DeBlieux, S. K. Madsen, J. Cavin, A. R. C. Milner, and L.

1711 Panzarin. 2010. New iguanodonts from the Cedar Mountain Formation of Utah and the

1712 evolution of thumb-spiked dinosaurs. PLoS ONE 5:e14075.

1713 Meyer, H. v. 1857. Beiträge zur näheren Kenntis fossiler Reptilien. Neues Jahrbuch für

1714 Mineralogie, Geologie und Paläontologie 1857:532-543.

1715 Milner, A. R., and D. B. Norman. 1984. The biogeography of advanced ornithopod dinosaurs

1716 (Archosauria: Ornithischia)-a cladistic vicariance model; pp. 145-150 in W. E. Reif and

1717 F. Westphal (eds.), Third Symposium on Mesozoic Terrestrial Ecosystems, Short Papers.

1718 Attempto Verlag, Tubingen.

1719 Molnar, R. E. 1996. Observations on the Australian ornithopod dinosaur, Muttaburrasaurus.

$1720 \quad$ Memoirs of the Queensland Museum 39:639-652.

1721 Morris, W. J. 1976. Hypsilophodont dinosaurs: a new species and comments on their

1722 systematics; pp. 93-113 in C. S. Churcher (ed.), Athlon: Essays on Palaeontology in

1723 Honour of Loris Shano Russell. Royal Ontario Museum, Toronto.

1724 Nesbitt, S. J., N. D. Smith, R. B. Irmis, A. H. Turner, A. Downs, and M. A. Norell. 2009. A

1725 complete skeleton of a Late Triassic saurischian and the early evolution of dinosaurs.

$1726 \quad$ Science 326:1530-1533. 
1727 Nesbitt, S. J., C. A. Sidor, R. B. Irmis, K. D. Angielczyk, R. M. H. Smith, and L. A. Tsuji. 2010.

1728 Ecologically distinct dinosaurian sister group shows early diversification of Ornithodira.

$1729 \quad$ Nature 464:95-98.

1730 Nopcsa, F. 1900. Dinosaurierreste aus Siebenbürgen (Schädel von Limnosaurus transsylvanicus

1731 nov. gen. et spec.). Denkschriften der Kaiserlichen Akademie der Wissenschaften.

1732 Mathematisch-Naturwissenschaftliche Classe 68:555-591.

1733 Nopcsa, F. 1915. Die Dinosaurier der siebenbürgischen Landesteile. Mitteilungen aus dem

1734 Jahrbuche der Koniglich-Ungarischen Geologischen Reichsanstalt 23:1-26.

1735 Norman, D. B. 1984. A systematic reappraisal of the reptile order Ornithischia; pp. 157-162 in

1736 W. E. Reif and F. Westphal (eds.), Third Symposium on Mesozoic Terrestrial

1737 Ecosystems, Short Papers. Attempto Verlag, Tubingen.

1738 Norman, D. B. 2004. Basal Iguanodontia; pp. 413-437 in D. B. Weishampel, P. Dodson, and H.

1739 Osmólska (eds.), The Dinosauria Second Edition. University of California Press,

$1740 \quad$ Berkeley.

1741 Norman, D. G. 2015. On the history, osteology, and systematic position of the Wealden

1742 (Hastings group) dinosaur Hypselospinus fittoni (Iguanodontia: Styracosterna).

1743 Zoological Journal of the Linnean Society. 173:92-189.

1744 Norman, D. B., L. M. Witmer, and D. B. Weishampel. 2004a. Basal Ornithischia; pp. 325-334 in

1745 D. B. Weishampel, P. Dodson, and H. Osmólska (eds.), The Dinosauria: Second Edition.

$1746 \quad$ University of California Press, Berkeley.

1747 Norman, D. B., L. M. Witmer, and D. B. Weishampel. 2004b. Basal Thyreophora; pp. 335-342

1748 in D. B. Weishampel, P. Dodson, and H. Osmólska (eds.), The Dinosauria: Second

1749 Edition. University of California Press, Berkeley. 
1750 Norman, D. B., H.-D. Sues, L. M. Witmer, and R. A. Coria. 2004c. Basal Ornithopoda; pp. 393-

1751412 in D. B. Weishampel, P. Dodson, and H. Osmólska (eds.), The Dinosauria: Second

1752 Edition. University of California Press, Berkeley.

1753 Novas, F. E. 1993. New information on the systematics and postcranial skeleton of

1754 Herrerasaurus ischigualastensis. Journal of Vertebrate Paleontology 13:400-423.

1755 Novas, F. E. 1996. Dinosaur monophyly. Journal of Vertebrate Paleontology 16:723-741.

1756 Novas, F. E., A. V. Cambiaso, and A. Ambrosio. 2004. A new basal iguanodontian (Dinosauria, 1757 Ornithischia) from the Upper Cretaceous of Patagonia. Ameghiniana 41:75-82.

1758 Ostrom, J. H. 1970. Stratigraphy and paleontology of the Cloverly Formation (Lower

1759 Cretaceous) of the Bighorn Basin area, Wyoming and Montana. Bulletin of the Yale

$1760 \quad$ Peabody Museum of Natural History 35:1-234.

1761 Owen, R. 1842. Report on British fossil reptiles, part II. Report of the British Association for the $1762 \quad$ Advancement of Science for 1841 9:60-204.

1763 Owen, R. 1861. Monograph on the fossil Reptilia of the Wealden and Purbeck Formations. Part

1764 V. Lacertilia. Palaeontographical Society Monograph 12:31-39.

1765 Parks, W. A. 1922. Parasaurolophus walkeri, a new genus and species of crested trachodont

1766 dinosaur. University of Toronto Studies, Geological Series 13:1-32.

1767 Parks, W. A. 1926. Thescelosaurus warreni. A new species of orthopodous dinosaur from the 1768 Edmonton Formation of Alberta. University of Toronto Studies, Geological Series 21:1$1769 \quad 42$.

1770 Paul, G. S. 1996. The complete illustrated guide to dinosaur skeletons. Gakken Mook, Tokyo, 98 $1771 \quad$ pp. 
1772 Peng, G. 1990. A new small ornithopod (Agilisaurus louderbacki gen. et sp. nov.) from Zigong,

1773 China. Newsletter of the Zigong Dinosaur Museum 2:19-27.

1774 Peng, G. 1992. Jurassic ornithopod Agilisaurus louderbacki (Ornithopoda: Fabrosauridae) from

1775 Zigong, Sichuan, China. Vertebrata PalAsiatica 30:39-51.

1776 Piechowski, R., and J. Dzik. 2010. The axial skeleton of Silesaurus opolensis. Journal of

1777 Vertebrate Paleontology 30:1127-1141.

1778 Pincemaille-Quillevere, M., E. Buffetaut, and F. Quillevere. 2006. Description ostéologique de

1779 l'arrière-crane de Rhabdodon (Dinosauria, Euornithopoda) et implications

1780 phylogénétiques. Bulletin de la Societe Geologique de France 177:97-104.

1781 Pol, D., and M. A. Norell. 2001. Comments on the manhattan stratigraphic measure. Cladistics

$1782 \quad 17: 285-289$.

1783 Pol, D., and M. A. Norell. 2006. Uncertainty in the age of fossils and the stratigraphic fit to

$1784 \quad$ phylogenies. Systematic Biology 55:512-521.

1785 Pol, D., M. A. Norell, and M. E. Siddall. 2004. Measures of stratigraphic fit to phylogeny and

1786 their sensitivity to tree size, shape and scale. Cladistics 20:64-75.

1787 Pol, D., O. W. M. Rauhut, and M. Becerra. 2011. A Middle Jurassic heterodontosaurid dinosaur

1788 from Patagonia and the evolution of heterodontosaurids. Naturwissenschaften 98:369-

$1789 \quad 379$.

1790 Prendini, L. 2001. Species or supraspecific taxa as terminals in cladistic analyses? Groundplans

1791 versus exemplars revisited. Systematic Biology 50:290-300.

1792 Rage, J. C. 1986. South American/North American terrestrial interchanges in the latest

1793 Cretaceous: short comments on Brett-Surman and Paul (1985) with additional data.

1794 Journal of Vertebrate Paleontology 6:382-383. 
1795 Ree, R. H., and S. A. Smith. 2008. Maximum likelihood inference of geographic range evolution

1796 by dispersal, local extinction, and cladogenesis. Systematic Biology 57:4-14.

1797 Ree, R. H., B. R. Moore, C. O. Webb, and M. J. Donoghue. 2005. A likelihood framework for

1798 inferring the evolution of geographic range on phylogenetic trees. Evolution 59:2299-

17992311.

1800 Reig, O. A. 1963. La presencia de dinosaurios saurisquios en los "Estratos de Ischigualasto"

1801 (Mesotriásico Superior) de las provincias de San Juan y La Rioja (República Argentina).

$1802 \quad$ Ameghiniana 3:3-20.

1803 Rich, T. H., and P. V. Rich. 1989. Polar dinosaurs and biotas of the Early Cretaceous of

1804 southeastern Australia. National Geographic Research 5:15-53.

1805 Rich, T. H., and P. Vickers-Rich. 1999. The Hypsilophodontidae from southeastern Australia;

1806 pp. 167-180 in Y. Tomida, T. H. Rich, and P. Vickers-Rich (eds.), Proceedings of the

1807 Second Gondwanan Dinosaur Symposium. National Science Museum Monographs,

$1808 \quad$ Tokyo.

1809 Rich, T. H., P. M. Galton, and P. Vickers-Rich. 2010. The holotype individual of the ornithopod

1810 dinosaur Leaellynasaura amicagraphica Rich and Rich, 1989 (late Early Cretaceous,

1811 Victoria, Australia). Alcheringa 34:385-396.

1812 Romer, A. S. 1956. Osteology of the Reptiles. University of Chicago Press, Chicago, $772 \mathrm{pp}$.

1813 Romer, A. S. 1966. Vertebrate Paleontology. 3rd Edition. University of Chicago Press, Chicago, $1814 \quad 468 \mathrm{pp}$.

1815 Romer, A. S. 1972. The Chanares (Argentina) Triassic reptile fauna. XV. Further remains of the 1816 thecodonts Lagerpeton and Lagosuchus. Breviora 394:1-7. 
1817 Ronquist, F. 1996. DIVA. version 1.1. Computer program and manual available by anonymous

1818 FTP from Uppsala University Available from: ftp://ftp.uu.se/ or ftp://ftp.systbot.uu.se/.

1819 Ronquist, F. 1997. Dispersal-Vicariance analysis: a new approach to the quantification of

1820 historical biogeography. Systematic Biology 46:195-203.

1821 Rosenbaum, J. N., and K. Padian. 2000. New material of the basal thyreophoran Scutellosaurus

1822 lawleri from the Kayenta Formation (Lower Jurassic) of Arizona. PaleoBios 20:13-23.

1823 Rozadilla. S., F. L. Agnolin, F. E. Novas, A. M. A. Rolando, M. J. Motta, J. M. Lirio, and M. P.

1824 Isasi. 2016. A new ornithopod (Dinosauria, Ornithischia) from the Upper Cretaceous of

1825 Antarctica and its paleobiogeographical implications. Cretaceous Research 57:311-324.

1826 Ruiz-Omenaca, J. I., X. P. Suberbiola, and P. M. Galton. 2006. Callovosaurus leedsi, the earliest

1827 dryosaurid dinosaur (Ornithischia: Euornithopoda) from the Middle Jurassic of England

1828 pp. in K. Carpenter (ed.), Horns and Beaks: Ceratopsian and Ornithopod Dinosaurs.

1829 Indiana University Press, Bloomington.

1830 Salgado, L., R. A. Coria, and S. E. Heredia. 1997. New materials of Gasparinisaura

1831 cincosaltensis (Ornithischia, Ornithopoda) from the Upper Cretaceous of Argentina.

$1832 \quad$ Journal of Paleontology 71:933-940.

1833 Santa Luca, A. P. 1980. The postcranial skeleton of Heterodontosaurus tucki (Reptilia,

1834 Ornithischia) from the Stormberg of South Africa. Annals of the South African Museum

$1835 \quad 79: 159-211$.

1836 Santa Luca, A. P., A. W. Crompton, and A. J. Charig. 1976. A complete skeleton of the Late

1837 Triassic ornithischian Heterodontosaurus tucki. Nature 264:324-328.

1838 Scheetz, R. D. 1999. Osteology of Orodromeus makelai and the phylogeny of basal ornithopod

1839 dinosaurs. Montana State University, Bozeman, 186 pp. 
1840 Seeley, H. G. 1887. On the classification of the fossil animals commonly named Dinosauria.

1841 Proceedings of the Royal Society of London 43:165-171.

1842 Sereno, P. C. 1986. Phylogeny of the bird-hipped dinosaurs. National Geographic Research $1843 \quad 2: 234-256$.

1844 Sereno, P. C. 1991. Lesothosaurus, "fabrosaurids", and the early evolution of Ornithischia.

$1845 \quad$ Journal of Vertebrate Paleontology 11:168-197.

1846 Sereno, P. C. 1993. The pectoral girdle and forelimb of the basal theropod Herrerasaurus

1847 ischigualastensis. Journal of Vertebrate Paleontology 13:425-450.

1848 Sereno, P. C. 1997. The origin and evolution of dinosaurs. Annual Revue of Earth and Planetary 1849 Sciences 25:435-489.

1850 Sereno, P. C. 1998. A rational for phylogenetic definitions, with application to the higher level 1851 taxonomy of Dinosauria. Neues Jahrbuch für Geologie und Paläontologie Abhandlungen

$1852 \quad 210: 41-83$.

1853 Sereno, P. C. 1999. The evolution of dinosaurs. Science 284:2137-2147.

1854 Sereno, P. C. 2005. The logical basis of phylogenetic taxonomy. Systematic Biology 54:595-619.

1855 Sereno, P. C., and A. B. Arcucci. 1994. Dinosaurian precursors from the Middle Triassic of

1856 Argentina: Marasuchus lilloensis, gen. nov. Journal of Vertebrate Paleontology 14:53-73.

1857 Sereno, P. C., and F. E. Novas. 1993. The skull and neck of the basal theropod Herrerasaurus 1858 ischigualastensis. Journal of Vertebrate Paleontology 13:451-476.

1859 Spencer, M. R. 2007. A phylogenetic analysis of the basal Ornithischia (Reptilia, Dinosauria).

1860 Department of Geology, Bowling Green State University, Bowling Green, Ohio, 140 pp.

1861 Sternberg, C. M. 1937. A classification of Thescelosaurus, with a description of a new species.

1862 Proceedings of the Geological Society of America 1936:375. 
1863 Sternberg, C. M. 1940. Thescelosaurus edmontonensis, n. sp., and classification of the

1864 Hypsilophodontidae. Journal of Paleontology 14:481-494.

1865 Sues, H.-D. 1980. Anatomy and relationships of a new hypsilophodontid dinosaur from the

1866 Lower Cretaceous of North America. Palaeontographica Abteilung a Palaeozoologie-

1867 Stratigraphie 169:51-72.

1868 Sullivan, R. M. 2006. A taxonomic review of the Pachycephalosauridae (Dinosauria:

1869 Ornithischia). New Mexico Museum of Natural History and Science Bulletin 35:347-365.

1870 Swinton, W. E. 1936. The dinosaurs of the Isle of Wight. Proceedings of the Geologists'

$1871 \quad$ Association 47:204-220.

1872 Swofford, D. L. 2002. PAUP*. Phylogenetic analysis using parsimony (* and other methods).

$1873 \quad 4.0 \mathrm{~b} 10$.

1874 Taquet, P. 1976. Géologie et Paléontologie du Gisement de Gadoufaoua (Aptien du Niger).

1875 Cahiers de Paléontologie, Éditions du Centre National de la Recherche Scientifique,

$1876 \quad$ Paris, $191 \mathrm{pp}$.

1877 Thulborn, R. A. 1970. The skull of Fabrosaurus australis, a Triassic ornithischian dinosaur.

$1878 \quad$ Palaeontology 13:414-432.

1879 Thulborn, R. A. 1972. The postcranial skeleton of the Triassic ornithischian dinosaur

$1880 \quad$ Fabrosaurus australis. Palaeontology 15:29-60.

1881 Thulborn, R. A. 1974. A new heterodontosaurid dinosaur (Reptilia: Ornithischia) from the Upper

1882 Triassic Red Beds of Lesotho. Zoological Journal of the Linnean Society 55:151-175.

1883 Upchurch, P., C. A. Hunn, and D. B. Norman. 2002. An analysis of dinosaurian biogeography:

1884 evidence for the existence of vicariance and dispersal patterns caused by geological

1885 events. Proceedings of the Royal Society B 269:613-621. 
1886 Varricchio, D. J., A. J. Martin, and Y. Katsura. 2007. First trace and body evidence of a

1887 burrowing, denning dinosaur. Proceedings of the Royal Society B: Biological Sciences

$1888 \quad 274: 1361-1368$.

1889 Virchow, H. 1919. Atlas and Epistropheus bei den Schildkröten. Sitzungsberichte der

$1890 \quad$ Gesellschaft Naturforschender Freunde zu Berlin 1919:303-332.

1891 von Huene, F. 1932. Die fossile Reptil-Ordnung Saurischia, ihre Entwicklung und Geschichte.

1892 Monographien zur Geologie und Palaeontologie, serie 1, 4:1-361.

1893 Weishampel, D. B., and R. E. Heinrich. 1992. Systematics of Hypsilophodontidae and basal

1894 Iguanodontia (Dinosauria: Ornithopoda). Historical Biology 6:159-184.

1895 Weishampel, D. B., C.-M. Juanu, Z. Csiki, and D. B. Norman. 2003. Osteology and phylogeny

1896 of Zalmoxes (N. G.), an unusual euornithopod dinosaur from the latest Cretaceous of

1897 Romania. Journal of Systematic Palaeontology 1:65-123.

1898 Weishampel, D. B., P. M. Barrett, R. A. Coria, J. Le Loeuff, X. Xing, Z. Xijin, A. Sahni, E. M.

1899 P. Gomani, and C. R. Noto. 2004. Dinosaur Distribution; pp. 517-613 in D. B.

1900 Weishampel, P. Dodson, and H. Osmólska (eds.), The Dinosauria. University of

1901 California Press, Berkeley.

1902 Wiens, J. J. 1998. The accuracy of methods for coding and sampling higher-level taxa for

1903 phylogenetic analysis: a simulation study. Systematic Biology 47:397-413.

1904 Wills, M. A. 1999. Congruence between stratigraphy and phylogeny: randomization tests and the 1905 gap excess ratio. Systematic Biology 48:559-580.

1906 Wills, M. A., P. M. Barrett, and J. F. Heathcote. 2008. The modified gap excess ratio (GER*)

1907 and the stratigraphic congruence of dinosaur phylogenies. Systematic Biology 57:891-

1908904. 
1909 Winkler, D. A., and P. A. Murry. 1989. Paleoecology and hypsilophodontid behavior at the

1910 Proctor Lake dinosaur locality (Early Cretaceous), Texas; pp. 55-61 in J. O. Farlow (ed.),

1911 Paleobiology of Dinosaurs. Geological Society of America Special Paper 238.

1912 Winkler, D. A., P. A. Murry, and L. L. Jacobs. 1997. A new species of Tenontosaurus

1913 (Dinosauria: Ornithopoda) from the Early Cretaceous of Texas. Journal of Vertebrate

$1914 \quad$ Paleontology 17:330-348.

1915 Xu, X., X. L. Wang, and H. L. You. 2000. A primitive ornithopod from the Early Cretaceous

1916 Yixian Formation of Liaoning. Vertebrata PalAsiatica 38:318-325.

1917 Xu, X., P. J. Makovicky, X. L. Wang, M. A. Norell, and H. L. You. 2002. A ceratopsian

1918 dinosaur from China and the early evolution of Ceratopsia. Nature 416:314-317.

1919 Xu, X., C. A. Forster, J. M. Clark, and J. Mo. 2006. A basal ceratopsian with transitional features

1920 from the Late Jurassic of northwestern China. Proceedings of the Royal Society B

$1921 \quad 273: 2135-2140$.

1922 You, H. L., and P. Dodson. 2003. Redescription of neoceratopsian dinosaur Archaeoceratops

1923 and earl evolution of Neoceratopsia. Acta Palaeontologica Polonica 48:261-272.

1924 Zan, S. Q., J. Chen, L. Y. Jin, and T. Li. 2005. A primitive ornithopod from the Early Cretaceous

1925 Quantou Formation of central Jilin, China. Vertebrata PalAsiatica 43:182-193.

1926 Zhao, X., Z. Cheng, and X. Xu. 1999. The earliest ceratopsian from the Tuchengzi Formation of 1927 Liaoning, China. Journal of Vertebrate Paleontology 19:681-691.

1928 Zheng, X.-T., H.-L. You, X. Xu, and Z.-M. Dong. 2009. An Early Cretaceous heterodontosaurid 1929 dinosaur with filamentous integumentary structures. Nature 458:333-336. 
1930 Zheng, W., X. Jin, M. Shibata, Y. Azuma, and F. Yu. 2012. A new ornithischian dinosaur from

1931 the Cretaceous Liangtoutang Formation of Tiantai, Zhejiang Province, China. Cretaceous

1932 Research 34:208-219. 
Table $\mathbf{1}$ (on next page)

Phylogenetic definitions used in this study. 


\begin{tabular}{|c|c|c|c|c|}
\hline Clade Name & Phylogenetic Definition & $\begin{array}{l}\text { Diagnosis } \\
\text { Type }\end{array}$ & Original Author & $\begin{array}{l}\text { Definition } \\
\text { Used }\end{array}$ \\
\hline Ankylopollexia & $\begin{array}{l}\text { Camptosaurus dispar (Marsh 1879), Parasaurolophus } \\
\text { walkeri Parks 1922, their most recent common ancestor } \\
\text { and all descendants. }\end{array}$ & Node & Sereno, 1986 & Sereno, 2005 \\
\hline Cerapoda & $\begin{array}{l}\text { Parasaurolophus walkeri Parks 1922, Triceratops } \\
\text { horrid us Marsh 1889, their most recent common } \\
\text { ancestor and all descendants. }\end{array}$ & Node & Sereno, 1986 & $\begin{array}{l}\text { Butler et al., } \\
\quad 2008 \mathrm{a}\end{array}$ \\
\hline Clypeodonta & $\begin{array}{l}\text { Hypsilophodon foxii, Edmontosaurus regalis, their most } \\
\text { recent common ancestor, and all of its descendants. }\end{array}$ & Node & Norman, 2015 & $\begin{array}{l}\text { Norman, } \\
2015\end{array}$ \\
\hline Dinosauria & $\begin{array}{l}\text { Triceratops horrid us Marsh 1889, Passer domestics } \\
\text { (Linnaeus 1758), their most recent common ancestor } \\
\text { and all descendants. }\end{array}$ & Node & Owen, 1842 & $\begin{array}{l}\text { Butler et al., } \\
\quad 2008 \mathrm{a}\end{array}$ \\
\hline Dryomorpha & $\begin{array}{l}\text { Dryosaurus altus (Marsh 1878), Parasaurolophus } \\
\text { walkeri Parks 1922, their most recent common ancestor } \\
\text { and all descendants. }\end{array}$ & Node & Sereno, 1986 & This Study \\
\hline Dryosauridae & $\begin{array}{l}\text { All iguanodontians more closely related to Dryosaurus } \\
\text { altus (Marsh 1878) than to Parasaurolophus walkeri } \\
\text { Parks } 1922 .\end{array}$ & Stem & $\begin{array}{l}\text { Milner and } \\
\text { Norman, } 1984\end{array}$ & Sereno, 2005 \\
\hline Elasmaria & $\begin{array}{l}\text { Talenkauen santacrucensis Novas, Cambia so, and } \\
\text { Ambrosia } 2004 \text { and Macrogryphosaurus gondwanicus } \\
\text { Calvo, Porphyry, and Novas 2007, their most recent } \\
\text { common ancestor and all descendants. }\end{array}$ & Node & $\begin{array}{l}\text { Calvo et al., } \\
2007\end{array}$ & $\begin{array}{l}\text { Calvo et al., } \\
\quad 2007\end{array}$ \\
\hline Euiguanodontia & $\begin{array}{l}\text { Gasparinisaura cincosaltensis Coria and Salgado 1996, } \\
\text { Dryosauridae Milner and Norman 1984, Ankylopollexia } \\
\text { Sereno 1986, their most recent common ancestor and all } \\
\text { descendants. }\end{array}$ & Node & $\begin{array}{c}\text { Coria and } \\
\text { Salgado, } 1996\end{array}$ & $\begin{array}{l}\text { Coria and } \\
\text { Salgado, } \\
1996\end{array}$ \\
\hline Euornithopoda & $\begin{array}{l}\text { All ornithischians more closely related to } \\
\text { Parasaurolophus walkeri Parks } 1922 \text { than to } \\
\text { Heterodontosaurus tucki Crompton and Charig 1962, } \\
\text { Pachycephalosaurus wyomingensis (Gilmore 1931), } \\
\text { Triceratops horridus Marsh 1889, or Ankylosaurus } \\
\text { marginventris Brown 1908. }\end{array}$ & Stem & Sereno, 1986 & Sereno, 2005 \\
\hline Genasauria & $\begin{array}{l}\text { Ankylosaurus magniventris Brown 1908, Stegosaurus } \\
\text { stenops Marsh 1877a , Parasaurolophus walkeri Parks } \\
\text { 1922, Triceratops horridus Marsh 1889, } \\
\text { Pachycephalosaurus wyomingensis (Gilmore 1931), } \\
\text { their most recent common ancestor and all descendants. }\end{array}$ & Node & Sereno, 1986 & $\begin{array}{l}\text { Butler et al., } \\
\quad 2008 \mathrm{a}\end{array}$ \\
\hline Heterodontosauridae & $\begin{array}{l}\text { All ornithischians more closely related to } \\
\text { Heterodontosaurus tucki Crompton and Charig } 1962 \\
\text { than to Parasaurolophus walkeri Parks 1922, } \\
\text { Pachycephalosaurus wyomingensis (Gilmore 1931), } \\
\text { Triceratops horridus Marsh 1889, or Ankylosaurus } \\
\text { marginventris Brown 1908. }\end{array}$ & Stem & Romer, 1966 & Sereno, 2005 \\
\hline
\end{tabular}




\begin{tabular}{|c|c|c|c|c|}
\hline Clade Name & Phylogenetic Definition & $\begin{array}{c}\text { Diagnosis } \\
\text { Type }\end{array}$ & $\begin{array}{l}\text { Original } \\
\text { Author }\end{array}$ & $\begin{array}{l}\text { Definition } \\
\text { Used }\end{array}$ \\
\hline Hypsilophodontidae & $\begin{array}{l}\text { All neornithischians more closely related to } \\
\text { Hypsilophodon foxii Huxley } 1869 \text { than to } \\
\text { Parasaurolophus walkeri Parks } 1922 \text {. }\end{array}$ & Stem & Dollo, 1882 & Sereno, 2005 \\
\hline Iguanodontia & $\begin{array}{l}\text { All ornithopods more closely related to } \\
\text { Parasaurolophus walkeri Parks } 1922 \text { than to } \\
\text { Hypsilophodon foxii Huxley } 1869 \text { or Thescelosaurus } \\
\text { neglectus Gilmore } 1913 \text {. }\end{array}$ & Stem & Dollo, 1888 & Sereno, 2005 \\
\hline Marginocephalia & $\begin{array}{l}\text { Triceratops horridus Marsh 1889, Pachycephalosaurus } \\
\text { wyomingensis (Gilmore 1931), their most recent } \\
\text { common ancestor and all descendants. }\end{array}$ & Node & Sereno, 1986 & $\begin{array}{c}\text { Butler et al., } \\
2008 \mathrm{a}\end{array}$ \\
\hline Neornithischia & $\begin{array}{l}\text { All genasaurians more closely related to } \\
\text { Parasaurolophus walkeri Parks } 1922 \text { than to } \\
\text { Ankylosaurus magniventris Brown } 1908 \text { or Stegosaurus } \\
\text { stenops Marsh 1877a. }\end{array}$ & Stem & Cooper, 1985 & $\begin{array}{c}\text { Butler et al., } \\
2008 \mathrm{a}\end{array}$ \\
\hline Ornithischia & $\begin{array}{l}\text { All dinosaurs more closely related to Triceratops } \\
\text { horridus Marsh } 1889 \text { than to either Passer domesticus } \\
\text { (Linnaeus 1758), or Saltasaurus loricatus Bonaparte } \\
\text { and Powell 1980. }\end{array}$ & Stem & Seeley, 1887 & $\begin{array}{c}\text { Butler et al., } \\
2008 \mathrm{a}\end{array}$ \\
\hline Ornithopoda & $\begin{array}{l}\text { All genasaurians more closely related to } \\
\text { Parasaurolophus walkeri Parks 1922, than to } \\
\text { Triceratops horridus } \text { Marsh } 1889 \text {. }\end{array}$ & Stem & Marsh, 1881 & $\begin{array}{c}\text { Butler et al., } \\
2008 \mathrm{a}\end{array}$ \\
\hline Orodrominae & $\begin{array}{l}\text { All neornithischians more closely related to } \\
\text { Orodromeus makelai Horner and Weishampel } 1988 \text { than } \\
\text { to Thescelosaurus neglectus Gilmore } 1913 \text { or } \\
\text { Parasaurolophus walkeri Parks } 1922 .\end{array}$ & Stem & $\begin{array}{c}\text { Brown et al., } \\
2013\end{array}$ & This Study \\
\hline Parksosauridae & $\begin{array}{l}\text { All neornithischians more closely related to } \\
\text { Parksosaurus warreni (Parks 1926) than to } \\
\text { Hypsilophodon foxii Huxley 1869, Dryosaurus altus } \\
\text { (Marsh 1878), or Parasaurolophus walkeri Parks } 1922 .\end{array}$ & Stem & $\begin{array}{l}\text { Buchholz, } \\
2002\end{array}$ & This Study \\
\hline Rhabdodontidae & $\begin{array}{l}\text { All iguanodontians more closely related to Rhabdodon } \\
\text { priscus Matheron } 1869 \text { than to Parasaurolophus } \\
\text { walkeri Parks } 1922 .\end{array}$ & Stem & $\begin{array}{l}\text { Weishampel } \\
\text { et al., } 2003\end{array}$ & Sereno, 2005 \\
\hline Saurischia & $\begin{array}{l}\text { All dinosaurs more closely related to Passer domesticus } \\
\text { (Linnaeus 1758) than to Triceratops horridus Marsh } \\
1889 .\end{array}$ & Stem & Seeley, 1887 & $\begin{array}{c}\text { Butler et al., } \\
2008 \mathrm{a}\end{array}$ \\
\hline Thescelosauridae & $\begin{array}{l}\text { Thescelosaurus neglectus, Orodromeus makelai, their } \\
\text { most recent common ancestor, and all of its } \\
\text { descendants. }\end{array}$ & Node & $\begin{array}{l}\text { Brown et al., } \\
2013\end{array}$ & $\begin{array}{c}\text { Brown et al., } \\
2013\end{array}$ \\
\hline Thescelosaurinae & $\begin{array}{l}\text { All neornithischians more closely related to } \\
\text { Thescelosaurus neglectus Gilmore } 1913 \text { than to } \\
\text { Orodromeus makelai Horner and Weishampel } 1988 \text { or } \\
\text { Parasaurolophus walkeri Parks } 1922 \text {. }\end{array}$ & Stem & $\begin{array}{c}\text { Sternberg, } \\
1937\end{array}$ & This Study \\
\hline Thyreophora & $\begin{array}{l}\text { All genasaurians more closely related to Ankylosaurus } \\
\text { magniventris Brown } 1908 \text { than to Parasaurolophus } \\
\text { walkeri Parks 1922, Triceratops horridus Marsh 1889, } \\
\text { or Pachycephalosaurus wyomingensis (Gilmore 1931). }\end{array}$ & Stem & Nopcsa, 1915 & $\begin{array}{c}\text { Butler et al., } \\
2008 \mathrm{a}\end{array}$ \\
\hline
\end{tabular}




\section{Table 2 (on next page)}

List of references consulted and specimens examined for this analysis.

Specimen numbers in bold indicate casts of that specimen were examined. Specimen numbers in italics indicate specimens for which additional photographs of those specimens were examined, but the specimen was not examined first hand. 


\begin{tabular}{|c|c|c|c|}
\hline Taxon & Age & References & $\begin{array}{l}\text { Specimens } \\
\text { Examined }\end{array}$ \\
\hline Abrictosaurus & $\begin{array}{l}\text { Hettangian- } \\
\text { Sinemurian }\end{array}$ & $\begin{array}{l}\text { Thulborn, 1974; } \\
\text { Hopson, } 1975\end{array}$ & \\
\hline Agilisaurus & Bathonian-Callovian & $\begin{array}{l}\text { Peng, 1992; Barrett } \\
\text { et al., } 2005\end{array}$ & \\
\hline Anabisetia & $\begin{array}{l}\text { Cenomanian- } \\
\text { Turonian }\end{array}$ & $\begin{array}{l}\text { Coria and Calvo, } \\
\text { 2002; Ibiricu et al., } \\
2010\end{array}$ & \\
\hline Archaeoceratops & Aptian-Albian & $\begin{array}{l}\text { You and Dodson, } \\
2003\end{array}$ & $\begin{array}{l}\text { IVPP V11114, } \\
\text { V11115 }\end{array}$ \\
\hline Asilisaurus & Anisian & Nesbitt et al., 2010 & \\
\hline Atlascopcosaurus & Albian & $\begin{array}{l}\text { Rich and Rich, } \\
\text { 1989; Agnolin et al., } \\
2010\end{array}$ & NMV P186153 \\
\hline Callovosaurus & Callovian & $\begin{array}{l}\text { Galton, 1980; Ruiz- } \\
\text { Omenaca et al., } \\
2006\end{array}$ & \\
\hline Camptosaurus & $\begin{array}{l}\text { Kimmeridgian- } \\
\text { Tithonian }\end{array}$ & Norman, 2004 & \\
\hline Changchunsaurus & Aptian-Cenomanian & $\begin{array}{l}\text { Zan et al., 2005; Jin } \\
\text { et al., 2010; Butler, } \\
\text { et al., } 2011\end{array}$ & \\
\hline Dryosaurus & $\begin{array}{l}\text { Kimmeridgian- } \\
\text { Tithonian }\end{array}$ & $\begin{array}{l}\text { Galton, } 1977,1981 \text {, } \\
1983\end{array}$ & \\
\hline Dysalotosaurus & Kimmeridgian & $\begin{array}{l}\text { Galton, } 1977,1981 \text {, } \\
1983\end{array}$ & \\
\hline Echinodon & Berriasian & $\begin{array}{l}\text { Galton, 1978; } \\
\text { Galton, } 2007\end{array}$ & \\
\hline Elrhazosaurus & Aptian & $\begin{array}{l}\text { Galton and Taquet, } \\
\text { 1982; Galton, } 2009\end{array}$ & \\
\hline Emausaurus & Toarcian & $\begin{array}{l}\text { Norman et al., } \\
2004 \mathrm{~b}\end{array}$ & \\
\hline Eocursor & Norian-Rhaetian & $\begin{array}{l}\text { Butler et al., 2007; } \\
\text { Butler, } 2010\end{array}$ & $S A M-P K-8025$ \\
\hline Fruitadens & Tithonian & Butler et al., 2010 & \\
\hline Gasparinisaura & $\begin{array}{l}\text { Santonian- } \\
\text { Campanian }\end{array}$ & $\begin{array}{l}\text { Coria and Salgado, } \\
\text { 1996; Salgado et al., } \\
\text { 1997; Coria, 1999; } \\
\text { Coria and Calvo, } \\
\text { 2002; Ibiricu et al., } \\
2010\end{array}$ & \\
\hline Haya & Santonian & $\begin{array}{l}\text { Makovicky et al., } \\
2011\end{array}$ & $\begin{array}{l}\text { IGM 100/2017, } \\
100 / 2014,100 / 2016\end{array}$ \\
\hline
\end{tabular}




\begin{tabular}{|c|c|c|c|}
\hline Taxon & Age & References & $\begin{array}{l}\text { Specimens } \\
\text { Examined }\end{array}$ \\
\hline Herrerasaurus & Carnian & $\begin{array}{l}\text { Novas, 1993; } \\
\text { Sereno, 1993; } \\
\text { Sereno and Novas, } \\
1993\end{array}$ & \\
\hline Heterodontosaurus & $\begin{array}{l}\text { Hettangian- } \\
\text { Sinemurian }\end{array}$ & $\begin{array}{l}\text { Crompton and } \\
\text { Charig, 1962; Santa } \\
\text { Luca et al., 1976; } \\
\text { Santa Luca, 1980; } \\
\text { Butler et al., 2008b }\end{array}$ & $\begin{array}{l}S A M-P K-K 337, \\
1332\end{array}$ \\
\hline Hexinlusaurus & $\begin{array}{l}\text { Bathonian- } \\
\text { Callovian }\end{array}$ & $\begin{array}{l}\text { He and Cai, 1984; } \\
\text { Barrett et al., } 2005\end{array}$ & \\
\hline Hypsilophodon & Barremian-Aptian & Galton, $1974 \mathrm{a}$ & \\
\hline Iguanodon & Valanginian-Albian & Norman, 2004 & \\
\hline Jeholosaurus & Barremian & $\begin{array}{l}\text { Xu et al., 2000; } \\
\text { Barrett and Han, } \\
2009\end{array}$ & $\begin{array}{l}\text { IVVP V 12529, } \\
\text { IVPP V 15718; } \\
\text { PKUP V 1061, } \\
1062,1063,1064 .\end{array}$ \\
\hline Kaiparowits Orodromine & Campanian & Gates et al., 2013 & $\begin{array}{l}\text { UMNH VP } 12665 \text {, } \\
12677,16281, \\
16772,16773, \\
19470,21091- \\
21099,21101- \\
21107\end{array}$ \\
\hline Koreanosaurus & $\begin{array}{l}\text { Santonian- } \\
\text { Campanian }\end{array}$ & Huh et al., 2011 & \\
\hline Leaellynasaura & Albian & $\begin{array}{l}\text { Rich and Rich, } \\
\text { 1989; Agnolin et al., } \\
\text { 2010; Rich et al., } \\
\text { 2010 }\end{array}$ & NVM P186047 \\
\hline Lesothosaurus & $\begin{array}{l}\text { Hettangian- } \\
\text { Sinemurian }\end{array}$ & $\begin{array}{l}\text { Galton, 1978; } \\
\text { Sereno, 1991; } \\
\text { Knoll, 2002a, b; } \\
\text { Butler, 2005 }\end{array}$ & $S A M-P K-401,1106$ \\
\hline Liaoceratops & Barremian & $\begin{array}{l}\text { Xu et al., 2002; Xu } \\
\text { et al., } 2006\end{array}$ & $\begin{array}{l}\text { IVPP V12738; } \\
\text { V12633 }\end{array}$ \\
\hline Lycorhinus & $\begin{array}{l}\text { Hettangian- } \\
\text { Sinemurian }\end{array}$ & $\begin{array}{l}\text { Haughton, 1924; } \\
\text { Gow, 1975; } \\
\text { Hopson, 1975; } \\
\text { Gow, } 1990\end{array}$ & \\
\hline Macrogryphosaurus & Coniacian & $\begin{array}{l}\text { Calvo et al., } 2007 ; \\
\text { Ibiricu et al., } 2010\end{array}$ & \\
\hline Marasuchus & Ladinian & $\begin{array}{l}\text { Sereno and Arcucci, } \\
1994\end{array}$ & \\
\hline
\end{tabular}




\begin{tabular}{|c|c|c|c|}
\hline Taxon & Age & References & $\begin{array}{l}\text { Specimens } \\
\text { Examined }\end{array}$ \\
\hline Micropachycephalosaurus & Campanian & $\begin{array}{l}\text { Dong, 1978, Butler } \\
\text { and Zhao, } 2009\end{array}$ & \\
\hline Muttaburrasaurus & Albian & $\begin{array}{l}\text { Bartholomai and } \\
\text { Molnar, 1981; } \\
\text { Molnar, } 1996\end{array}$ & \\
\hline Notohypsilophodon & $\begin{array}{l}\text { Cenomanian- } \\
\text { Coniacian }\end{array}$ & $\begin{array}{l}\text { Martinez, 1998; } \\
\text { Ibiricu et al., } 2010\end{array}$ & \\
\hline Orodromeus & Campanian & Scheetz, 1999 & $\begin{array}{l}\text { MOR 294, 403, } \\
473,1136,1141 ; \\
\text { PU 23246, } 23442\end{array}$ \\
\hline Oryctodromeus & Cenomanian & $\begin{array}{l}\text { Varricchio et al., } \\
2007 ; \\
\text { Krumenacker, } 2010\end{array}$ & $\begin{array}{l}\text { BYU 19342, } \\
\text { 19347; MOR } \\
1636 a, 1636 b .\end{array}$ \\
\hline Othnielosaurus & $\begin{array}{l}\text { Kimmeridgian- } \\
\text { Tithonian }\end{array}$ & $\begin{array}{l}\text { Galton and Jensen, } \\
\text { 1973; Galton, 1977; } \\
\text { Galton, 1978; } \\
\text { Galton, 1983; } \\
\text { Galton, 2007 }\end{array}$ & $\begin{array}{l}\text { BYU ESM-163R; } \\
\text { UW } 24823\end{array}$ \\
\hline Ouranosaurus & Aptian & $\begin{array}{l}\text { Norman et al., } \\
2004 b\end{array}$ & \\
\hline Parksosaurus & Maastrichtian & $\begin{array}{l}\text { Parks, 1926; } \\
\text { Galton, } 1973\end{array}$ & ROM 804 \\
\hline Pisanosaurus & Carnian & $\begin{array}{l}\text { Casamiquela, 1967; } \\
\text { Bonaparte, 1976; } \\
\text { Gow, 1981; Irmis et } \\
\text { al., } 2007\end{array}$ & \\
\hline Qantassaurus & Albian & $\begin{array}{l}\text { Rich and Vickers- } \\
\text { Rich, 1999; } \\
\text { Agnolin et al., } 2010\end{array}$ & $\begin{array}{l}\text { NMV P198962, } \\
\text { P199075 }\end{array}$ \\
\hline Rhabdodon p. & $\begin{array}{l}\text { Santonian- } \\
\text { Maastrichtian }\end{array}$ & $\begin{array}{l}\text { Garcia et al., 1999; } \\
\text { Pincemaille- } \\
\text { Quillevere et al., } \\
2006\end{array}$ & \\
\hline Sanjuansaurus & Carnian & $\begin{array}{l}\text { Alcober and } \\
\text { Martinez, } 2010\end{array}$ & \\
\hline Scelidosaurus & Sinemurian & $\begin{array}{l}\text { Norman et al., } \\
2004 b\end{array}$ & \\
\hline Scutellosaurus & $\begin{array}{l}\text { Hettangian- } \\
\text { Sinemurian }\end{array}$ & $\begin{array}{l}\text { Colbert, 1981; } \\
\text { Rosenbaum and } \\
\text { Padian, } 2000\end{array}$ & $\begin{array}{l}\text { TMM 43647.7, } \\
43663.1,43664.1, \\
43687.16\end{array}$ \\
\hline Silesaurus & Carnian & $\begin{array}{l}\text { Dzik, 2003; } \\
\text { Piechowski and } \\
\text { Dzik, } 2010\end{array}$ & \\
\hline
\end{tabular}




\begin{tabular}{|c|c|c|c|}
\hline Taxon & Age & References & $\begin{array}{l}\text { Specimens } \\
\text { Examined }\end{array}$ \\
\hline Stenopelix & Berriasian & $\begin{array}{l}\text { Butler and Sullivan, } \\
2009\end{array}$ & \\
\hline Stormbergia & $\begin{array}{l}\text { Hettangian- } \\
\text { Sinemurian }\end{array}$ & Butler, 2005 & $S A M-P K-1105$ \\
\hline Talenkauen & Maastrichtian & $\begin{array}{l}\text { Novas et al., 2004; } \\
\text { Ibiricu et al., } 2010\end{array}$ & \\
\hline Tawa & 213-215 myr & Nesbitt et al., 2009 & \\
\hline Tenontosaurus dossi & Aptian & Winkler et al., 1997 & \\
\hline Tenontosaurus tilletti & Aptian-Albian & Forster, 1990 & \\
\hline $\begin{array}{l}\text { Thescelosaurus } \\
\text { assiniboiensis }\end{array}$ & Maastrichtian & $\begin{array}{l}\text { Galton, 1989; Galton, } \\
\text { 1997; Brown et al., } 2011\end{array}$ & RSM P 1225.1 \\
\hline Thescelosaurus garbanii & Maastrichtian & Morris, 1976 & \\
\hline Thescelosaurus neglectus & Maastrichtian & $\begin{array}{l}\text { Gilmore, 1913, 1915; } \\
\text { Sternberg, 1940; Galton, } \\
\text { 1974b, 1995, 1997, } \\
\text { 1999; Morris, 1976; } \\
\text { Boyd et al., 2009 }\end{array}$ & $\begin{array}{l}\text { NCSM 15728; } \\
\text { USNM } 7757 \\
7758 .\end{array}$ \\
\hline Tianyulong & $\begin{array}{l}\text { Oxfordian- } \\
\text { Kimmeridgian }\end{array}$ & $\begin{array}{l}\text { Zeng et al., 2009; Gao } \\
\text { and Shubin, } 2012\end{array}$ & \\
\hline Valdosaurus & $\begin{array}{l}\text { Barriasian- } \\
\text { Barremian }\end{array}$ & Barrett et al., 2011 & \\
\hline Wannanosaurus & $\begin{array}{l}\text { Campanian- } \\
\text { Maastrichtian }\end{array}$ & $\begin{array}{l}\text { Hou, 1977; Butler and } \\
\text { Zhao, } 2009\end{array}$ & \\
\hline Yandusaurus & Oxfordian & $\begin{array}{l}\text { He, 1979; He and Cai, } \\
\text { 1984; Barrett et al., } \\
2005\end{array}$ & \\
\hline Yinlong & Oxfordian & Xu et al., 2006 & IVPP V14530 \\
\hline Yueosaurus & Albian-Cenomanian & Zheng et al., 2012 & \\
\hline Zalmoxes robustu & Maastrichtian & Weishampel et al., 2003 & \\
\hline Zalmoxes shqiperorum & Maastrichtian & $\begin{array}{l}\text { Weishampel et al., 2003; } \\
\text { Godefroit et al., } 2009\end{array}$ & \\
\hline Zephyrosaurus & Aptian & Sues, 1980; Kutter, 2004 & YPM 56695 \\
\hline
\end{tabular}




\section{Table 3(on next page)}

Results of the stratigraphic consistency calculations.

Values of MIG are reported in millions of years. Abbreviations: DSRC $=$ derivative strict

reduced consensus tree; GER = gap excess ratio; MAS = maximum agreement subtree; MIG = minimum implied gap; $\mathrm{MSM}^{*}=$ modified manhattan stratigraphic measure; $\mathrm{MR}=$ majorityrule consensus tree; $\mathrm{SCC}=$ strict component consensus tree. 


\begin{tabular}{llllll}
\hline & \# of Taxa & MIG & GER & MSM* & Result \\
\hline Full Ornithischian Dataset & 65 & $1908-1388$ & $0.82-0.74$ & $0.13-0.09$ & - \\
This Analysis & 19 & $480-356$ & $0.80-0.67$ & $0.37-0.26$ & More Congruent \\
Buchholz (2002) & 19 & $573-400$ & $0.76-0.59$ & $0.32-0.23$ & \\
\hline This Analysis & 16 & $289-212$ & $0.92-0.80$ & $0.76-0.57$ & Equally \\
Spencer (2007) & 16 & $260-208$ & $0.94-0.84$ & $0.80-0.63$ & Congruent \\
\hline This Analysis & 35 & $852-611$ & $0.86-0.76$ & $0.28-0.19$ & More Congruent \\
Butler et al. (2008a) SCC & 35 & $1582-844$ & $0.77-0.49$ & $0.20-0.10$ & \\
\hline This Analysis & 35 & $852-611$ & $0.86-0.76$ & $0.28-0.19$ & More Congruent \\
\hline Butler et al. (2008a) MR & 35 & $1170-877$ & $0.77-0.65$ & $0.19-0.14$ & \\
\hline This Analysis & 28 & $723-489$ & $0.86-0.75$ & $0.34-0.23$ & More Congruent \\
\hline Butler et al. (2008a) MAS & 28 & $816-620$ & $0.81-0.70$ & $0.27-0.20$ & \\
\hline This Analysis & 30 & $772-531$ & $0.86-0.74$ & $0.32-0.21$ & More Congruent \\
\hline Butler et al. (2008a) DSRC & 30 & $967-661$ & $0.81-0.67$ & $0.25-0.17$ & \\
\hline
\end{tabular}




\section{Figure 1 (on next page)}

Recent phylogenetic hypotheses of basal ornithischian relationships.

Tree topology reported by Buchholz (2002) based on analysis of 97 characters for 20 terminal taxa $(A)$, strict consensus of four most parsimonious trees recovered by Spencer (2007) based on analysis of 97 characters for 19 terminal taxa (B), and strict consensus of 756 most parsimonious trees recovered by Butler et al. (2008a) based on analysis of 221 characters for 46 terminal taxa (C). In (B) bootstrap values $>50 \%$ are listed below nodes. In (C), Bremer support values $>1$ are to the left of nodes while bootstrap values $>50 \%$ are to the right of nodes. 

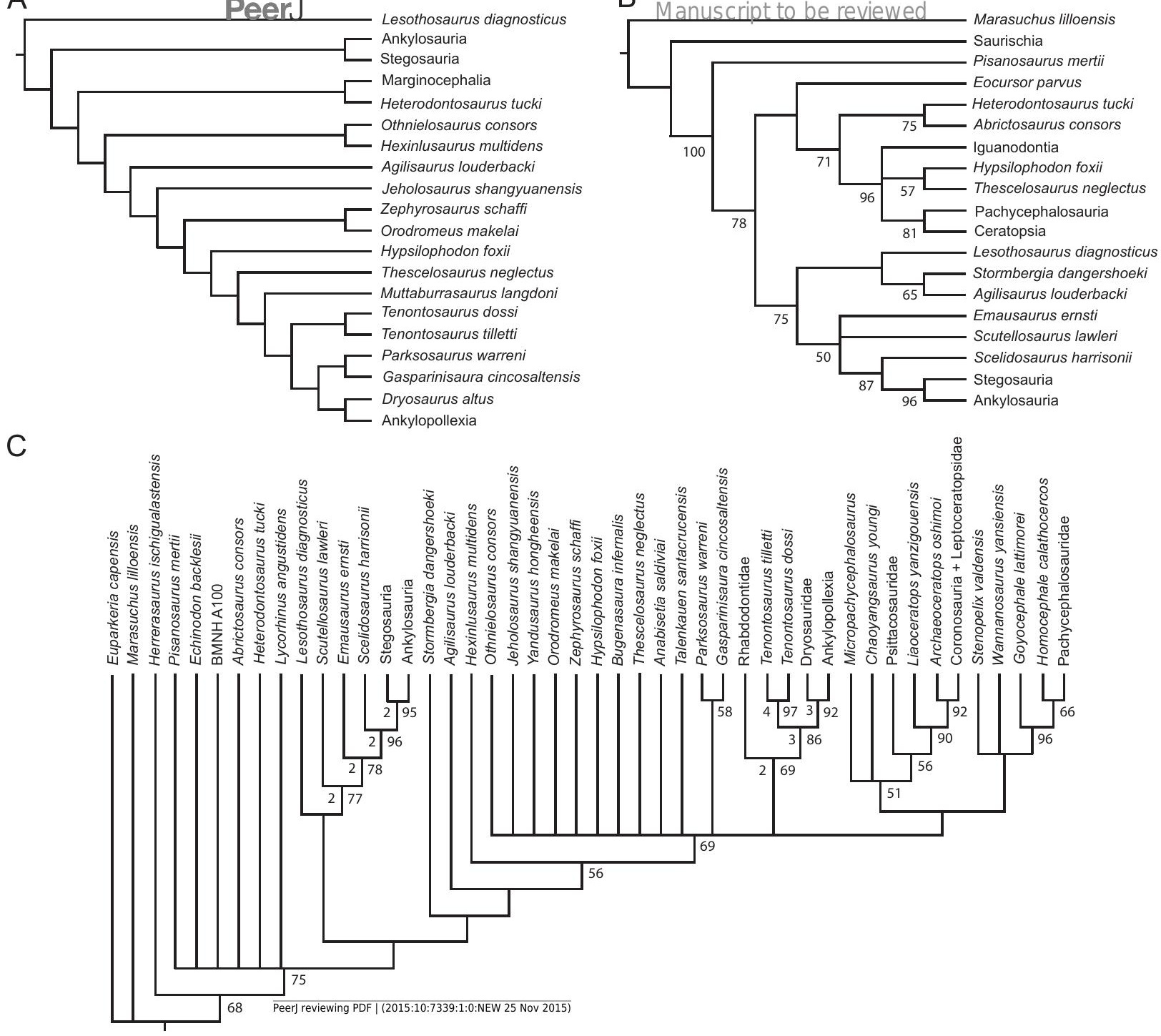
Figure 2 (on next page)

Strict consensus of the 36 most parsimonious trees recovered by this study.

Major ornithischian subclades are labeled either along branches (stem-based definitions) or at nodes (node-based definitions). See Table 1 for phylogenetic definitions. Numbers above nodes refer to the list of unambiguous character changes reported for each node in Supplementary Table 4. Bold numbers beneath nodes are Bremer support numbers $>1$, while non-bold numbers beneath nodes are bootstrap support values $>50 \%$. 


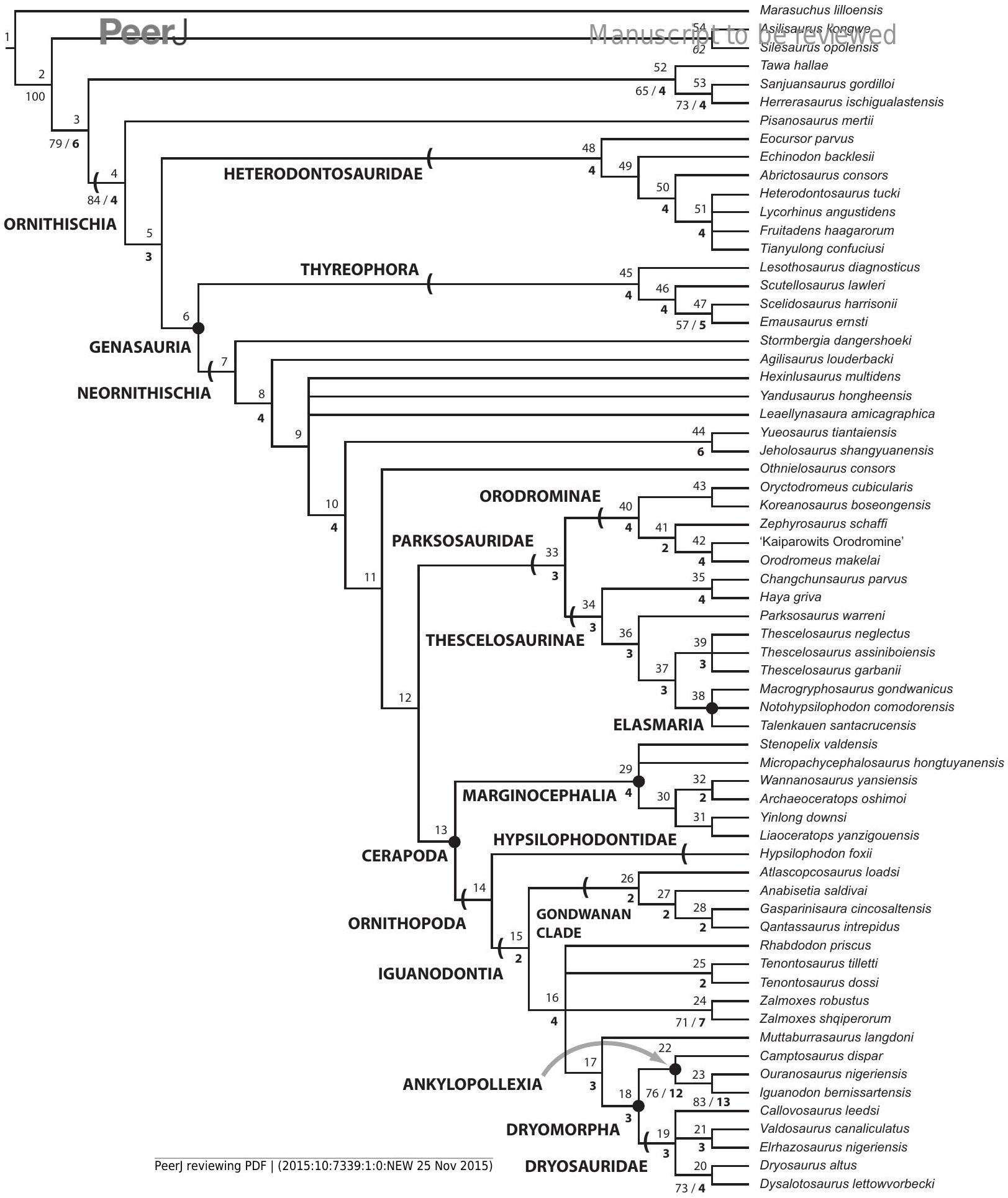




\section{Figure 3 (on next page)}

Parsimony-based reconstructions of ancestral geographic areas.

Tree topology based on Figure 2. The pie charts at each node represent the level of support for each ancestral (See Supplementary Table 5 for precise values). Each color represents a different geographic area (see key). Numbers next to nodes refer to those used in Supplementary Table 5. 
Figure 4(on next page)

Likelihood-based reconstructions of ancestral geographic areas.

Results obtained when all branch lengths were equal ( $A$ ) versus results obtained when time calibrated branch lengths were included and set equal to inferred missing fossil records (B). Tree topology based on Figure 2. The pie charts at each node represent the level of support for each ancestral area (See Supplementary Table 5 for values). Each color represents a different geographic area (see key). Numbers next to nodes refer to Supplementary Table 5. 
Marasuchus

Asilisaurus

Silesaurus

Tawa

Sanjuansaurus

Herrerasaurus

Pisanosaurus

Eocursor

Echinodon

Abrictosaurus

Heterodontosaurus

Lycorhinus

Fruitadens

Tianyulong

Lesothosaurus

Scutellosaurus

Scelidosaurus

Emausaurus

Stormbergia

Agilisaurus

Hexinlusaurus

Yandusaurus

Leaellynasaura

Yueosaurus

Jeholosaurus

Othnielosaurus

Oryctodromeus

Koreanosaurus

Zephyrosaurus

Kaiparowits Oro.

Orodromeus

Changchunsaurus

Haya

Parksosaurus

$T$. neglectus

T. assiniboiensis

T. garbanii

Macrogryphosaurus

Notohypsilophodon

Talenkauen

Stenopelix

Micropachycephalosaur

Wannanosaurus

Archaeoceratops

Yinlong

Liaoceratops

Hypsilophodon

Atlascopcosaurus

Anabisetia

Gasparinisaura

Qantassaurus

Rhabdodon

T. tilletti

T. dossi

Z. robustus

Z. shqiperorum

Muttaburrasaurus

Camptosaurus

Ouranosaurus

Iguanodon

Callovosaurus

Valdosaurus

Elrhazosaurus

North America

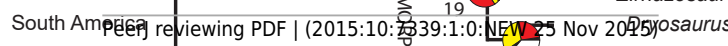

$B$
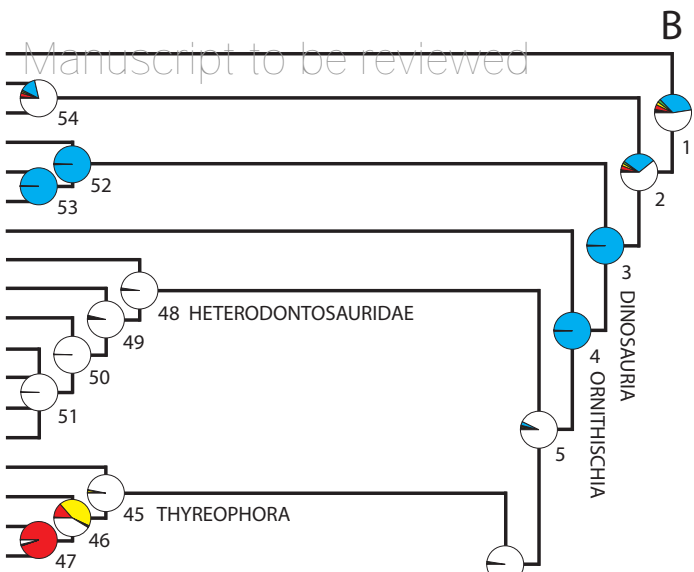

6
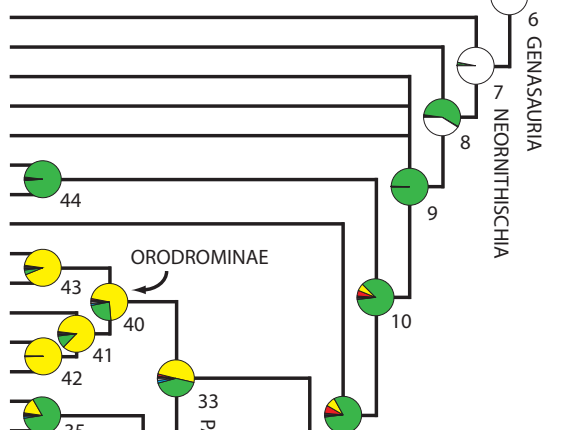


\section{Figure 5 (on next page)}

Time-calibrated phylogeny of Ornithischia.

White boxes indicate the uncertainty around the age of first appearance for each terminal taxon (not the known occurrences), while black lines represent implied missing fossil records (i.e., ghost lineages). Note: some branches are necessarily drawn deeper in time due to drawing constraints. Numbers positioned along branches or at nodes indicate the position of major ornithischian subclades. 1: Ornithischia; 2: Heterodontosauridae; 3: Genasauria; 4: Thyreophora; 5: Neornithischia; 6: Parksosauridae; 7: Orodrominae; 8: Thescelosaurinae; 9: Elasmaria; 10: Cerapoda; 11: Marginocephalia; 12: Ornithopoda; 13: Hypsilophodontidae; 14: Iguanodontia; 15: unnamed Gondwanan clade; 16: Dryomorpha; 17: Dryosauridae; 18: Ankylopollexia. 
